\title{
The Importance of Graphical Representation for Reaching Agreement Using the InterNeg Negotiation Support System
}

\author{
by \\ Michael L. Weber, B.Sc. \\ A thesis submitted to the Faculty of Graduate Studies and Research in partial \\ fulfillment of the requirements for the degree of: \\ Master of Management Studies \\ Sprott School of Business \\ Carleton University \\ Ottawa, Ontario \\ Canada
}

20 September 2005

(C) Copyright

2005, Michael Weber 


$\begin{array}{ll}\begin{array}{l}\text { Library and } \\ \text { Archives Canada }\end{array} & \begin{array}{l}\text { Bibliothèque et } \\ \text { Archives Canada }\end{array} \\ \begin{array}{l}\text { Published Heritage } \\ \text { Branch }\end{array} & \begin{array}{l}\text { Direction du } \\ \text { Patrimoine de l'édition }\end{array} \\ \begin{array}{l}\text { 395 Wellington Street } \\ \text { Ottawa ON K1A ON4 }\end{array} & \begin{array}{l}\text { 395, rue Wellington } \\ \text { Ottawa ON K1A ON4 } \\ \text { Canada }\end{array}\end{array}$

Your file Votre référence

ISBN: 0-494-10128-8

Ourfile Notre référence

ISBN: 0-494-10128-8

NOTICE:

The author has granted a nonexclusive license allowing Library and Archives Canada to reproduce, publish, archive, preserve, conserve, communicate to the public by telecommunication or on the Internet, loan, distribute and sell theses worldwide, for commercial or noncommercial purposes, in microform, paper, electronic and/or any other formats.

The author retains copyright ownership and moral rights in this thesis. Neither the thesis nor substantial extracts from it may be printed or otherwise reproduced without the author's permission.
AVIS:

L'auteur a accordé une licence non exclusive permettant à la Bibliothèque et Archives Canada de reproduire, publier, archiver, sauvegarder, conserver, transmettre au public par télécommunication ou par l'Internet, prêter, distribuer et vendre des thèses partout dans le monde, à des fins commerciales ou autres, sur support microforme, papier, électronique et/ou autres formats.

L'auteur conserve la propriété du droit d'auteur et des droits moraux qui protège cette thèse. $\mathrm{Ni}$ la thèse ni des extraits substantiels de celle-ci ne doivent être imprimés ou autrement reproduits sans son autorisation.
In compliance with the Canadian

Privacy Act some supporting forms may have been removed from this thesis.

While these forms may be included in the document page count, their removal does not represent any loss of content from the thesis.
Conformément à la loi canadienne sur la protection de la vie privée, quelques formulaires secondaires ont été enlevés de cette thèse.

Bien que ces formulaires aient inclus dans la pagination, il n'y aura aucun contenu manquant.

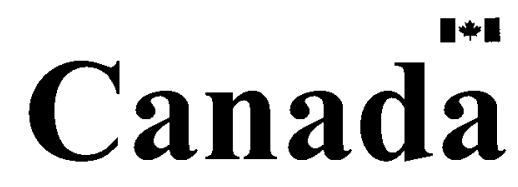




\section{Abstract}

The increasingly globalized economy and the omnipresent use of the internet in business communication has amplified the number of negotiations occurring electronically. Internet based negotiation is currently supported by a number of technologies including e-mail, decision support systems, group decision support systems, and negotiation support systems (NSS). NSS usually interface with the user via a natural language system or graphical display. The NSS system used by a negotiator can affect the negotiation outcome as a result of the technological support provided to the individual or group. A NSS system currently in use is the InterNeg INSPIRE (InterNeg Support Program for Intercultural Research) system.

This thesis investigated the effect of graphical representation on reaching agreement in bilateral negotiation using the InterNeg INSPIRE NSS system compared to the same system without graphical representation. No difference was observed in the proportion of dyads that reached agreement with graphical representation compared to one without. The number of offers submitted affected the probability of reaching agreement for both models. Affect and feelings of satisfaction were higher for successful negotiations, but appear to be related to the negotiation outcome rather than graphical support. The we/l ratio was determined to be lower for negotiations reaching agreement suggesting that an individualistic orientation, as determined by the relative frequency of singular 
to plural pronoun use in textual messages, increased the likelihood of reaching agreement for dyads with and without graphical support. The total message size per dyad was observed to be over 300 words greater for successful negotiations without graphical support, but the number of messages was not significantly different. This may reflect a requirement for more extensive textual explanation of the position and offer without graphical support. Settlements equidistant from the opening offers occurred less frequently than biased settlements for both models. Negotiations with graphical support had fewer agreements equidistant from the opening offers than did negotiations without graphical support. 


\section{Acknowledgements}

This research would not have been possible without the support of many people. I would like to thank Gregory Kersten for his continued patience, encouragement and advice. Michael Hine and George Haines are owed much for their thoughtful guidance, insightful comments, and sincere commitment to helping me complete this research. The timely help of Warren Thorngate is also appreciated.

The InterNeg research group is a collaborative effort and all are due thanks. The assistance of Gordon Lo in setting up the experimental model and Greg Schmidt for all his help is also acknowledged. Countless thanks are also due to Joan for always helping me at work, and Nicki for guiding me through the paperwork. I cannot name all the individuals to whom I am indebted, but wish to express my gratitude to them now - you know who you are!

Above all, special appreciation is due to my wife Kim, and our daughters Julia, Jessica, Allison, and Shannon who have uncomplainingly put up with the time committed to this project. My mother Vicki and my grandmother Lilith gave me optimism and my father Mel taught me much, but especially they gave me the ability to accomplish my goals. Without these people, this would never have been possible. 


\section{Table of Contents}

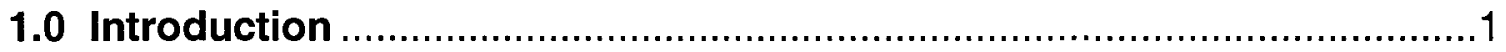

2.0 Bargaining and Negotiation Models ................................................

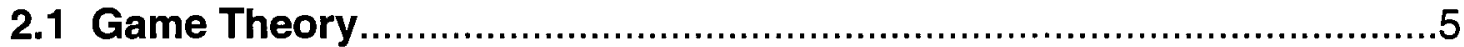

2.2 Economic Approach: Bargaining Theorists ..................................

2.3 Social Manipulative Model .......................................................11

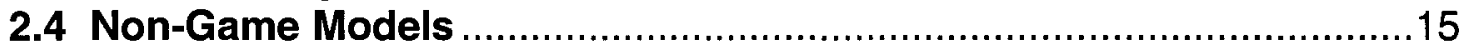

3.0 Human Cognitive Limitations............................................................17

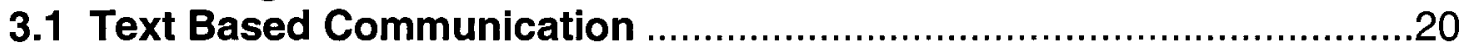

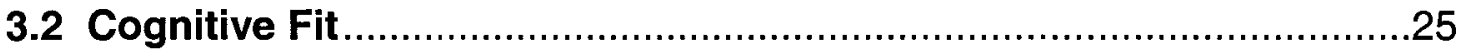

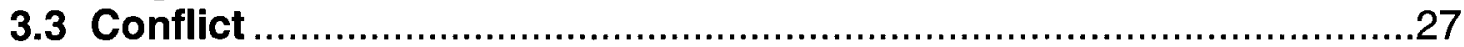



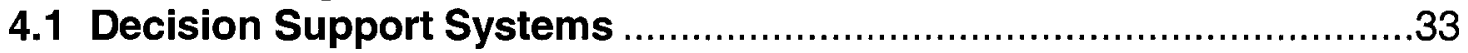



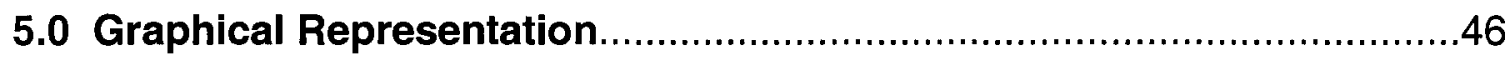

6.0 Creating Value and Reaching Agreement ........................................59

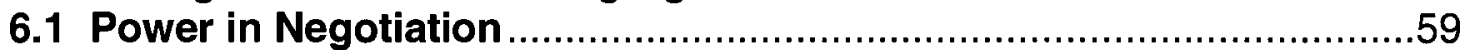

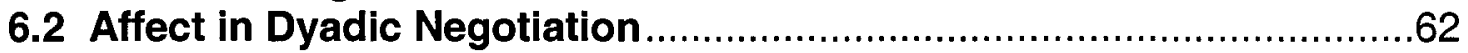

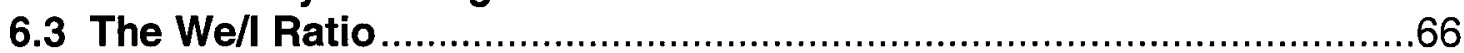

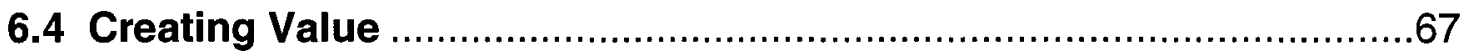

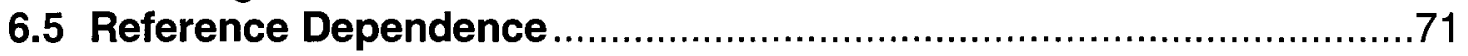

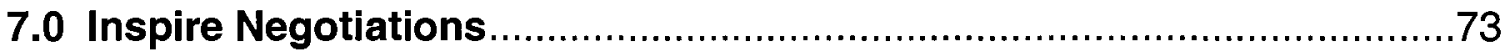

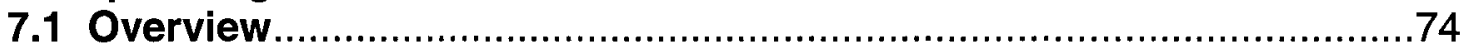

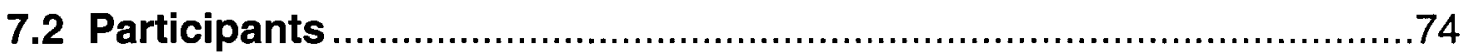



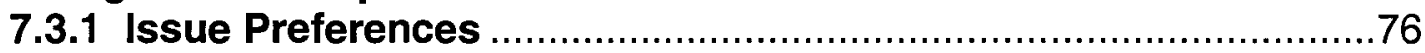

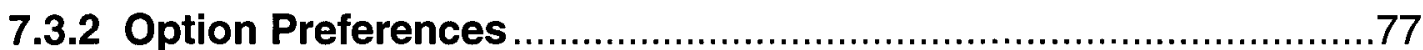

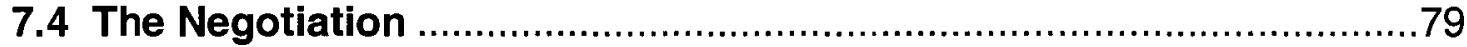

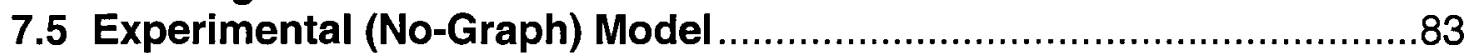



8.0 Research Objectives and Hypotheses ..............................................84 


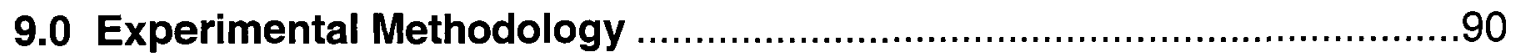

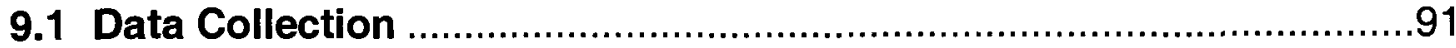

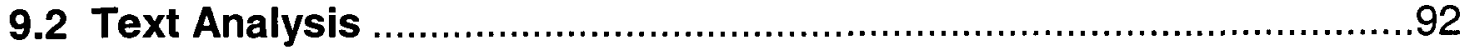

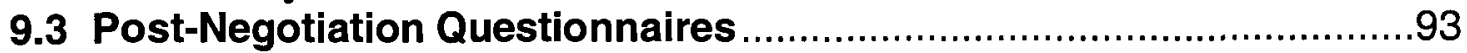

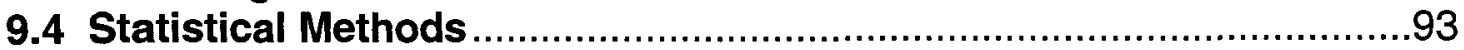

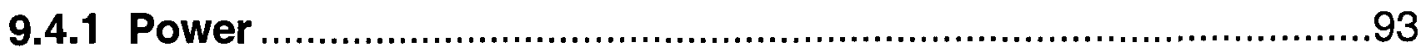

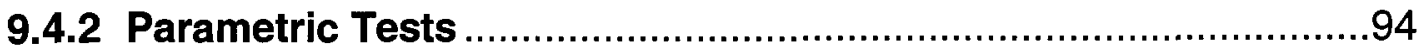

9.4.3 Nonparametric Tests ...............................................................95

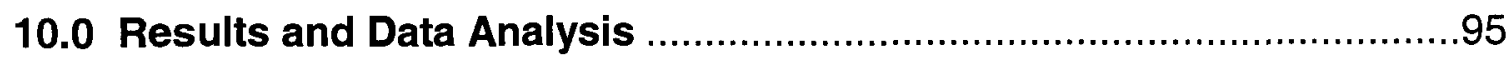

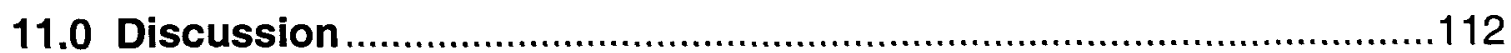

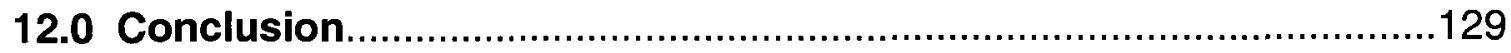

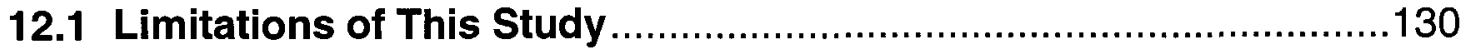

12.2 Future Research ...................................................................132



15.0 Appendix B: Itex Manufacturing Case........................................143

16.0 Appendix C: Pre-Negotiation Questionnaire ..................................145

17.0 Appendix D: Post-Negotiation Questionnaire ..............................147 


\section{List of Figures}

Figure 1: Sample Graphical Display of Offers for Jay ...................................82

Figure 2: Sample Graphical Display of Offers for Yuyo.................................82

Figure 3: History of Offers Graph for Yuyo (Itex Manufacturing)..................83 


\section{List of Tables}

Table 1: Pre-Negotiation Self-Identification of Occupation ...........................75

Table 2: Sample Issue Preferences for the Cypress Cycles Negotiator........77

Table 3: Sample Issue Preferences for the Itex Negotiator ............................77

Table 4: Sample Option Ratings for Jay Representing Cypress Cycles ......78

Table 5: Sample Package Ratings for the Buyer (Cypress Cycles)...............79

Table 6: Sample Offer with Text Message from the Seller (Yuyo, Itex) .......80

Table 7: Sample Offer with Message from the Buyer (Jay, Cypress Cycles) 80

Table 8: Bilateral Negotiations Full Model Dataset Countries.......................91

Table 9: Negotiation Pairings by Country for the No-Graph Model ...............92

Table 10: Calculation of Sample Size ............................................................94

Table 11: F-test Results for Variance .............................................................96

Table 12: Demographic \& Case Difficulty Data................................................97

Table 13: Proportion of Negotiations Reaching Agreement...........................98

Table 14: Number of Offers Submitted to Reach Agreement........................99

Table 15: Comparison of Offers Submitted Between Negotiations.............100

Table 16: Post-Negotiation Response Data Descriptive Statistics ..............101

Table 17: Test Results for Full Model Post-Negotiation Response Data ...103

Table 18: Fisher's Exact (two-tailed) for No-graph Response Data ............104

Table 19: Pronoun Use Frequency in Dyadic Textual Communication......105

Table 20: Within Model for Pronoun Use in Textual Communication..........105

Table 21: Between Model Comparison of We/l Ratio.......................................106

Table 22: Message and Word Count Descriptives .........................................108

Table 23: Between Model Comparison of Messages and Word Count ......110

Table 24: First Offer and Response Offer .....................................................111

Table 25: Proportion of Settlements Equidistant From Initial Offers .........111 


\subsection{Introduction}

Success, both in life and in business, often depends upon obtaining the cooperation of others. According to Deutsch (1967) page 359, "It is often man's lot to obtain an other's cooperation under conditions which are unclear and when little is known about the other." Cooperation can be obtained by force, threat of force, by friendship, or by negotiation. In the increasingly globalized economy, force and friendship are not normally options to obtain cooperation, leaving negotiation as the only feasible alternative. The main advantages of negotiation are that it is usually less costly and easier to find a mutually acceptable solution (Carnevale \& Pruitt 1992). Negotiation is an essential element of all interpersonal and intergroup interactions and can be found at all levels of society (Pruitt 1981; Carnevale \& Lawler 1986). According to Robinson \& Volkov (1988), negotiation is a process where participants bring their goals to the table, strategically share information and search for an efficient solution that is mutually beneficial.

Negotiation is an exchange activity that can promote mutually beneficial outcomes for the participants. Negotiation is unique due to the concurrent aspects of cooperation and conflict required in order to secure a joint settlement and a relatively favourable individual outcome (Gulliver 1979; Graham et al. 1994). The decision to negotiate is usually based on the assumption that an acceptable agreement can be reached (Lebow 1996; Kersten 2001), generally 
referred to as "good faith" negotiating. ${ }^{1}$ The parties involved must somehow exchange information relevant to a prospective transaction about the terms upon which either (or both) is willing to conclude the transaction, and the subsequent acceptance or rejection of these terms (Stevens 1958; Pruitt 1981; Raiffa 1982; Kersten 2001). Negotiations are increasingly being conducted electronically using the Internet and negotiation support systems (NSS) (Kersten \& Noronha 1998; Weigand et al. 2003), and are increasingly important to the world economy.

Negotiation support systems may be defined as a composite of computer techniques that support the social or analytical aspects of negotiation (Robinson \& Volkov 1998). NSS are useful as they can improve the quality of negotiation outcomes through their various functionalities (database management, computational speed, etc.) (Holsapple et al. 1998). As the frequency and amount of electronic negotiation increases so to does the need for NSS and decision support systems (DSS) due to human limitations (Zachary 1986; Rangaswamy \& Shell 1997). NSS functionality often includes graphical representation aids (Jelassi \& Foroughi 1989; Lim \& Benbasat 1993) to aid human cognitive limitations (Vessey 1991; Massey \& Wallace 1996). Although there is a considerable body of literature concerning the advantages of multimedia (e.g., graphical displays), most of this concerns the pedagogical basis for its use in

\footnotetext{
${ }^{1}$ A party may enter into negotiations with the sole intention of preventing a competitor from negotiating an agreement.
} 
schools (Lim \& Benbasat 2002), or comparisons of decision speed and/or accuracy between graphs and tables (Tversky 1969; Painton \& Gentry 1985; Jarvenpaa 1989; Vessey 1991; Vessey \& Galletta 1991).

This study will investigate the importance of using graphical representation in a negotiation situation using the InterNeg INSPIRE negotiation system, as well as reasons why successful negotiations are achieved. This paper contributes to the negotiation literature, and provides insights into the role of graphical representation aids in decision making. The remainder of this paper will be divided into seventeen sections. The literature review includes six chapters on: bargaining and negotiation models, human cognitive limitations, electronic negotiations and the use of negotiation support systems (NSS), graphical representation, and, creating value and reaching agreement. Chapter seven describes the INSPIRE NSS system. Chapters eight and nine concern the research objectives and hypotheses, and experimental methodology, respectively. Chapter ten gives the results and analysis which is discussed in chapter eleven. Chapter twelve concerns the conclusions of this study, limitations of this study, and future research. The remaining chapters are the references and appendixes. 


\subsection{Bargaining and Negotiation Models}

For many researchers, negotiation and bargaining are used interchangeably, although the two terms are distinct. In any exchange transaction (e.g., a retail purchase) a bargain (contract) regarding the terms of the exchange is struck - offer and acceptance - that may or may not require haggling. Bargaining consists of the exchange of more or less specific, substantive proposals (demand, offer, bid, etc. and their counteroffers) about the terms of agreement for the outcome of one or more issues (Gulliver, 1979).

In bargaining experiments, actors attempt to divide a fixed value. Exchange theorists (Emerson 1981; Molm 1994) have debated if this truly constitutes exchange. Strictly speaking, it does not as dividing a fixed value is ultimately a form of allocation, not of exchange. The two are similar in that one can always take the total value of two resources that are exchanged and transform it into a single value, which is then divided. However, most bargaining models fail to take into account that disputes and conflicts often involve multiple issues (objectives, goals, etc.) and multiple attributes (characteristics, qualities, and variables) that define the negotiation space (Hirshleifer, 1995). The interrelationship of the issues usually does not allow them to be settled separately, for example by distributive means. When a party is faced with intransitive issues reducing the issues to a single divisible value is virtually impossible and negotiation for that set of issues is required (Luce \& Raiffa 1957). 
The literature on negotiation is both speculative and empirical. Speculative theory was the earlier of the two, as models developed by economists and game theorists (Young 1975) and as ideas based on observations from areas such as industrial and international relations (Walton and McKersie, 1965). The theoretical approaches to negotiation includes literature encompassing strategies, tactics, decision making, psychology, adjustment, reaction, prescriptive strategies and tactics, game theory, communication, and collective bargaining (Kemper \& Kemper 1994). Most negotiation studies have taken one of four approaches: a normative or prescriptive approach ${ }^{2}$ derived from economic and game-theoretic perspectives, an individual differences approach that focuses primarily on personality factors, a structural approach based on sociological conceptions of bargaining, or a cognitive or information-processing approach (Kramer \& Messick 1995). Several representations have proposed to model the process.

\subsection{Game Theory}

Games have been used by social psychologists, political scientists, and economists to test theories of human behaviour in the abstract and are characterized by hypothetical situations of decision making (Nash 1950; Luce \&

\footnotetext{
${ }^{2}$ The focus of normative studies is on the design of models of rational negotiators and procedures of interaction among them. Prescriptive studies are concerned with design of procedures that define the goodness of the negotiation process and its outcomes, identify 'good' processes and compromises, and help negotiators to achieve good outcomes. Descriptive studies involve understanding how people negotiate, why they engage in a particular type of process, and why particular outcomes are achieved.
} 
Raiffa 1957). These models assume that each player decides their strategy in advance for all possible situations, effectively making the players an auxiliary component of the process. The theorist attempts to deduce what the strategy of a player in a given situation will be resulting from interdependent strategies and choices. Game theory emphasizes rational solutions using generalized models with a known or assumed payoff matrix. The ability of game theory to model reality is usually unsatisfactory (Aumann \& Shapley 1992) as it compresses the separate categories of preferences, opportunities, and perceptions into a single numerical value representing the net payoffs for alternative strategies (Hirshleifer, 1984). The game-theoretic model has several faults that limit, from a prescriptive standpoint, its usefulness including assumptions of player rationality, a fixed and known environment, finite time limits, and numerous equilibria (Sebenius 1992). Player rationality assumes that for a fixed set of alternatives with known probability distributions of outcome for each alternative (i.e., perfect knowledge) each player will maximize their expected utility value. These assumptions may result in extremely different negotiation outcomes, even for identical negotiating situations.

In actuality, it cannot be assumed that participants are as knowledgeable, single-minded, and as mathematically adept as is assumed by game theory. Some game theorists have argued that in a perfect information, cooperative situation, it would be unreasonable to allow for any outcome that is not Pareto 
optimal (Cross, 1977). For example, Nash (1953) introduced the possibility of manipulative actions such as "threats" influencing the outcome, although the assumption was that the fully informed negotiator took this into account and therefore did not need to carry them out. The result is a simplifying assumption for game theory, that of pure self-interest (Camerer 1997). To actually negotiate in this manner is clearly beyond the abilities of most negotiators (Cross, 1977). According to evolutionary theory (Kandori et al. 1993), players are not assumed to be so rational or knowledgeable as to be able to correctly anticipate the choices of other players. Instead, an explicit dynamic process is specified describing how players adjust their choices over time as they learn about the other players choices and values.

By the individualistic, rationality assumption, each party should accept any settlement point that creates value over no agreement (assuming no malice or vindictiveness) (Sebenius 1992). In reality, the motivational orientation of the negotiator may be individualistic, altruistic, cooperative, or competitive (Deutsch 1958). Game theoretic models allow only an individualistic orientation, where players are only concerned with their outcome (Carnevale \& Pruitt 1992). In negotiations, possible outcomes are frequently unclear, and seldom consist of a finite set; probabilities are generally indeterminate. Only approximately does negotiator behaviour resemble that of the game-theoretic models. Negotiators do not seek to maximize the product of their utilities as prescribed by Nash's 
theory (Nash, 1950) or single-mindedly seek a solution that is Pareto optimal as negotiators do not generally work consciously with utilities or pursue an optimal strategy, and frequently leave unrealized joint gains on the table (Sebenius 1992; Holsapple et al. 1998). The learning processes prior to final bargaining by which negotiators try to sort out their preference sets, reduce ignorance and inconsistency, adjust expectations, etc, are frequently ignored in game theory. Idealized models assume that all this is somehow accomplished and that the parties therefore know the possible options, their probabilities, their preferences, and thus their optimal choices and actions. The structure and interrelationships of an actual negotiation are not taken into account.

\subsection{Economic Approach: Bargaining Theorists}

The economics based paradigm attempts to understand negotiation as “interdependent" decision making (Greenhalgh \& Chapman 1995; Raiffa 1996). Here interdependence means that each negotiator must decide on a course of action that both maximizes their utilities and is acceptable to the other party (as each has the power to refuse to settle). Utility optimization depends upon at least satisfying the other party's minimum needs, but may also involve joint maximization (Greenhalgh and Chapman, 1995). The utility functions assume that each party is concerned with their own payoff, but indifferent to the payoff received by their opponent (Cross, 1977). 
The economic approach under conditions of bilateral monopoly has reference to real life problems, such as the determination of prices between buyer and seller. Bargaining theorists, in contrast to game theorists, seek to develop dynamic models involving offers and counteroffers and interdependent concession making. They are primarily concerned with the participant interactions rather than with strategies (Gulliver, 1979). Actors in economic models are typically considered to be totally self-interested utility maximizers, who derive utility primarily from tangible goods (Kaplowitz, 1977). The problem is that this neglects the fact that human behaviour involves social norms that judge certain types of behaviour as moral and others as immoral. There therefore exists a conflict between utility maximization and morality that is ignored by the economic model. According to Kaplowitz (1977) subjects view equitable play as being consistent with their self-interest rather than contrary to it. Luce and Raiffa (1957) suggest that people derive utility from moral behaviour (i.e., virtue is its own reward) supporting the proposition that moral considerations can influence the subjective probability of outcomes. This was found to apply to negotiation conditions where the opponent was thought to be a person rather than a computer (Kaplowitz, 1977). Often, this model assumes that negotiations occur in a social and cultural vacuum (Hirshleifer, 1995). This assumes axiomatic rationality and a focus on the outcome rather than the process used to achieve the outcome (Weigand et al. 2003). 
In experiments, people routinely reject profitable bargains they think are unfair, and do not take full advantage of others when they can (exhibiting surprisingly little 'moral hazard') (Hirshleifer 1993). Generally, people are neither entirely altruistic nor entirely Machiavellian, but fall somewhere between the two extremes. Social values and culture probably exert considerable effect on both the process and the outcome. To effectively model a negotiation requires including social values such as fairness, altruism, or revenge - values widely observed in real negotiations.

In reality, the participants, the process and the environment are all important. Individuals are social decision makers in the negotiation environment. This distinguishes it from most economic and game-theoretic formulations of decision-making which have generally advanced what Granovetter (1985) characterizes as an 'undersocialized' conception of human action. In contrast, the social contextualist paradigm assumes at the outset that individuals are inherently social actors. Even when negotiations involve strangers, they occur against a similar set of social and cultural expectations about norms, roles, duties, obligations, etc. (Kramer and Messick, 1995) and are affected by the arena in which the negotiations occur. All humans have been shaped by a similar cultural evolution and even extremely diverse cultures exhibit similar psychological patterns. For example, Harvard students and Ecuadorian Indians both exhibit similar ability to detect cheaters that does not depend on education 
or social differences (Sugiyama et al. 2002).

\subsection{Social Manipulative Model}

Social-psychological models are largely descriptive rather than prescriptive; they interpret the negotiation process from various perspectives including sociological, psychological, learning, or joint decision making. According to Bartos (1977), the Nash solution to bargaining is consistent with the notion of justice as negotiators view the midpoint between their past demands and offers as a fair settlement point and strive to achieve it. Cross (1977) views negotiation as a learning process with negotiators attempting to optimize payoffs from their perspective of the situation through their bargaining strategy. If their perception is incorrect, expectations will change and this will affect the strategy chosen. Zartman (1977) interprets negotiation as a joint decision-making process that is characterized by the existence of a jointly agreeable formula. This formula includes aspects of justice, common perceptions, and implementation details for the settlement along with the possibility of power altering expectations and acceptances.

In the social model of negotiation the impact of player's interactions with each other (expectations, tactics, risk assessment, objectives, etc.) is emphasized. This model more closely approximates the real world. However, due to the majority of these models being deterministic, controversy concerning 
the theoretical circumstances and limited range of variables exists (Gulliver, 1979). Information that is usually not available in an actual negotiation is required to make valid predictions, resulting in a considerably simplified negotiation process (Bartos, 1974). Typically, solutions are contained in highly abstract mathematical formulae. These formulae have two main problems concerning their validity and applicability, the inclusion of abstractly defined components and determinant variables, and, the nature of the simplifying assumptions. The result in a static representation of a dynamic process. Theorists such as Pen (1952) attempted to take these dynamics into account, although none appears to have been successful. Full flexibility and variability has proven too complex to be described or represented mathematically. The simplifying solution has been to hold some variables constant even though this is never true for actual negotiations (e.g., completely rational players, known parameters, perfect knowledge, a closed system, no coercive tactics, etc.) (Gulliver 1979). In reality, controlling the component variables inevitably alters the conditions and processes under study creating an artificial situation.

The assumption of rationality is central to the construction of these models, and is defined in terms of outcome (utility) maximization. This is an oversimplification as rationality does not adequately reflect the actual process where a negotiator attempts to reach agreement. Minimally, the negotiator should choose an outcome that is not less satisfactory than their position relative 
to the status quo, their reservation value, or BATNA (Kersten 2001). Any compromise (settlement point) must dominate these three alternatives. Although rationality states that a negotiator will prefer a high payoff to a low payoff, this is not always true of real negotiations (Bartos, 1974). Generally it is considered rational that negotiators will not accept less than the value of no agreement (i.e., they will not concede below their BATNA) (Raiffa 1982; Carnevale \& Pruitt 1992).

In the real world, it is seldom only a matter of a larger payoff being inherently better than a smaller one. Except in the case of a single issue auction, other factors usually impact on the negotiation. It is therefore difficult, if not impossible, to quantify a negotiation outcome strictly in terms of a distributive payoff as for bargaining theory. For example, a more attractive price may have less desirable conditions attached, or status might be preferred to monetary gain. Many negotiations involve monetary values and honour. The former is quantifiable, but the latter is an ambiguous concept that differs in importance with individuals and situations. These models therefore oversimplify the real world. In an actual negotiation, goals, preferences, possible outcomes, costs, and others factors are continuously subject to change and to manipulation by the negotiating parties. Negotiators are also not always able to consciously, and therefore deliberately and rationally, articulate and organize their interests and values, their wants and preferences, and their probability assessments (Gulliver 1979). 
Quantifying intangibles is difficult. For example, prestige and honour - two areas commonly involved in disputes - indicate the obvious difficulties with trying to approximate intangibles. Even where quantitative measures exist (for example, monetary values in the market) these do not necessarily correlate with a party's subjective preferences. To deal with the difficulty of measuring qualitative values, theorists use the concept of utility where a negotiator's subjective preferences are expressed numerically. This avoids problems of measurement and comparison and allows for the mathematical treatment of theoretical issues.

In practice, negotiators attempt to simplify the conditions under which they negotiate, but never achieve the simplified conditions of theoretical games (Raiffa 1982). During the negotiation phases a learning process occurs where the parties try to clarify and establish interactive rules and seek to obtain more knowledge of the negotiation issues, including potential outcomes and their acceptability. Their preferences and expectations are solidified as much as possible and readjusted while they simultaneously attempt to discover those of their opponent through an exchange of information (Gulliver 1979; Kemper \& Kemper 1994). Although the final result is probably never perfect knowledge, it is probably the best approximation possible. As Young (1975) points out, the choices of the opposed parties are reciprocally interdependent; one party cannot make a definitive prediction of the probable behaviour, preferences, and choices 
of the other party as these vary depending upon feedback about their preferences and choices.

\subsection{Non-Game Models}

The types of non-game models and the particular areas they emphasize relating to joint decision making have been reviewed by Patchen (1970). These models are of two principal types. Bargaining models concerned with the processes of offer-counter-offer by which parties attempt to reach settlement, and manipulative models concentrating on processes by which the parties influence the expectations, assessments, and behaviour of the other while searching for agreement and affecting the outcome in their favour. These manipulative models are of three types:

1. Reaction process models focus on spontaneous rather than cognitive reactions and assume that each party has established a stable set of preferences and expectations that they are unwilling, or unable, to modify. The action by each actor is a response to the previous action by their counterpart. This largely ignores the learning process by which parties modify expectations and preferences and make deliberate decisions about strategy and action. Where actions are effectively instinctual, an actionreaction situation such as this may spiral out of control leading to conflict escalation and negotiation deadlock.

2. Learning models concern how the actions of each party are affected by the results of past actions (e.g., previous negotiating experience) and situations. As negotiations continue, each party accumulates information about their opponent based upon the interaction.

3. Cognitive models are concerned with the attempt by each party to influence the expectations of their opponent to their advantage using threats, promises, misinformation, and references to rules and ideology. This approach is not primarily concerned with the outcome or when it will be reached, but with the process leading to the agreement. 
Negotiation behaviour is determined by cognitive factors (the perception of intentions, attitudes and beliefs about the other, situational perceptions, etc.) making up each person's construction of social reality (Deutsch 1982). Negotiator knowledge is represented in cognitive structures containing information about the negotiation that guide the behaviour of the individual. If different information forms the basis for decisions, or if individuals give differing importance to the same information, conflict may occur in a negotiation. Contentious behaviour may be perpetuated by selective perception and memory or lack of information (Carnevale \& Pruitt 1992). For example, the zero sum perception occurs when negotiators believe that the other party's interests are directly opposed to their own (Pruitt 1981; Kersten 2001).

At the abstract level, both parties attempt to define the general issues and principles that encompass the negotiation space. Structuring the negotiation is one of the most important aspects as once a structure has been identified and agreed upon, details can be dealt with. Several strategies may be used to structure the negotiation by either: (1) setting a formal agenda, (2) ranking the issues, (3) reducing the issues to a common denominator (e.g., monetary terms), or, (4) engaging in trading of issues (logrolling) (Gulliver, 1979). Reaching agreement on an agenda is often difficult and also ignores the fact that issues are often interconnected. Quantifying issues is often impossible for reasons stated above. The two most common negotiating strategies are to trade issues 
where one side compromises on an issue in return for compromise by their opposite on another issue and/or ranking the issues and settling either the most important or least important issues first (Gulliver 1979; Greenhalgh \& Chapman 1995). The problem with ranking issues is that this also ignores interconnectivity and it is frequently difficult to agree on what the most important issues are. Human intellectual capacity severely limits the number of issues that can be considered simultaneously. Dealing with the issues singly is also rarely an option as negotiation issues are usually highly interrelated.

\subsection{Human Cognitive Limitations}

Human mental resource limitations affect decision performance. These limitations are numerous in the literature and include narrow bandwidth of shortterm and perceptual memory (Card et al. 1983), individual short-term memory variability (Lohse 1997), quantitative operations difficulties (Dawes 1979), and, unreliability and/or bias in recall processes (Kahneman \& Tversky 1973) to list just a few.

Decision makers usually have complex criteria by which a given alternative is evaluated. Choosing a specific option involves a comparative value judgement versus other options according to the evaluative criteria involved (Raiffa 1982). When decisions are made under difficult circumstances (e.g., time constraints), when stakes are extremely high, when external noise is present, or 
where miscommunication occurs inconsistency and uncertainty may occur for the decision maker. Often this results from the person not considering the various dimensions of a decision simultaneously but rather sequentially (Zachary 1986). Sequential processing involves evaluating decision alternatives one attribute or aspect at a time, and discarding unacceptable alternatives as they are determined to be unacceptable on that aspect.

According to Zachary (1986) decision makers must deal with data, information, and knowledge. Data refers to messages physically available in the decision environment, while information refers to data that has been interpreted by the decision maker in the context of their knowledge about the decision situation. Knowledge then becomes a purely internal (i.e., cognitive) arrangement of classes of information that the decision maker uses to reason with and understand specific information. The decision maker uses information to make a decision and constructs it by accessing data (via sensory input) and interpreting this data by accessing knowledge (from long-term memory). Often, a common problem in decision making was imprecise and/or insufficient data. Recently the problem has become one of information overload causing difficulty in reaching the correct decision. For example, a person may not perceive important information even though the necessary data and knowledge are available. Decision makers may also struggle to perceive the meaning of data due to difficulty relating very detailed data to abstract knowledge constructs 
required to make the decision. When the number of variables is very large and/or the values change frequently the unaided decision maker may find it impossible to successfully monitor the values and subsequently make incorrect decisions.

Most problem-solving difficulties arise due to human cognitive limitations (Card et al. 1983). As an information processor, humans have an almost infinite capacity for long-term storage of information, although the information retrieval system is slow and frequently unreliable (Zachary 1986). The number of pieces of information that can be actively maintained in the working or short-term memory is limited, meaning that data manipulations from memory tend to be slow compared to computers. For this reason, computers are useful for information control and manipulation. The three most common forms are accessing, organizing, and monitoring (Holsapple et al. 1998). Access techniques allow the user to efficiently store and retrieve information from databases, organization techniques help the user impose structure and order among the items contained in knowledge bases or databases, and monitoring techniques allow the decision maker to detect the existence of complex conditions or patterns in databases.

When humans solve problems, they use both internal representations stored in their brains (short-term and long-term memory) and external representations on some type of media (e.g., paper, computer screen, etc.) 
(Larkin \& Simon 1987). It is believed that the cognitive processes involved in a decision (aided or unaided) are strongly dependent on the internal mental representation used by the decision maker during the problem solution (see (Pylyshyn 1984) for a review). If the decision maker lacks the knowledge needed to mentally simulate and understand the process then content-oriented support is considered useful. Should a person not have difficulty understanding the process but be unable to predict the outcome or outcome directions (i.e., due to short-term memory limitations) or because the process is internally represented visually and the complexity of the process dynamics can not be clearly managed in a pure mental visualization, information management structural support and/or a visual representation technique (e.g., graphic display) is considered useful (Zachary 1986).

\subsection{Text Based Communication}

Reading text-based information is cognitively intensive and often results in incomplete understanding. Mayer (1985) classifies knowledge into two categories: descriptive knowledge where key components or events are described but not explained (e.g., facts, events, instructions, etc.) and explanative knowledge where the functional relationships among two or more variables are expressed and the underlying rules or mechanisms are explained. Both descriptive and explanative information are the precursors to creative problem solving (the ability to solve problems different from those already 
learned by the individual). Both types of knowledge are required for a true understanding, and hence inference capacity, by the individual (Lim \& Benbasat 2002).

According to Van Dijk (1983) text comprehension consists of two levels of processing. At the surface level is the verbatim representation of text fragments called a microstructure. At a higher level is the hierarchical structure reflecting the meaning of elements extracted from the microstructure called the macrostructure or theme. When reading text, the reader carries along a small portion of the macrostructure in working memory. If the reader understands the information in the text and perceives a relationship between the information and the macrostructure in their working memory the new information is connected to the macrostructure. The sequence is therefore that a reader must construct a macrostructure from the microstructure and then connect the macrostructure to their existing knowledge structure in either their working memory or long-term memory. These processes are cognitively intensive and comprehension failure may occur at any of the stages. Macrostructures capture the essential ideas at the expense of omitting some specific details. If the reader is focused on specific details they may, due to cognitive limitations, lose an overview and not be able to construct the macrostructure (failure to see the forest for the trees!) needed to fully comprehend all the information. This may be the reason negotiators focusing on distributive aspects in a negotiation tend to lose sight of the overall 
aim of reaching an integrative agreement (Kersten 2001). The macrostructure is essentially the glue holding the isolated text fragments together. These fragments can only be integrated into their existing knowledge structure if they can comprehend a relationship between the fragments (microstructure) and the macrostructure in their working memory.

Representation of information in multiple formats has been argued to lead to better retention and retrieval (Vessey \& Galletta 1991; Lim \& Benbasat 2002). The use of dual representations can moderate the limitations of using one representation alone. For example, researchers often present their results in both figure and text form for improved understanding by the reader. Using complementary cues improves the comprehension of explanative information related to macrostructural elements but not necessarily descriptive information (isolated facts) related to microstructure. Visual representation may improve comprehension as providing the macrostructure to the reader reduces their cognitive load by making relationships between pieces of information explicit (Lim \& Benbasat 2002).

Most human communication occurs through words and symbols. According to dual coding theory (Paivio 1986) humans possess two interconnected cognitive systems for processing and storing information: an imagery system for nonverbal information and a verbal system for linguistic 
information. This theory states that the two systems are both functionally and structurally distinct; data are encoded in memory as images and text (words). The systems are functionally distinct as they process visual and verbal information separately and independently of each other and are structurally distinct as they store information in representation units that are mode specific known as logogens and imagens. Both types of representations retain some of the properties of the stimuli that generated them. Imagens correspond to natural objects and enable the construction of mental images of real objects and are amenable to dynamic spatial transformations. Spatial transformations are not possible with verbal representations (logogens). Another structural difference between the two types of representations is their organization. Neuralphysiological research using positron emission tomography (PET) imaging indicates that the brains of humans have a separate working memory for verbal, spatial, and visual objects (Jonides et al. 1993). Visual information has the advantage that it is organized in a synchronous manner, which allows many parts of a mental image to be available for simultaneous processing. On the other hand, logogens are organized in larger units in sequential fashion and are therefore subject to the constraints of sequential processing, which allows limited processing of information per unit of time. When verbal and visual information is presented contiguously in time and space it enables people to more easily form associations between visual and verbal material during encoding. This can increase the number of paths that learners can take to retrieve information as a 
stimulus may activate both verbal and visual representations (Clark \& Paivio 1991).

In a problem-solving situation, text is processed via a linear attentioncontrol mechanism (Larkin \& Simon 1987). Attention is initially at the first sentence. After each inference is made, the attention remains at the beginning of the last sentence in which relevant information was found. New elements added to the data structure are searched first, and in reverse order of their addition, until the required element is found. Diagrams are valuable due to perceptual enhancement, as they allow conclusions to be read directly from the representation using direct perceptual operations (Larkin \& Simon 1987). People can focus on part of a diagram, detect cues, and then use them to retrieve problem-relevant inference operators from memory. Diagrams can (Larkin \& Simon 1987):

- Group together information that is used together, reducing search time for the elements needed to make a problem-solving inference.

- Use location to group information about a single element, avoiding the need to match symbolic labels.

- Automatically support a large number of perceptual inferences.

The advantages of diagrams are computational according to Larkin (1987). Diagrams act as better representations not because of richer information content, but because the indexing of the information provides more efficient computational processes. However, this also implies that such diagrams are only useful to those having the appropriate computational skills to utilize them 
correctly. Large amounts of information are not easily processed in a sequential fashion, although this is frequently necessary in problem solving in order to arrive at a solution (Clark \& Paivio 1991). Information visualization (e.g., graphical displays) enable users to quickly assimilate large amounts of data. Without a graphical display, the task becomes more difficult due to the cognitive load imposed to comprehend the microstructure (Van Dijk \& Kintsch 1983).

\subsection{Cognitive Fit}

Although graphical and tabular representations may contain the same information, the former emphasizes spatial information while the latter emphasizes symbolic information. Tasks, such as negotiation, may be considered as either a spatial or a symbolic task depending upon the type of information required. Task performance will be enhanced when there is a cognitive fit or similarity between the information representation format and the information required by the task type (Jarvenpaa 1989; Vessey 1991). As humans are cognitively limited in terms of information processing, more effective problem solving usually occurs if complexity in the task environment is reduced (Vessey \& Galletta 1991; Massey \& Wallace 1996). This is termed cognitive fit and states that complexity in the task environment will be reduced if the problemsolving aids (tools, techniques, problem representation) support the task strategies (methods or processes) required to perform the task (Vessey 1991). 
As problem solving is directly related to the mental representation of the problem that is comprised of the problem representation and problem solving task, the mental representation is a subset of the total problem space (Vessey 1991). Matching representation to task leads to the use of similar, and therefore consistent, problem-solving processes and to the formulation of a consistent mental representation. Problem solving with cognitive fit leads to effective and efficient problem solving performance. When a mismatch occurs, similar processes cannot be used simultaneously to work on the problem representation and seek a solution. People formulate a mental representation based on either the problem representation or the task. If the mental representation is based on the problem representation then the person needs to transform it to derive a solution; if a mental representation is formulated based on the task they need to transform the data from the problem representation into a compatible mental representation suitable for task solution (Vessey 1991).

Cognitive fit encourages the use of consistent (optimal) problem-solving processes in task solution, which increased performance (Vessey \& Galletta 1991). The cognitive fit paradigm usually applies to fairly simple tasks (elementary information and perceptual processes) (Vessey 1991). For more complex problem-solving tasks (e.g., negotiation where strategy is important), it is necessary to decompose the problem into a series of subtasks. This may be 
difficult for individuals to do consistently and lead to different interpretations of the same information resulting in conflict.

\subsection{Conflict}

Traditional theories of human conflict often portray greed as the motivating factor. Social judgement theory proposed by Hammond (1965) argues that human judgement itself is a major source of conflict due to interpersonal conflicts. This is thought to be due to the subjective judgement each person relies on in the decision-making process, inaccuracy due to individual cognitive limitations, and, inconsistent behaviour in comparable circumstances (Hammond 1971; Balke et al. 1973). Self-understanding for negotiators is frequently poor and often results in the transmission of inaccurate or false information, a barrier to achieving settlement (Balke et al. 1973).

A negotiation is considered to consist of four key factors: the negotiation parties, social knowledge and goals, social norms, and communication (Thompson et al. 1995). This negotiation space encompasses the basis for agreement or deadlock, depending upon the orientation of the parties (Walton \& McKersie 1965) and the learning process as people have a limited ability to receive, decode, and act upon information they receive in the course of the interaction (Kandori et al. 1993). This is affected by the initial distribution of information, beliefs about the appropriateness of sharing information, the 
negotiation context (Thompson et al. 1995), and the cognitive processes of each party.

Informational asymmetries often result in conflict. Three interacting determinants affect conflict, preferences (benevolence or malevolence toward the other party), opportunities (prospect for gain at the expense of the other side), and perceptions (ability to evaluate the motives, capacities, and requirements of the other party) (Hirshleifer, 1995). The aim of information exchange during negotiation is usually to change the other party's perception of the values for the payoff matrix (Stevens, 1958).

Negotiation might therefore be regarded as the search for equilibrium having two sides: one dealing with the search for mutual advantage through exchange, and the other being the pursuit of advantage via conflict. In standard theory, such an equilibrium must satisfy Coase's Theorem (Coase 1960), which states that in equilibrium no one will reject an opportunity for mutually advantageous exchange. If a prospective allocation is inefficient, there is incentive to exchange offers toward a Pareto improvement. In conflict theory the analogous proposition might be called Machiavelli's Theorem, stating that no one will fail to capitalize on a profitable opportunity at the expense of another (Hirshleifer, 1995). 
Conflict is considered to be, in a large part, an educational process and tends to occur when one or both parties is overly optimistic about their demands or how far the other party will concede. Conflict causes the parties to readjust their expectations to more realistic levels (Hirshleifer 1984). However, the same evidence that causes one party to become less confident of their aspirations/goals may cause the other party to become more optimistic due to differences in human cognitive processes. The result is difficulty in adjusting perceptions to the reality of the negotiation space. Eventually, a potential settlement region emerges (or an existing settlement region grows larger) so that conflict tends to end by mutual consent either by reaching agreement or accepting the status quo (Raiffa 1996). Negotiators are thought to accede to others wishes to the extent that failing to do so is costly (loss of time, goods, opportunity, status, etc.) (Hirshleifer, 1995).

Negotiators encode (evaluate and interpret) information in a manner that fits their initial expectations, and they often ignore or discount information that is inconsistent with their expectations (Gulliver 1979; Fiske \& Taylor 1991). Interpretation bias occurs when people perceive the same stimuli but evaluate it differently (Ross \& Nisbitt 1991). Situational interpretation depends on the personal perspective of the individual such that one person's view may be contrary to that of another due to their individual bias and reasoning (Kahneman \& Tversky 1973; Zachary 1986). The result is a tendency for a negotiator to view 
the other side's interests as more opposed to their own than is actually the case. Partisan perspectives promote an adversarial viewpoint in which one side believes that any benefit for the other party must be detrimental to them, and vice versa (Thompson et al. 1995).

Disputed issues at the start of negotiations are not necessarily those that are, or become, most important for either party. As more information becomes available, better appreciation of what is probable, possible, and impossible are gained, and the opportunity costs. The result is that each party continually refines and adjusts their preference set throughout the negotiations. Even near the end of negotiations a complete understanding of the variables is unlikely to be achieved, nor is the preference set likely to be totally consistent (Gulliver, 1979). This may be due to human inability to fully comprehend the information in the negotiation space.

The theory of bounded rationality (Simon 1978; Kersten 2001) states that there are cognitive limits to the knowledge of individuals and their capacity to act rationally. Computer graphics are said to provide a means for coping with these human limitations by providing immediate analyses of the judgement process and pictorial, non-technical process descriptions (Balke et al. 1973). This allows a decision-maker to more accurately exercise judgement by reducing inconsistency by the use of external aids. 
Research has indicated that providing negotiators with graphical displays of the problem task established a common framework in which they interacted and communicated perspectives more efficiently (Massey \& Wallace 1996). Shared cognition creates the potential for, but does not necessarily lead to, settlement by facilitating communication. Shared cognition can allow negotiators to improve their understanding of and communication about disputed issues, and possibly more quickly reach agreement (Swaab et al. 2004). Causing shared cognition to occur using NSS is thought possible by giving the same feedback to all participants (e.g., visual displays) (Umanath \& Scamell 1988). These displays provide similar information to all participants during the negotiation concerning potential decisions and thus influence the cognition of negotiators about the problem and possible solutions. Promoting shared cognition among negotiators facilitates communication, and therefore information exchange, allowing them to reach agreement more quickly (Swaab et al. 2004).

\subsection{Electronic Negotiations}

Many people consider face-to-face (FTF) to be the best medium for negotiation despite the fact that it may personalize the conflict. Electronic negotiations can be used instead. Computer-mediated communication (CMC) is synchronous or asynchronous electronic mail and computer conferencing by which senders encode text messages that are relayed from senders' computers to receivers (Walther 1992). A comparison of CMC with FTF communication in 
group decision tasks found that $\mathrm{CMC}$ had the following effects

(Rangaswamy and Shell, 1997):

1. A reduction of communication bandwidth, resulting in fewer exchanges of information although the proportion of task-related information exchanges was higher.

2. Increased anonymity, possibly inducing less cooperative or more uninhibited behaviour.

3. A restriction of spontaneous expression due to communication by turntaking.

Electronic communication allows separated members to interact as it they are in close physical proximity, but differs from face-to-face communication in terms of the exchange activities and cues available due to proximity (Lim 2000). Rangaswamy and Shell (1997) found that simply using computer technology did not improve negotiation outcomes in multi-issue negotiations as compared to FTF negotiations. Rather, they state that the key to achieving integrative trades is to set and maintain high aspirations in conjunction with a problem-solving orientation - a learning environment. High expectations provide the motivation to search for integrative trades rather than satisficing, while a problem-solving orientation provides the approach for identifying alternative proposals to offer to the other party that allows gains for both parties.

Experiments conducted primarily in task-oriented research on $\mathrm{CMC}$ and their findings cannot be generalized to all domains of electronic communication. Differences in experimental research designs (i.e., group characteristics and 
members, group task requirements, communication systems, and group temporal structure) are rarely addressed, oversimplifying the forces that affect CMC. Walther (1992), calculated that the median time allowed for CMC in timerestricted experiments was 30 minutes. As $\mathrm{CMC}$ communication tends to be slower than face-to-face this may restrict communication richness. The typical laboratory setting for $\mathrm{CMC}$ experiments is highly artificial and neglects the social richness and complexity normally found in the environment. For example, even the most perfunctory of negotiations have a social dimension (Greenhalgh \& Chapman 1995). However, computer support is thought to be of benefit for data manipulation and to alleviate human cognitive limitations in a task-related (e.g., negotiation) setting.

\subsection{Decision Support Systems}

Computer support technology has been utilized to aid decision makers for approximately 40 years. Generally these are known as decision support systems (DSS) and vary from relatively simple spreadsheets to combinations of artificial intelligence and operations research technologies (Wilkenfeld et al. 1995). Decision support system (DSS) is a computer-based system used by decisionmakers in semi-structured decision tasks by directly interacting with data and models (Lim \& Benbasat 1993). Zachary (1986) identifies six types of computer support that can be provided to human decision makers. These are: process models, choice models, information control techniques, analysis and reasoning 
techniques, representation aids, and, judgement amplification/refinement techniques.

Prescriptive theories of negotiation attempt to maximize the payoffs for one or more parties by relying mainly on the strategies of the participants while descriptive theories seek to understand the negotiation as an interaction process (Kemper \& Kemper 1994). The rationality assumption of the prescriptive approach necessary to effectively form and implement strategies is rarely possible due to the cognitive limitations of humans. These limitations often contribute to unrealized joint gains that might be realized with the help of electronic support.

Decision making requires identifying and configuring relevant facts in order to support hypothesized inferences. Detecting and using logical configurations of related facts is a difficult activity from external information sources (e.g., text) but becomes easier when the information source is the human memory mechanism itself. When a task requires information processing of greater sophistication than basic fact retrieval, such as that required for deductive reasoning or decision making, facts structured appropriately in memory are considered to be superior to external information sources (Umanath \& Scamell 1988). The general superiority of imagninal over verbal mediators is often explained by the parallel versus sequential processing hypothesis (Clark \& 
Paivio 1991). It is theorized that with imaginal mediators the associative information is stored in parallel while verbal mediators are stored sequentially (Umanath \& Scamell 1988). The difference in the type of organization provided by these two processing systems is correlated with differences in the ease of information access and processing. Assuming that a stimulus functions as an effective recall cue, parallel processing allows the image to be quickly scanned and decoded. With sequential processing of verbal mediators memory load during storage is greater, requires more time, and can be more susceptible to error.

Electronic negotiations can range from exchanges of offers to complex communicative acts concerning packages of products and/or services. The three main models of electronic negotiations are electronic auctions, negotiation agents, and negotiation support (Kersten \& Noronha 1998; Schoop et al. 2003). Negotiation agents take over all or some of the negotiation process for the human stakeholder. The main problem with automated agents is that they are useful only for products that allow detailed descriptions that are easily quantifiable and therefore amenable to distributive compromise. Current automated approaches do not allow support for the purchase of more complex goods (Schoop et al. 2003) or where imprecisely defined aspects (e.g., prestige) are included (Raiffa 1996). Auctions and agents have the advantage of specifying detailed agreements, where possible, but are unable to provide a 
comprehensive solution for electronic negotiations.

With the rapid growth of the Internet, increasing use of electronic business transactions, information overload, and human cognitive limitations, the need for negotiation support has increased. Negotiation support approaches do not automate the negotiation process itself, but provide support for complex multiattribute negotiations. Ultimate control over the negotiation process remains with the human negotiators. There are two classes of negotiation support systems, solution driven systems that assist decision-making and provide alternative solutions and process-driven systems that support and enhance the entire negotiation process (Kersten et al. 1999; Schoop et al. 2003).

\subsection{Negotiation Support Systems}

NSS can be defined as a composite of computer techniques that support the social or analytical aspects of the negotiation life cycle (Robinson \& Volkov 1998). Specialized packages known as NSS form a subset of DSS and GSS systems (Holsapple et al. 1998). Approaches to negotiation support take three basic forms, support for a negotiation group, mediation support, and support for individual negotiators (Wilkenfeld et al. 1995). See Wilkenfeld (1995) for examples of NSS systems. Identification of mutually beneficial resolutions (MBR's) is a computationally intensive task that would be extremely difficult for a negotiating agent (or person) without automated support. NSS are useful as they 
are able to improve the quality of negotiation outcomes through their various functionalities (database management, computational speed, etc.) (Rangaswamy \& Shell 1997; De Moor \& Weigand 2004).

Most GSS systems are designed on the premise that decisions can be improved if the system removes or considerably attenuates social processes from the decision making process based on the belief that social relationships are counterproductive to making good decisions leading to integrative agreements (Swaab et al. 2004). However, this is not actually true as integrative agreements are often the result of trust (a social aspect) between the parties (Pruitt 1971; Lebow 1996). Good relations between the parties are vital to a successful outcome. Negotiators with prosocial motives engage in more problem solving, less contentious behaviour and achieve higher outcomes compared to negotiators with an egoistic motive (Kahai \& Cooper 1999; De Dreu et al. 2000). The social richness of the negotiation environment may facilitate negotiation success (Polzer et al. 1995). The precondition for business relations is a sufficient amount of trust, that normally depends on personal contact and norms, between the stakeholders (Deutsch 1958; Kimmel et al. 1980; Weigand et al. 2003).

A negotiation support system is not limited to the technological features alone, but acts as one aspect in the ecology of the negotiation itself. Three 
different entities are distinguished in the negotiation environment: a negotiator, their opposite negotiating partner, and the decision environment. A negotiation process may be considered to be comprised of two processes, the negotiation itself and the negotiation context (issue space, participants, norms and rules the nature and scope of the issues involved in a negotiation) (Holsapple et al. 1998). Negotiation support systems are thought to stimulate a common cultural identity among negotiators in the negotiation setting. Shared cognition and shared identity are relatively powerful predictors of negotiation outcomes and are related to the communication and information aspects of the negotiation setting (Swaab et al. 2004).

Negotiation Support Systems (NSS) are a special class of Group Support Systems (GSS) emphasizing computerized assistance for problem-solving, bargaining, consensus seeking, and conflict resolution (Jelassi \& Foroughi 1989; Lim 2000). Due to the cognitive limitations of humans, negotiation approaches have evolved from being considered an 'art' (e.g., (Raiffa 1982)) to that of a rational, knowledge-based process. NSS are considered interactive, computer based tools intended to support negotiating parties in reaching agreement. This is accomplished by the provision of communication technologies, databases for data management and analysis, decision support software, etc. Jelassi and Foroughi (1989) list five factors impacting negotiations and relevant to NSS design: 
1. Separation of the negotiating parties from the problem.

2. Providing communication between negotiators.

3. Help in identifying the real interests of the parties.

4. Generating options for mutual (integrative) gain.

5. Promoting the use of objective criteria.

Negotiation is conceptualized as a process by which two or more purposive actors arrive at a specific agreement under conditions of strategic interaction or interdependent decision making (Kersten 2001). NSS are designed to assist negotiators in reaching mutually satisfactory decisions by providing communication and decision models to aid in requirement and strategy analysis functions (Lim 2000). Without support, negotiating parties often fail to reach the maximum joint outcome that is possibly attainable (i.e., joint gains are left on the table), or a fair outcome (from the perspective of the Nash solution). The main problem is that the rationality assumption of the prescriptive approach necessary for effectively forming and carrying out the necessary strategies cannot always be met due to human information-processing limitations (Zachary 1986; Lohse 1997). These systems are designated Negotiation Support Systems (NSS).

NSS consist of networked decision support and group support systems. The DSS component helps to elicit and develop negotiators objectives and allows the evaluation of preferences and analysis of external data (Rangaswamy \& Shell 1997; Kersten 2002). The role of DSS is to support decision makers in solving ill-structured problems through the use of decision analysis. In 
negotiations, NSS accomplish this by implementing techniques of negotiation and decision analysis (Kersten \& Noronha 1998). The electronic GSS communication component improves the effectiveness of the negotiating parties by focusing the attention of the negotiators on issues, encouraging equal participation, and, reducing the power differences between participants (Rangaswamy \& Shell 1997; Lim 2000). The DSS may be used in an analytic role (e.g., to rank alternatives) while the GSS supports communication between the parties. A NSS can support a negotiation by either assisting a participant or serving as a participant (agent or mediator) (Holsapple et al. 1998).

Most theories about negotiation are descriptive rather than prescriptive, which complicates their use as a basis for NSS (De Moor \& Weigand 2004). Negotiation is also a complicated process consisting of several distinct stages. These stages have been described as the antecedent, concurrent, and consequent phases (Graham et al. 1994). These are the equivalent of the prenegotiation, negotiation, and post-negotiation (post-settlement) stages (Kersten \& Noronha 1998). Weigand et al (2003) recognize the information, negotiation, and fulfilment stages. Robinson (1998), drawing from the software life cycle, recognize the negotiation analysis, negotiation design, and implementation stages. Other models include those of Lim and Benbasat (2002) and (Gulliver 1979). All models consist of a search or information exchange stage, a stage where the actual negotiation contract is determined, and a finalization stage. 
A comprehensive theory of the negotiation process does not yet exist that would allow for the construction of a NSS broadly applicable for negotiation analysis. The ultimate goal of negotiation analysis is negotiation support providing prescriptive advice to the negotiator; see Kersten (2001) for a review. In order for a negotiation to be adequately supported, prescriptive guidance is required in the form of negotiation protocols (protocols that standardize agents communication patterns via the interchange of structured communications) rather than mere descriptive advice (De Moor \& Weigand 2004). Robinson \& Volkov (1998) state that such negotiation protocols regulate four types of behaviour: revealing agent models, identifying conflicts, searching for alternatives and/or conflict resolution, and selecting a settlement point. This would allow the use of negotiation strategies by human and/or machine agents (De Moor \& Weigand 2004). Protocols are an important aspect for human negotiations as they increase transparency and engender feelings of trust for the participants, and are necessary if the process is to be delegated to software agents (Robinson \& Volkov 1998).

Negotiation is a key component in e-commerce. Although some functions may be automated, most negotiations will continue to be carried out by humans. Market transactions in the electronic forum consist of three phases: the information phase where customer and supplier find each other, the agreement phase where an offer is made, and the settlement or fulfilment phase where the 
agreed terms are fulfilled (delivery and payment) (Kersten 1988; Weigand et al. 2003). Currently there is very little automated support for the contract negotiation phase (Weigand et al. 2003).

As the opportunities for humans and software agents to interact increases with the rise of the internet commerce, the mediating role of NSS becomes more important. Improvements in functionality have resulted the embedding of negotiation systems in group meeting systems, concurrent engineering and design tools, software agents, and electronic commerce systems (Robinson \& Volkov 1998). These range from specialized expert systems that help negotiators prepare for a negotiation to mediation and interactive negotiation systems that structure how negotiations take place (Rangaswamy \& Shell 1997; Kersten \& Noronha 1998; De Moor \& Weigand 2004).

Preferences and trade-offs are specified by the individual decision maker using NSS. Automated systems are usually highly reliable, but the increased complexity associated with automation may also increase the possibility of error. Algorithmic calculations are critical in solving multi-criteria problems, but it is the decision maker, not the algorithm, that must make the final decision(s) (Delaney et al. 1997). The accuracy of decision tasks may be reduced if decisions depend on estimates made by the human decision-maker (Montgomery 1999). For 
example, sample mean and the sequence of stimulus events appear to affect the decision-makers estimates (Montgomery 1999).

At the outset of negotiations neither party has complete knowledge of the set of possible offers. Each party attempts to learn this information, together with the other party's objectives, through negotiation (Kersten 2001). The objective of distributive negotiation is to achieve an efficient compromise and could be accomplished using multiattribute auctions or negotiation software agents (NSA's). Both are currently used in e-commerce (Kersten 2001). The objective of integrative negotiation is value creation for both parties. Problem restructuring and the formulation of new offers may be limited by the cognitive abilities of the negotiator and the NSS used. Presentation of the problem, and novel alternatives, is limited both by the constraints of the NSS (current NSS's hardwire the issues and/or their semantics), the user's cognitive ability, and the tools for problem decomposition and representation (information management using graphical aids) (Kersten 2001). NSS may also aid in building trust between the parties, possibly leading to increased openness and information exchange. By reducing the demands for information search, assessment, and processing of information for the participants, NSS can play a significant role in value creation in a negotiation (Kersten 2001). Regardless if one takes a distributive or integrative perspective, agreement requires that, at least, the minimum acceptable terms of each side are satisfied. The sheer amount of information, 
and the computational requirements necessary to process it, make this a cognitively intense process for all but the most simplistic of negotiations. Due to the human cognitive limitations, a support system having information about the negotiators and the negotiation problem could be considered to be a useful aid to this process.

Conflicts can sometimes become so complex that practical resolutions are not reached due to the cognitive difficulty of identifying and understanding the solutions. NSS can potentially improve the negative effects of cognitive limitations, cognitive biases, and dysfunctional socio-emotional aspects of negotiator behaviour. Even when an agreement is reached, joint gains are often left on the table. According to the decision making approach, each party in a negotiation is a decision maker whose behaviour is a result of choices based on judgements s/he makes about the negotiation situation (Loewenstein et al. 1989). In an effort to compensate for their cognitive limitations negotiators typically use decision heuristics or simplifying rules called knowledge structures based on their particular set of past experiences (Fiske \& Taylor 1991). The problem with this is that knowledge structures can lead to cognitive, judgemental biases that adversely affect decision quality and the negotiators ability to achieve an optimal resolution to the conflict (Foroughi 1998; Kahneman 2002). 
Empirical studies (Delaney et al. 1997) have indicated that the GSS component of an NSS increases satisfaction for negotiators compared with those not using electronic communication. However, as communication tends to be asynchronous, this may inhibit or slow some negotiation segments, especially offer exchange (bargaining) (De Moor \& Weigand 2004). Examples of commercially available business-to-business NSS are Fair Internet Trader, diCarta, and Ozro Negotiate.

In general, NSS tend to be oriented toward providing a specific functionality related to a single aspect of the negotiation process rather than providing comprehensive support for the entire negotiation process (Kersten 1988; Holsapple et al. 1998; Kersten et al. 1999). No individual NSS has all functions described by the theoretical model of Holsapple (1998). In general, NSS functionality depends on the specific use of the NSS system and the degree of sophistication (communication, DSS, NSS) required. Zachary (1986) states that, in terms of decision-aiding technology, form should follow function. The reasons for this are based on two assumptions about decision aids, that they work by supporting the cognitive processes of their users, and, the opportunities for cognitive support in a specific decision situation are a combination of situational and structural factors specific to the negotiation space. 
NSS generally consist of two components, an individual DSS and an electronic communication channel. Rational negotiation requires substantial information processing capacity (utility calculation, strategy elicitation and evaluation, etc.) that may exceed human cognitive capacity. The use of NSS (external memory and processing capacity) may extend human information processing capacity (Lim \& Benbasat 1993). Graphical representation aids incorporated into NSS are also thought to be able to improve human cognitive performance.

\subsection{Graphical Representation}

In a problem solving situation, each individual constructs a mental representation or cognitive structure in order to comprehend, and organize the beliefs, they hold about a situation (Massey \& Wallace 1996). These mental representations can be shared with others through interactive processes. Mental representations are subject to change as new information is incorporated and old information updated or deleted. However, because communication is typically a verbal interaction, miscommunication frequently occurs resulting in reduced knowledge and problem solving ability. Representational decision aids are reported to help overcome mental resources limitations and extend human processing abilities (Larkin \& Simon 1987; Vessey 1991). These aids are useful in representing and communicating problem perspectives. Internal representations are constrained by, for example, individual technical and social 
background, previous experience with similar systems, and the structure of the information processing system. When internalized mental representations can be explicitly presented in graphical form (e.g., diagrams, maps, pictures, flow charts, etc.) the graphical form can be used as the common framework allowing members to interact with each other and communicate their perspectives.

Decision making with computer support is fundamentally different from unaided decision making. In the unaided situation, the person acquires, assimilates, and forms a mental representation of the problem entirely on their own. With computer support the person must also develop an understanding and mental representation of the problem as it is represented by the decision support system. Representation aids are interfaces providing a method to present the problem customized to the needs and capabilities of human cognitive processes (Zachary 1986). These techniques focus on the natural ways humans acquire and represent decision problems, either visually (pictorial or spatial representations) or verbally (linguistic representation). Humans cannot deal intuitively with a problem expressed as a series of equations, generally the form in which utility values are expressed (algorithms) (Kersten 2001). However, they can deal effectively with the same problem represented graphically. Humanaided optimization techniques rely upon, and work in tandem with, representational aiding techniques (Zachary 1986). In a negotiation, the most straightforward way to provide context is to present offers as a graphical display. 
According to Fry (1981) (page 389), "Graphs...tend to show the "big picture' or gestalt...Often interrelationships can be seen better with a graph than with a purely verbal or numerical presentation." Umanath (1988) report that business managers overwhelmingly used only line or bar charts for graphical reports. They also found the graphical form of information superior to tabular forms both for recall of directional order and pattern recall.

The general explanation for graphical aids enhancing performance is thought to be due to the increased efficiency of acquiring and processing information by enhancing graphical perception and cognition. Working memory is a known bottleneck in graphical information processing (Vessey \& Galletta 1991; Lohse 1997). Larkin and Simon (1987) argue that diagrams improve information processing by indexing information needed to solve a problem more effectively and efficiently. The literature indicates that graphs tend to improve decision speed but not accuracy (Jarvenpaa 1989; Vessey 1991; Vessey \& Galletta 1991). The benefit of a specific graphical format tends to be dependent upon task and decision aid fit (Vessey 1991; Vessey \& Galletta 1991). Modifying the graphical aid may simply change the efficiency of the graphical perception task. 
Spatial proximity and commonality of colour decrease information access cost by reducing eye and head movement necessary to acquire the information. Reduced information access costs result from the automaticity by which perceptual operations are carried out. Colour is automatically detected, and mental operations carried out in working memory can be replaced with automatic perceptual operations thus reducing mental load (Lohse 1997). Subtle graphic design changes within similar graphical aids (e.g., changing a line graph from black and white to colour) does not change the strategy used to acquire information from the graphical aid, but only changes the efficiency of data acquisition. The segregation of colour channels in the human brain is an example of parallel organization in the mammalian visual system (Hill \& Wyse 1989). Colour allows grouping of items having the same target colour so that they can be scanned separately from other items in the display. When a colour coding scheme is used, items of a different colour than the target have virtually no effect on search time (Lohse 1997). Serial processing of the visual features of a graph reduces our ability to process complex visual information. For example, having to discriminate among monocolour shapes imposes an additional load on working memory such that some information may be lost in the process forcing the viewer to reread some part of the graph at the cost of increased processing time, and perhaps increased error rate. Grid lines were found to provide vertical and horizontal baselines for slope comparison and facilitate the speed and accuracy of perceptual judgements thus reducing information processing 
demands. Subjects using a colour graph with grid lines tended to be more accurate than those using a monocolour graph without grid lines (Lohse 1997).

Wickens (1995), states that graphs reduce cognitive load by shifting some of the information acquisition demands to our visual perception system which frees cognitive resources for use elsewhere in the problem-solving task. However, this is only assumed to result in improved decision performance if the decision-maker has capacity-constrained cognitive resources which are thereby freed for use elsewhere in the problem-solving process (Lohse 1997). When cognitive demands are substantially increased graphical aids reduce problemsolving effort by conserving cognitive resources allowing individuals to perform more difficult tasks than if the information was presented in another format (Lohse 1997). The explanation by Lohse (1997) for this is that subjects make the same mental calculations, but differ in computation efficiency depending upon the capacity (high or low) of their working memory. The difference was especially prominent at high levels of task complexity.

The usefulness of a given graphical display appears to be related to the decision problem (Jarvenpaa 1989). Studies on the role of tabular displays in consumer information behaviour have indicated that the format used to present the information affects decision outcomes through the format's influence on cognitive processes (Tversky 1969; Painton \& Gentry 1985). Alternative and 
attribute processing strategies are used by people to acquire and combine information from different displays. In alternative processing, information is processed on several attributes of a single alternative before information is processed on any other alternative. In attribute processing, information is processed on one attribute for several alternatives before information is processed on any other attribute. The format the information is presented in (i.e., alternative or attribute format) dictates the processing format for the decision maker. However, decision makers use both alternative and attribute processing when information is presented in matrix format (Bettman \& Kakkar 1977).

Payne (1982) has proposed an explanation for the effects of display format on problem-solving strategy. He argues that strategy selection is a deliberate compromise between the benefits of minimizing errors and the cognitive costs (effort) in a particular task environment. The organization of information on a display affects this cost-benefit trade-off by making some strategies easier to use than others. The term incongruence is used to refer to situations in which the processing directions required for a decision strategy and those encouraged by the graphical presentation format are in conflict (Jarvenpaa 1989). The cost/benefit principle suggests that incongruence must invoke some cost, either in increased time (effort) or in decreased accuracy (error), or both. Jarvenpaa (1989) empirically demonstrated that the cognitive costs and benefits explain the interaction effects of graphical formats and task demands for the 
acquisition and evaluation of information. Incongruent situations may make decision makers acquire information in the direction encouraged by the display format, but evaluate the information in the direction required by the formulated evaluation strategy. Information acquisition entails information search, storage, and retention; information evaluation combines the acquired information to arrive at a choice. The processes of acquisition and evaluation are the first two stages in the concept of decision making (Einhorn \& Hogarth 1981).

Research into decision making under uncertainty indicates that decision makers use three heuristics: representativeness, availability, and, anchoring and adjustment (Kahneman \& Tversky 1973; Kahneman \& Tversky 1984; Kahneman 1991). Availability is the phenomenon where decision makers reach conclusions based on perceptions of the frequency of an event's past occurrence or to the probability of its present occurrence. Anchors are estimates of the starting (initial) value generated by an individual where the actual value is unknown or uncertain. A vivid information display makes the information in a problem representation more available, and available in a more easily processed form, to facilitate decision making (Vessey 1991).

Representation aids are of three types (Zachary 1986). The first allows a person to interact with the aiding algorithm in a natural manner (e.g., using natural language or a pictorial metaphor). This minimizes the cognitive load 
imposed by the decision aid requiring the decision maker to translate between their internal representation of the problem and that of the decision aid. The second is to represent the problem in a stylized way that capitalizes on human cognitive processing ability, usually the powerful parallel processing ability of human visual perception. Humans are good at directly perceiving spatial relationships, as compared to indirectly inferring them, when presented with the appropriate visual terms. Also, humans can reason about relationships in spatial terms by using visual metaphors. For example, a strictly numerical optimization problem may be represented by depicting the objective function as a surface on a 3D graph. The highest point, representing the optimum solution, is easily identified by simple visual inspection. This is not true if the same information is presented in matrix format. The third type is to capture the representation or mental model used by expert decision makers (i.e., expert systems composed of rule-based models) and incorporate this into a DSS interface.

A mental model is a mental representation of a system that can be used to describe, explain, and predict future system states (Swaab et al. 2002). Mental models allow individuals to understand phenomena, make inferences, and experience events by proxy. A shared mental model of the task serves to organize the beliefs of the individuals about the nature of a problem and possible solutions in a given situation. Often in negotiations people see what they wish, or expect, to see due to differences in a priori knowledge (Swaab et al. 2002). The 
motives they have during the negotiation also influence their perceptions. The result is that each party has a different conceptualization of the problem situation. Inconsistencies between their understanding of the problem and potential solutions may result in conflict beyond the scope of the negotiation itself. Conversely, parties having similar knowledge might be expected to recognize commonalities between them, possibly forming the basis for convergence and settlement. The recognition of similarity is generally a good predictor of social attraction and therefore may promote development of some form of common identity (Berry 1998). Both liking and common identity reflect a pro-social climate, a strong precursor to mutually satisfactory negotiation and decision making (Kahai \& Cooper 1999; De Dreu et al. 2000). A shared mental model can influence negotiation outcomes by providing a common view of the problem, and potential solutions, to the negotiators and indirectly by fostering a pro-social climate.

In a negotiation setting, people perceive the information they are exposed to. During the initial attention phase, a person encodes the information by structuring, evaluating, interpreting and transforming the information into a mental representation. This information is then stored in memory to, possibly, be retrieved later in the negotiation (Swaab et al. 2002). If people perceive or encode the information they are exposed to differently then a divergent cognition situation occurs, possibly hindering the negotiation process. Visual 
representation is one method to reduce message ambiguity. The basis for this is that representational aids (images, charts, maps, etc.) are easily comprehended and thus minimize the scope for divergent interpretation compared to textual and verbal information (Massey \& Wallace 1996). Graphical representations may provide a common framework to allow negotiators to directly perceive the problem space thus reducing the time required to frame possible solutions compared to relying solely on logical inferences based on interpretations of language.

Graphs are considered to be imaginistic (convey continuous information) while tables are verbal in nature (convey discrete information) (Pracht \& Courtney 1988; Vessey 1991). Graphs are spatial problem representations as they present spatially related information that emphasizes information about relationships in the data. Tables are symbolic data representations as they present information that is symbolic in nature. Tables represent discrete data values. Graphs and tables are problem representations that emphasize different characteristics of a given data set. Spatial representations (graphs) facilitate viewing the information at a glance without addressing the elements separately or analytically. Therefore, perceptual processes provide an appropriate access to graphical data. Symbolic representations facilitate extracting specific data values. Therefore, analytical processes provide an appropriate access to the data in tables (Vessey 1991). 
Computer graphics is the most common technique for conveying spatial representations. In applying graphics as a decision-aiding technique, the basic relationships are first transformed into a pictorial representation expressing the relationships in meaningful spatial terms. The decision aid interface is then implemented to physically communicate the corresponding input and output for the pictorial representation via computer graphics in, for example, a NSS. The problem is determining and implementing a spatial problem representation that is compatible with both the input/output requirements for the decision aiding technique and one that is easily internalizable by human decision makers.

Tasks may be classified into elementary tasks and those involving higher level decision-making activities. Elementary tasks require just one operation on the data (e.g., yes or no) and mainly involve information acquisition tasks or tasks involving comparison of two data values. Decision-making tasks, such as those involving judgement or inference in a negotiation, are more complex tasks that must usually be decomposed into several subtasks. They involve both information acquisition and information evaluation. The paradigm of cognitive fit may be applied to those tasks in which the nature of the task and/or subtasks can be determined.

Umanath and Scamell (1988) empirically validated these two basic task types in a recall experiment. Point value recall was facilitated by tables while 
simple comparison was facilitated by graphs (Umanath et al. 1990). Spatial tasks include interpolating values while symbolic tasks (facilitated by tables) involve extracting discrete values. Spatial tasks require making associations or perceiving relationships in the data. These tasks are best accomplished using perceptual processes. Perceptual processes view data values in context - they enable a set of data points to be examined simultaneously. Since symbolic tasks lead to precise data values they are best accomplished using analytical processes used to extract and act on discrete data values. Analytical processes are used in both symbolic information acquisition and information evaluation for carrying out computations on data (Vessey 1991). Tables facilitate the recall of specific amounts, pictographs of simple comparisons, and line graphs of trends.

According to Larkin and Simon (1987), external representations are of two kinds of symbolic expressions for problem definition, sentential representation or diagrammatic representation. Sentential representation expresses the problem in a sequence of sentences in a natural language description. Each expression is a direct translation into a simple formal language of the corresponding natural language sentence. Diagrammatic representation expressions correspond on an equivalent basis to the components of a diagram describing the problem. Each expression contains the information that is stored at one particular locus in the diagram, including information about relations with adjacent loci. The fundamental difference between the two is that diagrammatic representations 
explicitly preserve the information about the relationship among the components of the problem, while sentential representations do not. Sentential representations may reflect other relations, for example, temporal, logical, or hierarchical.

Two representations are considered informationally equivalent if all of the information in one is inferable from the other and vice versa. Each could effectively be constructed using the information contained in the other (Larkin \& Simon 1987). Two representations are computationally equivalent if they are informationally equivalent and any inference that can be drawn from the information can also be drawn from the other with equivalent ease and speed. In general, the computational efficiency of a representation depends on the data structure, program, and attention management factors and how well they work collectively. The usefulness of a representation depends on what productions (inference rules) are available for searching the data structure, for recognizing relevant information and for drawing inferences from that information (Simon 1978).

In a negotiation context, positional comparisons and utility evaluations are required in order to determine if an offer should be accepted. This is considered a spatial task and therefore, based on the above, would have a matching representation to the task with a graph. During the negotiation, positional 
comparisons are required in order to construct, defend and modify reservation and utility values. According to Kersten (2001), offer acceptance or rejection can only be determined on a comparative basis with the utility value of other offers. The easiest method to perform this comparison is using a graphical aid. Graphical representation aids are expected to positively affect negotiation outcomes.

\subsection{Creating Value and Reaching Agreement}

\subsection{Power in Negotiation}

The simplest method to conclude a negotiation is to determine what an opponent minimally requires and accede to it. However, if an opponent's power is sufficient to encourage this type of concession, it is unlikely they would accept the minimum or that their opponent would be able to discover their reservation value. Power is usually defined as the ability to influence another party (Pruitt, 1981). In the negotiation context, it is the capacity to make successful demands and elicit concessions from the opponent. Power includes all of the conditions that encourage unilateral concession-making by an opponent and encompasses the successful use of all competitive tactics and the conditions (e.g., credibility) allowing the use of these tactics (Pruitt 1981).

Power is a broad phenomenon that is usually ignored by game and bargaining theorists. It is usually assumed that power, skills, and knowledge are 
equally distributed and that power is determined by the eventual outcome (Cross 1969; Gulliver 1979). This is generally stated as: "He who wins is more powerful" (Gulliver, 1979) page 206. Similarly, there is Weber's notion of macht or imperative control by which a person is seen as exercising control over others so as to bring about compliance (Weber 1947). In reality, power is a variable by which one party attempts to manipulate the other's perceptions and preferences to their advantage. Power can be conceptualized in several ways: strategic, normative, or relationship based (Polzer et al. 1995). Strategic power depends upon the alternatives available to the negotiator. Normative power has no strategic function, but arises from beliefs about what constitutes an equitable settlement using two types of resources, non-normative (economic, physical, political) or normative (rules, standards, morals). Relationship based power depends on the relative power structure and distribution between individuals. For example, one person in a relationship may have superior power due to greater knowledge, skill, technology, or trust. However, a difference must be recognized between potential power and the actual ability to utilize it successfully. The possessor of potential power may not appreciate it, may not attempt to use it, or may not be able or willing to communicate it's possession to the other party. In a negotiation, an attempt to exercise potential power may be resisted and countered by the other party's exercise of their power. In effect, a feedback mechanism exists to modify the perceptions, expectations and limits of the participants with respect to their negotiating power (Polzer et al. 1995). 
When two individuals interact repeatedly over time, a social relationship that may be friendly, neutral, or unfriendly is likely to develop (Lawler and Yoon, 1995). The relationship that develops likely depends upon the social context giving rise to the interaction, the strategic action adopted in response to that context, and the joint results produced. Structural power establishes the contextual conditions for negotiations between actors in a network by providing incentives for them to negotiate repeatedly and to arrive at satisfactory agreements. Structural power concerns the objective relations of dependence and interdependence of the two actors (Baccharach \& Lawler 1981; Emerson 1981). Where the relationship provides greater benefit (expected value) to each actor than the alternative, a synergistic effect occurs. The assumption by Lawler \& Yoon (1995) is that if people act on these power conditions and repeatedly negotiate satisfactory agreements with each other, they will develop an emotional/affective commitment to their relationship that will change the context for future negotiations. At the base level, each successful transaction event creates a positive relationship leading to trust, reciprocity, and more positive outcomes. As stated by Berger \& Luckmann (1967) the relationship becomes a "third force." The degree of dependence varies positively with the value actors ascribe to the outcomes, resources, or issues at stake, and negatively with the availability of such outcomes or resources from elsewhere (i.e., vs. BATNA) (Baccharach \& Lawler 1981). Successful intra-negotiation outcomes will positively affect the negotiation outcome. 
Emerson's exchange theory takes the form of a causal chain where structural power is linked to commitment through the frequency of exchange (Emerson 1981). Frequent exchange among the same actors produces commitment by reducing uncertainty or increasing interpersonal attraction (Lawler \& Yoon 1995). The two intervening mechanisms, that the actors come to know each other better (uncertainty reduction) or they come to like each other more (interpersonal attraction), may explain the link of repetitive exchange and commitment.

\subsection{Affect in Dyadic Negotiation}

Decision makers tend to substitute more efficient problem-specific decision processes in place of less efficient general problem-solving strategies (Zachary 1986). These expert strategies are based on domain-specific reasoning methods combined with problem representation. Both the reasoning strategy and the representation are learned and domain specific. When a complex problem is unable to be solved due to insufficient time, cognitive limitations, or other reasons, the decision maker may revert to a less complicated, general reasoning method, a heuristic.

Most behaviour is intuitive, skilled, unproblematic and successful (Kahneman 2002). People rely on a limited number of heuristic principles that allow them to reduce the complex tasks of assessing probabilities and predicting 
values to simpler judgemental operations. Although, generally, these heuristics are quite useful they may cause heuristic-induced bias (Tversky \& Kahneman 1974). A judgement is said to be mediated by a heuristic when the individual assesses a specified target attribute of a judgement object by substituting a related heuristic attribute that comes more readily to mind. Heuristics can be stimulus induced, and not always consciously. The idea of an affect heuristic was proposed by Slovic (2002) to explain how basic affective reaction can be used as the heuristic for a wide variety of more complex evaluations.

The negotiation process in a dyadic setting is composed of two components. The relatively fixed situational context the negotiation takes place in and the thoughts, plans, and actions of the negotiators (Barry \& Oliver 1996). Affect refers to feelings, moods, or emotional states that individuals experience in response to situations and circumstances. These vary from strong to weak and from positive to negative. In evolutionary terms, the ability to recognize negative affect (i.e., danger) in an aggressor and the ability to achieve negative affect, in order to muster the fight or flight response, were key to survival. In contrast, positive affect (joy) has fewer survival implications. The maintenance of positive affect, as opposed to negative affect (e.g., anger, contentiousness, etc.), is thought to enhance the joint outcomes for negotiations (Carnevale \& Isen 1986). Positive affect is said to exist within social relationships where the interacting parties have, or develop, a personal relationship characterized by friendship, 
trust, closeness, or congeniality; negative affect is characterized by distrust, acrimony, vengeance, loathing and hostility (Barry \& Oliver 1996). Affect is thought to be a function of prior perceptions and experiences that negotiators bring to the table (Carnevale \& Isen 1986). When a positive affect relationship (friendship, trust, etc.) occurs, a negotiator often becomes more aware of the other party's needs and is less motivated to use extreme offers or tactics to improve their position. Although trust is an important factor, it is not measured as it is beyond the scope of this study.

Oliver et al (1994) found that satisfaction with a negotiated settlement is positively associated with the desire for future interaction with the same opponent. Frequent exchange was also found to foster positive affect that yielded an affective commitment to the exchange process (Lawler \& Yoon 1995). Positive affect or pleasant feelings can have important effects in negotiation as they can encourage cooperation and creative problem solving, and, lessen anger and hostility (Carnevale \& Isen 1981; Baron 1990).

Affect states influence choices actors make among available behavioural options and thus mediate the tactics employed by negotiators. Here tactical behaviour refers to an actor's motivational orientation (Pruitt 1981) which is distinct from competition and cooperation (Deutsch 1973). Those with a competitive orientation are concerned primarily with their own outcomes while 
those with a cooperative orientation make choices reflecting a concern for joint interests (Barry \& Oliver 1996). Tactically, those having a competitive orientation try to persuade their opponents to make concessions while cooperative individuals engage in problem-solving behaviour in order to reach a more integrative outcome (Pruitt 1981). Evidence suggests that cooperative behaviour elicits interpersonal trust that may in turn be construed as enhancing interpersonal affect (Tsui \& Barry 1986). Conversely, Fry (1983) report a negative relationship between couple involvement and joint profit for dating dyads (couples). This was thought to result from fear that conflict would harm the relationship. Therefore, positive affect may not always produce higher joint gains in negotiations. Barry \& Oliver (1996) argue that expectations depend if affect is related to an interpersonal relationship with the opponent and that the outcomes obtained by the individual negotiator influence post-negotiation levels of positive affect. Positive affect increases relative to the extent that negotiators achieve outcomes exceeding expectations, and is reduced by outcomes the do no meet prior expectations. These post-settlement levels of affect may lead to perceptions of greater satisfaction and an increased desire for future interaction with the bargaining opponent (Oliver 1993). An indirect indicator of satisfaction can be the willingness of participants to take part in another negotiation and the perception of the friendliness of the process. 


\subsection{The We/l Ratio}

Liking, identification, future dependence, and good mood are expected to facilitate obtaining concessions (Pruitt, 1981). There is evidence that we are particularly helpful to people we like (Baron 1971). Therefore, it is to a negotiator's advantage to attempt to induce a positive mood in the other party. This tactic is commonly employed by behaving in a friendly manner, seconding the other's attitudes, and respecting the other's values. The principles of cognitive dissonance and self-perception imply that one will come to like a person treated in a pleasant and rewarding manner. If the other becomes pleasant and rewarding in response to this positive behaviour, their value is enhanced (Berry, 1998).

Carnevale \& Isen (1981) have shown that explicit information exchange and joint benefit are enhanced by positive mood which was reduced if the participants were separated. The perception of being helpful may affect concession making. According to Staub (1978), "When we define people as 'we,' we are more likely to help them (page 313)." This suggests that a negotiator is more likely to have a coordinative orientation if they feel they have a common bond with the other party. This form of information exchange is also correlated with a measure of psychological closeness, specifically the ratio of first person plural to first person singular pronouns used in the negotiations (Pruitt, 1981). This is known as the we/l ratio, and is determined to consist of two types of first 
person plural pronouns in communications, references to both participants as a single entity (we or us) and references to themselves alone (me or I). Increased reference to the negotiators as a single entity is considered an indicator of common group membership (in-group) and psychological closeness (Staub 1978). These pronouns are easily distinguishable by means of context, and are indicative of feelings of common group membership.

\subsection{Creating Value}

Many negotiations are characterized by suboptimal tradeoffs, failed communication, and lost opportunities (Pruitt, 1981). Although some negotiations have more integrative potential than others, if only one issue exists a zero-sum situation occurs as what is gained by one person is lost to the other. In this type of distributive bargaining situation, there is no possibility for trade-offs or joint gains (Raiffa, 1982). For distributive bargaining, both sides are assumed to have full knowledge as to the elements of the set of possible agreements, with the exception that each may be unaware of the exact benefit (or utility) of an agreement to the other (Cross 1977; Gulliver 1979). The problem is therefore reduced to that of selecting one settlement point from the possibilities (Pruitt, 1981). The emphasis is placed on division and reaching a compromise rather than cooperation (Cross, 1977). Integrative agreements can be contrasted with compromises involving conceding to a middle point on some obvious dimension of value. The distinction between integrative agreements and compromises is 
most clearly seen in situations with many possible solutions having different levels of joint benefit. A compromise is one that only partly satisfies the parties' interests; it is often the result of an arbitrary decision (e.g., split the difference) and is generally not Pareto optimal ${ }^{3}$ (Carnevale \& Lawler 1986). Between two alternatives, one is said to be more integrative if it provides greater joint benefit, or utility, to both parties. The object of integrative negotiation is to create a contract that satisfies both parties.

Generally it is thought that the greater the number of issues on the table the greater will be the integrative possibilities due to the potential for logrolling or issues trading based on preference differences (Naquin 2003). Having multiple issues allows the negotiator to realize differences in preferences or differences in how issues are valued. Higher joint gains may be realized by trading issues of lesser value for those that are more highly valued. For integrative bargaining Walton \& McKersie (1965) believe that the fullest disclosure of information is preferable as it is most effective. If each party is able to discover what possibilities are available they can therefore coordinate with the other to achieve an agreement more mutually satisfactory than would be possible in competition with less knowledge of the situation (Umanath \& Scamell 1988).

\footnotetext{
${ }^{3}$ The solution to a multiobjective problem is usually not a particular value, but a set of decision variables such that none of the objective functions can be further increased without a decrease of some of the remaining object functions (Nash, 1950). Every such value is referred to as Pareto optimal.
} 
Kersten(2001) provides a detailed review of the distinctions between distributive and integrative negotiations. Value creation is considered one of the key characteristics of integrative negotiation. Each party enters the negotiation intent on satisfying at least their minimum requirements, although each probably desires more. As there may be overlap in their preferences, there often many feasible solutions to any negotiation (Lebow, 1996). The outcome is often a compromise between the initial demands and expectations of each, or the joint creation of some novel solution. If the minimum requirements of each party are met, agreement becomes possible. As each party is assumed to negotiate in order to improve their position relative to the status quo then every negotiation has the possibility for value creation rather than simple positional improvement (Kersten 2001). People will not, unless forced to, negotiate without an expectation of improving their position relative to the status quo, their reservation value, or BATNA. Any compromise (settlement point) must dominate these three alternatives. In most negotiations, a party does not have to settle but may instead opt to accept their best alternative to a negotiated agreement (BATNA). In a negotiation, a person will usually not accept an agreement that is of lesser value than their BATNA (Yukl 1974; Raiffa 1996; Kersten 2001). For any value below the limit, the player will refuse to accept the negotiated agreement. Tactically, the more favourably their BATNA is portrayed as being less costly, more efficient, less risky, having more desirable attributes, or fewer bad, the 
smaller is the apparent need for the negotiation and the higher is the standard of value that any proposed settlement must have (Sebenius 1992).

According the theory of Boulwarism, named after Lemuel Boulware of General Electric, soon after negotiations commence each party will have a common, although unstated, understanding of what the final agreement will be (i.e., it will be in the range delineated by the opening bids) (Cross, 1977). The stated maxima by each side effectively delineates the agreement space. There are a number of reasons why most real-life negotiations do not follow the "take it or leave it" of Boulwarism, some intrinsic to the negotiation process itself, and others dictated by the negotiation setting. Should one side suggest that the negotiator's split the difference there is a good chance that the other party will use this advantage to extract a larger payoff from the other party. The effect of one party proposing to split the difference moves the agreement range toward the other party. Assuming that both agree that splitting the difference is fair, the new midpoint for agreement now favours the side that did not suggest splitting the difference. Opening bids therefore tend to be relatively small and incremental. According to Bartos (1977), the size of the first concession is dictated by factors tangential to the negotiation (e.g., trust, perceived toughness, time pressure, etc.). The Nash solution (Nash 1950) states that it is fair to split the difference and agree on a settlement point that lies midway between the party's most recent bids. However, while the Nash solution provides a method to 
determine a fair agreement, the antecedent must be a determination of what is considered a "fair" payoff for both parties. With incomplete information, a quick agreement is unlikely to occur as the actors are uncertain if joint gains exist. Therefore, learning must occur before agreement can be reached which prolongs the negotiations.

\subsection{Reference Dependence}

Uncertainty is poorly represented in intuition, as well as in perception. The concept of judgement heuristics was proposed to accommodate the observation that intuitive judgements of probability are mediated by attributes such as similarity and associative fluency, which are not intrinsically related to uncertainty (Kahneman 2002). In most descriptions of decision making, decision makers evaluate outcomes by the utility of the final asset positions stemming from Expected Utility Theory first proposed by Bernoulli (1954) in 1738. Although Bernoulli's model is reference independent, this is not actually the case as utility depends not only on current wealth but also on a reference point to the individuals' current level of wealth (Kahneman 1991; Kahneman 2002). Prospect theory (Kahneman \& Tversky 1979), states that preferences are referent dependent according to the perceived wealth change rather than wealth sum. Prospect theory concerns short-term outcomes as opposed to the long-term results of Bernoulli's theorem (favoured by the descriptive norms of rational decision making). Utility cannot be divorced from emotion, and emotion is 
triggered by changes such that life is lived in the present rather than the longterm. A choice theory that ignores losses (pain) and mistakes (regret) is descriptively unrealistic and may lead to prescriptions that do not maximize outcome utility (Kersten 2001).

According to prospect theory (Kahneman \& Tversky 1979), unidimensional decision outcomes (e.g., money) are coded as gains or losses relative to a reference point. Therefore, if negotiators change their reference point, they frame decision outcomes differently as either gains or losses relative to that reference point. Neale (1985) showed that when a negotiation task was positively framed agreement was more likely than if it was negatively framed. A negotiator not only evaluates an offer but also makes a counteroffer relative to their reference point at that time. Kahneman (1991) suggests that an anchoringadjustment process may be involved such that an initial offer is used by the receiver as an anchor (reference) point from which calculations are made to generate the counteroffer. The counteroffer often falls in the range of splitting the difference (Lebow, 1996). One explanation for this is that due to the cognitive requirements of reaching a rational decision, the parties go for some conspicuous but arbitrary point (e.g., splitting the difference, using a round number, etc.). This point has been referred to as an 'intrinsic magnetism' - a point obvious to both allowing a resolution (Schelling 1960). When there is no conspicuous point, it may be possible to create one (a common tactic by 
mediators) by focussing on a middle position (Gulliver, 1979). However, the counteroffer can be expected to differ depending on the anchor point chosen by the negotiator (Kristensen \& Garling 1997).

If both parties share the principle of fairness and it is applicable to the negotiation situation, then a settlement should be easy to agree upon as both sides are likely to view the same settlement point as being correct. Also, by the principle of fairness, both sides are likely to view this as the inevitable outcome knowing the other side will not accept less (Carnevale \& Pruitt 1992; Kersten 2001). Research by Pruitt (1985) found faster and/or more reliable settlement was reached when an option outcome provided equal benefit to both parties, or was equidistant from the starting point such that it could be reached by equal concessions (Joseph \& Willis 1963). As splitting the difference is commonly considered fair the initial offers should bound the settlement point which should be equidistant from these offers.

\subsection{Inspire Negotiations}

A detailed description of the system design, offer exchange process, and data logging methodology is contained in Kersten and Noronha (1998), Kersten et al. (1999), and Kersten and Zhang (2003). 


\subsection{Overview}

This study involved a comparison of multi-issue bilateral negotiation using two variations the INSPIRE NSS. The InterNeg (http://interneg.org) computerized NSS designated INSPIRE is designed to simulate the main characteristics of a real negotiation (Kersten \& Noronha 1998). The INSPIRE database consists of over 3000 bilateral negotiations conducted since 1996. Analytical support allows each negotiator to assess their position in the negotiation in a numerical format.

\subsection{Participants}

The majority of participants $(57 \%)$ self-identified as undergraduate university students, although others (e.g., professionals, instructors, or interested individuals) also participated (Table 1). Of over six thousand participants, only a very few self-identified as a professional negotiator $(n=4)$. Each participant was normally paired with a counterpart from another university. The international nature of the negotiations often resulted in a participant being paired with a person from another country. No monetary incentive was offered for participation, although some received academic credit for participation or may have used the system for negotiation training. Participation was both anonymous and voluntary; the negotiation could be discontinued by either party at any time. 
Table 1: Pre-Negotiation Self-Identification of Occupation

\begin{tabular}{|l|c|c|}
\hline \multirow{2}{*}{ Occupation } & \multicolumn{2}{|c|}{ Percentage of Population } \\
\cline { 2 - 3 } & Control Model (graph) & Experimental Model (no graph) \\
\hline Student & 56.6 & 64.2 \\
\hline Professional & 16.9 & 30.2 \\
\hline Undefined & 22.7 & 5.7 \\
\hline Other & 0.04 & 0.0 \\
\hline Negotiator & $<0.00$ & 0.0 \\
\hline
\end{tabular}

\subsection{Negotiation Preparation}

In the preparatory phase, the parties are given, and asked to read, the case material in electronic format. The case description each party reads depends on the role they are assigned (i.e., buyer or seller). Buyers represented Cypress Cycles, a firm that assembles and sells bicycles (Appendix A); sellers represented Itex Manufacturing, a manufacturer of bicycle parts (Appendix B). Participants were required to reach agreement on four different issues (the price of the bicycle components, delivery schedules, payment terms, and defective parts return). Each case was neutrally framed. Participants were asked to negotiate for the benefit of their respective company, not for themselves. Each party was also informed that their firm was interested in achieving a compromise agreement, but that other suppliers and buyers are possible so there were other options to an unsatisfactory outcome. The negotiators made their own decisions regarding preferences, strategies, and tactics. 
Each party then distributes points across the four issues to be negotiated (price, delivery, payment, and, returns) according to (1) the relative preference among the issues, and, (2) the relative preferences among the options for each issue depending upon their role as buyer or seller. The importance of each issue relative to the other issues was determined solely by each party acting in their respective role as a buyer or a seller. Each negotiator then completes a mandatory pre-negotiation questionnaire (Appendix C). All the pre-negotiation steps are conducted independently; one negotiator cannot view the preferences and ratings that the other negotiator enters.

\subsubsection{Issue Preferences}

Each party prepares a preference structure template in accordance with their individual preferences. This allows the participants to more clearly formulate their preferences and construct their utility function. The preference structure is constructed by distributing a total of 100 points among the four issues being negotiated (Table 2). The issue of highest importance is awarded the most number of points, and the issue of lowest importance is awarded the least number of points. For example, in Table 2 the negotiator representing Cypress Cycles (Jay) has ranked price as the most important issue and returns as the least important issue. A similar template prepared by the Itex Manufacturing negotiator (Yuyo) ranks price as the primary issue, but does not rate it as high in importance (Table 3). 
Table 2: Sample Issue Preferences for the Cypress Cycles Negotiator

\begin{tabular}{|l|c|}
\hline Negotiation Issue & Rating \\
\hline Price & 60 \\
\hline Delivery & 25 \\
\hline Payment & 10 \\
\hline Returns & 5 \\
\hline
\end{tabular}

Table 3: Sample Issue Preferences for the Itex Negotiator

\begin{tabular}{|l|c|}
\hline Negotiation Issue & Rating \\
\hline Price & 40 \\
\hline Delivery & 30 \\
\hline Payment & 15 \\
\hline Returns & 15 \\
\hline
\end{tabular}

\subsubsection{Option Preferences}

There are only a limited number of options for each issue (Table 4). Each option for the four issues (price, payment, delivery, and, returns) is assigned points determining the most preferable and least preferable issue option values. Jay (Cypress Cycles) has done this in Table 4. His choices indicate a lower price (\$3.47) is preferable to a higher price for Cypress Cycles (the buyer). Issue and option ratings may be changed at any time prior to the termination of the negotiation to reflect a preference change by the negotiator. A similar template of option ratings is prepared by the negotiator representing the seller (Itex Manufacturing) according to his/her preferences. 
Table 4: Sample Option Ratings for Jay Representing Cypress Cycles

\begin{tabular}{|c|c|c|c|c|}
\hline Price & $\begin{array}{c}\text { Rating } \\
(\mathbf{M a x}=60)\end{array}$ & & & \\
\hline $3.47 \$$ & 60 & Delivery & \multicolumn{2}{|c|}{$\begin{array}{c}\text { Rating } \\
(\operatorname{Max}=25)\end{array}$} \\
\hline $3.71 \$$ & 40 & 20 days & \multicolumn{2}{|c|}{$\longdiv { 2 5 }$} \\
\hline $3.98 \$$ & 20 & 30 days & \multicolumn{2}{|r|}{20} \\
\hline $4.12 \$$ & 5 & 45 days & \multicolumn{2}{|r|}{10} \\
\hline $4.37 \$$ & 0 & 60 days & \multicolumn{2}{|r|}{0} \\
\hline Payment & $\begin{array}{c}\text { Rating } \\
(\mathbf{M a x}=\mathbf{1 0})\end{array}$ & \multicolumn{3}{|c|}{$\begin{array}{r}\text { Rating } \\
(\operatorname{Max}=5)\end{array}$} \\
\hline Upon delivery & 0 & Full price & & 5 \\
\hline 30 days after delivery & 5 & $75 \%$ refund with $5 \%$ spoilag & & 2 \\
\hline 60 days after delivery & 10 & $75 \%$ refund with $10 \%$ spoilas & ge & 0 \\
\hline
\end{tabular}

INSPIRE then calculates rating values for the complete packages (possible offers) that are the subject of the negotiation (Table 5). User preferences are rated numerically indicating the most preferable and least preferable offers (Table 5). The distribution of points ensures that the worst outcome, according to the option ratings and preferences submitted by the negotiator, in the negotiation (equivalent to BATNA) has a value equal to zero, and the best outcome has a value equal to 100. For example, as this negotiator represents the buyer, the most desirable terms (Table 5) are a low price, short delivery time, extended payment terms, and a full refund for any returned parts. The offer reflecting these preferences is rated at a value of 100 (Table 5). The least preferable terms would be a high price, long delivery time, payment upon delivery, and only 
a partial refund for returned merchandise; this offer is rated at a value of zero and would be equivalent to BATNA. Package ratings can be adjusted by the user to reflect a more or less desirable package; this will affect the utility value calculated by the system. The 'constant sum' scale also has interval level properties. Similar ratings would be generated by INSPIRE for the seller reflecting their preferences.

\section{Table 5: Sample Package Ratings for the Buyer (Cypress Cycles)}

\begin{tabular}{|c|c|c|c|c|}
\hline Price & Delivery & Payment & Returns & Rating \\
\hline $3.47 \$$ & 20 days & 60 days after delivery & Full price & 100 \\
\hline $3.47 \$$ & 20 days & 60 days after delivery & $75 \%$ refund with $5 \%$ spoilage & 97 \\
\hline $3.47 \$$ & 30 days & 60 days after delivery & Full price & 95 \\
\hline $3.47 \$$ & 20 days & 30 days after delivery & Full price & 90 \\
\hline $3.47 \$$ & 20 days & 60 days after delivery & $75 \%$ refund with $10 \%$ spoilage & 90 \\
\hline $3.47 \$$ & 20 days & Upon delivery & Full price & 85 \\
\hline $3.47 \$$ & 45 days & 60 days after delivery & Full price & 85 \\
\hline $3.71 \$$ & 20 days & 60 days after delivery & Full price & 80 \\
\hline $3.47 \$$ & 60 days & 60 days after delivery & Full price & 75 \\
\hline $3.98 \$$ & 20 days & 60 days after delivery & Full price & 60 \\
\hline $4.12 \$$ & 5 20 days & 60 days after delivery & Full price & 45 \\
\hline $4.37 \$$ & b 20 days & 60 days after delivery & Full price & 40 \\
\hline
\end{tabular}

\subsection{The Negotiation}

The negotiation involves multiple issues differing in utility to the negotiator (Table 5), and follows the traditional offer-counter-offer negotiation format. Negotiation involves exchanging offers and/or messages (Table 6), offer 
evaluation, and negotiation progress evaluation. Offers relate to the negotiated issues and are formulated by choosing a single value for each issue. The offer rating is automatically displayed beneath the table containing the offer. The offer may contain a textual message, or participants may send messages without an offer. Participants could also exchange messages using personal email if they chose to reveal these addresses. The offer rating for each side cannot be viewed by the other party as this would indicate their preferences.

Table 6: Sample Offer with Text Message from the Seller (Yuyo, Itex)

\begin{tabular}{|c|c|c|}
\hline Price & $4.37 \$$ & \multirow{4}{*}{$\begin{array}{l}\text { Dear Jay, } \\
\text { The people of my company and I studied your } \\
\text { offer and concluded that it is not a viable solution } \\
\text { for us. We came up with this offer that we think } \\
\text { will give both companies a win-win situation. I } \\
\text { hope you agree with me and see you soon to } \\
\text { close the deal. } \\
\text { Best regards, } \\
\text { Yuyo } \\
\text { Itex Manufacturing }\end{array}$} \\
\hline Delivery & 60 days & \\
\hline Payment & Upon delivery & \\
\hline Returns & $\begin{array}{l}75 \% \text { refund with } \\
10 \% \text { spoilage }\end{array}$ & \\
\hline \multicolumn{3}{|c|}{ Itex Manufacturing Rating: $\mathbf{1 0 0}$} \\
\hline
\end{tabular}

Table 7: Sample Offer with Message from the Buyer (Jay, Cypress Cycles)

\begin{tabular}{|c|c|c|}
\hline Price & $3.47 \$$ & $\begin{array}{l}\text { Dear Yuyo, } \\
\text { We regretfully inform you that Cypress Cycles is }\end{array}$ \\
\hline Delivery & 30 days & we have revised our terms in order to reflect an \\
\hline Payment & $\begin{array}{l}60 \text { days after } \\
\text { delivery }\end{array}$ & $\begin{array}{l}\text { offer that we are sure you will find superior to the } \\
\text { one initially submitted. } \\
\text { Jay }\end{array}$ \\
\hline Returns & $\begin{array}{l}75 \% \text { refund with } 5 \% \\
\text { spoilage }\end{array}$ & \\
\hline
\end{tabular}


During the negotiation, support for offer construction and counteroffer evaluation is given via ratings based on the utility function together with a graphical depiction of the negotiation progress that can be accessed by the user. Offer ratings are displayed for individual offers below the offer and message table (Tables $6 \&$ 7) and are only known to, and reflect the preferences of, the respective party. Negotiation progress can be evaluated by viewing a graphical display showing the users' ratings of offers sent (in green) and received (in red) and the time that the offers were sent (Figures $1 \& 2$ ). The graphical display indicates the negotiation variations for all issues in parallel (i.e., submitted offers are displayed for both participants). The graphical display gives an indication of distance between the offers submitted and the offers received (i.e., how far apart the two sides are). For example, Figure 1 displays graphically the rating of the offers sent and received from the perspective of the buyer (Jay representing Cypress Cycles) while Figure 2 displays graphically the rating of the offers sent and received form the perspective of the seller (Yuyo representing Itex Manufacturing). The graphical view of the other party cannot be viewed as each contains utility values indicating preferences. Due to the utility construction function, what may be considered a concession by one party may not be viewed as a concession by the other side. 


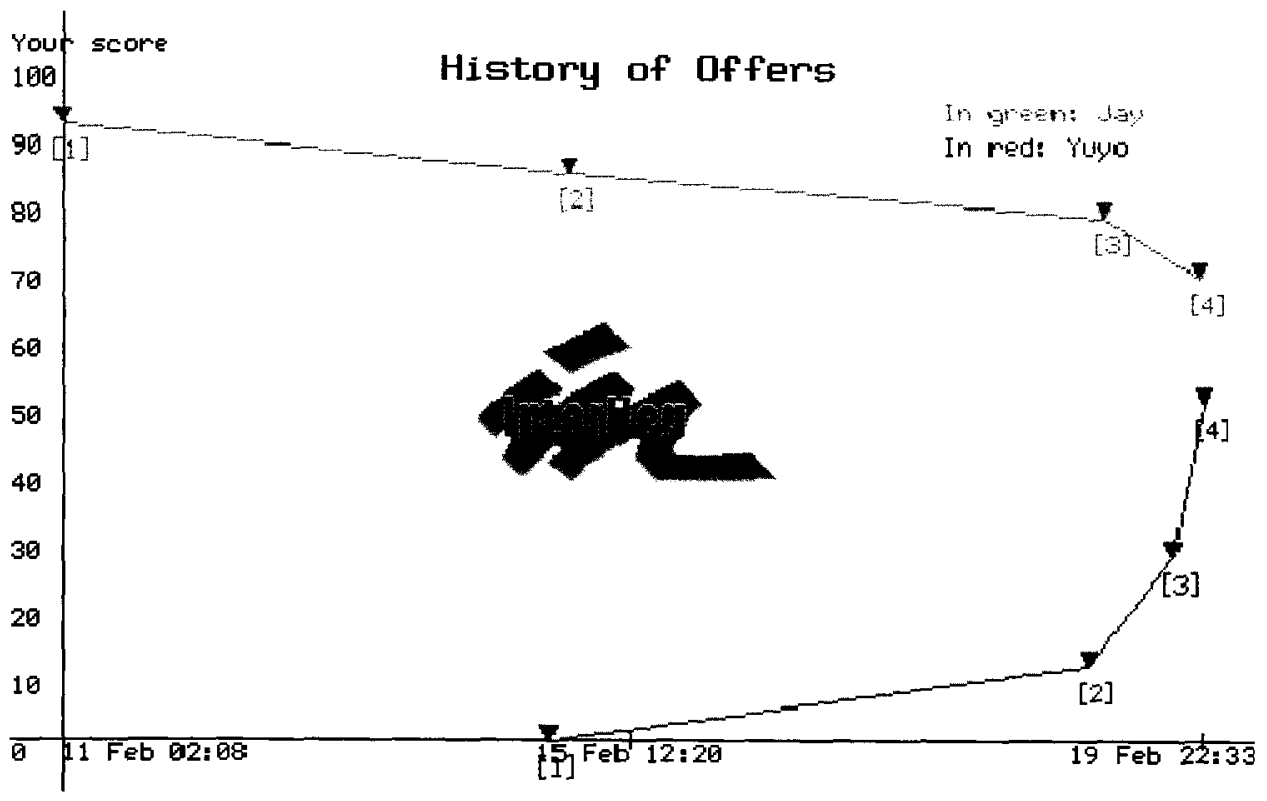

Figure 1: Sample Graphical Display of Offers for Jay

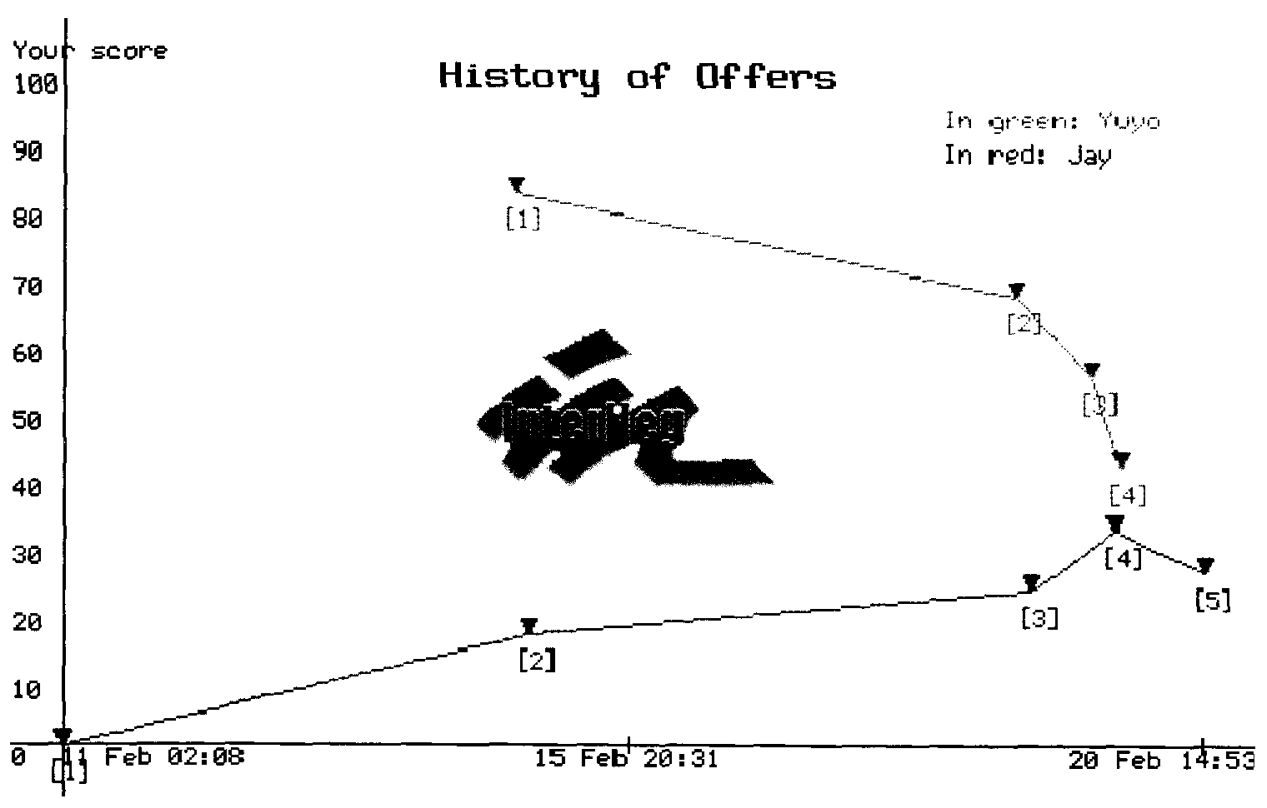

Figure 2: Sample Graphical Display of Offers for Yuyo

Each issue has a range of possible values, but participants are free to select the value of their choice from this range and may submit the same offer repeatedly if they so choose. The parties exchange messages and/or offers until 
a settlement point is agreed upon, one of the participants breaks off the negotiations, or the predetermined deadline is reached. Figure 3 represents the graph viewed by Yuyo, representing the seller (Itex Manufacturing), indicating that agreement has been reached. The settlement point rating values are 62 for Jay (Cypress Cycles) and 38 for Yuyo (Itex Manufacturing). A similar graph could be viewed by Jay representing Cypress Cycles.

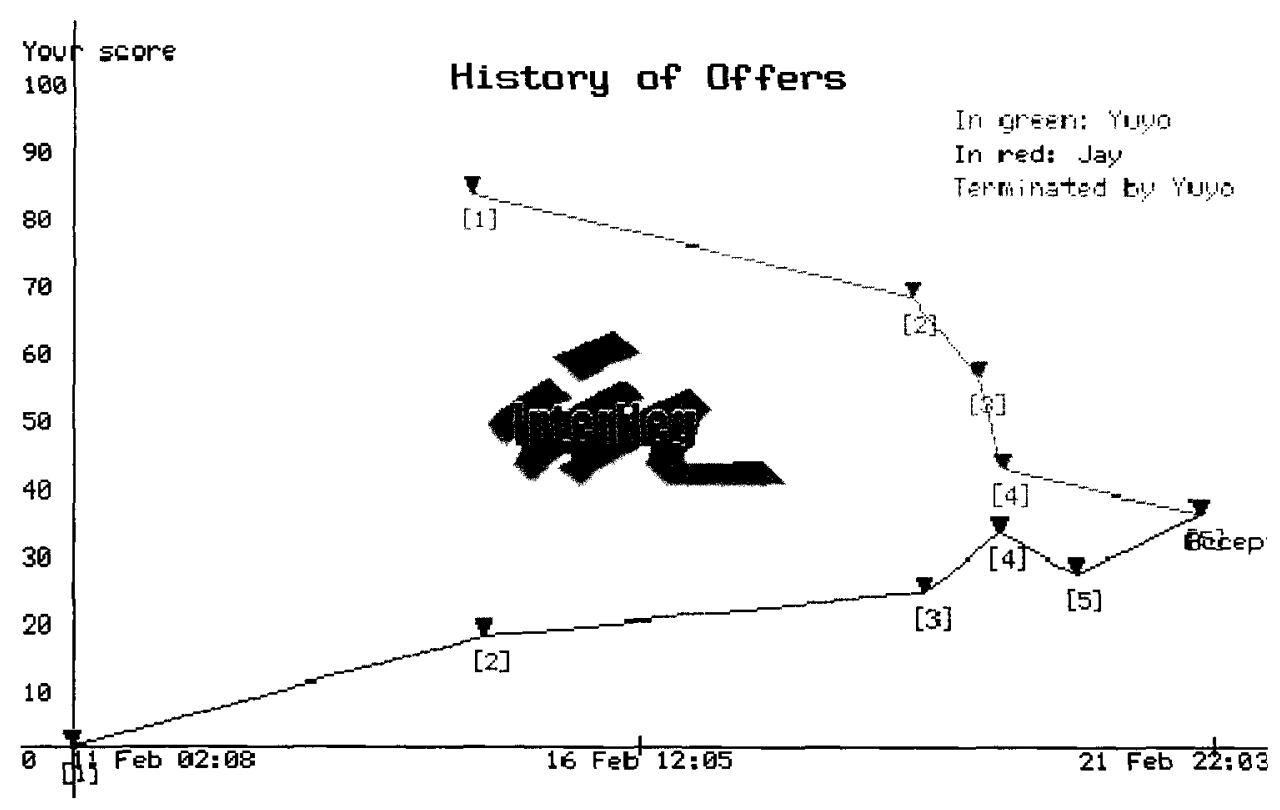

Figure 3: History of Offers Graph for Yuyo (Itex Manufacturing)

\subsection{Experimental (No-Graph) Model}

The experimental system was the same as for the full model described above with the exception that the graphical display (Figures 1, 2, 3) was turned off for both parties (buyer and seller); all other features functioned normally and 
the same as for the full model. No indication was given to either party that system functionality had been altered. Each party was able to know the value of their position (offer) from the offer rating automatically displayed beneath the table containing the offer (Tables $7 \& 8$ ), but was unable to know the relative distance between offers sent and offers received by viewing the graphical display.

\subsection{Post-Negotiation}

The post-settlement phase involves evaluation of the negotiation outcomes generated during, and after, the negotiation. These outcomes include information about the settlement point. If the agreement (settlement) achieved is inefficient (i.e., joint gains are left on the table), INSPIRE will suggest up to five more efficient offers that can be selected. These offers must be Pareto efficient meaning that the offer is better for at least one party than the accepted agreement and not worse for any party. The negotiation ends with the completion of an optional post-negotiation questionnaire (Appendix D).

\subsection{Research Objectives and Hypotheses}

The research objective is to investigate the role of graphical support (independent variable) in reaching a negotiated agreement (dependent variable) using the INSPIRE NSS. 
In a negotiation context, positional comparisons and utility evaluations are generally required in order to determine if an offer should be accepted. This is considered a spatial task and easier for humans to accomplish with cognitive fit and parallel processing (Vessey \& Galletta 1991). By using an appropriate representation to the task it is easier to construct a mental model and hence solve the problem (Zachary 1986; Larkin \& Simon 1987). The reduction in cognitive load by using the appropriate representation may free cognitive resources and reduce problem-solving effort (Lohse 1997). During a negotiation, positional comparisons are required in order to construct, defend and modify reservation and utility values. According to Kersten (2001), offer acceptance or rejection can only be determined on a comparative basis with the utility value of other offers. The easiest method to perform this comparison is using a graphical aid. It is therefore hypothesized that the provision of graphical representation will improve the number of dyads reaching agreement.

\section{$H_{1}$ - Providing graphical support will increase the number of dyads reaching agreement.}

Graphical support is expected to reduce cognitive load and problemsolving effort for offer formulation and evaluation in a negotiation situation. Offer construction and counteroffer evaluation for the INSPIRE NSS are given via ratings based on the utility function for each party, and is expected to be more cognitively challenging to evaluate without graphical support. Where information 
equivalence exists, computational efficiency depends on the data structure (Larkin \& Simon 1987). A cognitively intense problem requires more effort to search the data, recognize and extract relevant information, and draw inferences (Simon 1978). Incongruence between the presentation format and the decision strategy must invoke a cost, such as increased time (effort), reduced accuracy (error), or both (Jarvenpaa 1989). For dyads reaching agreement, graphical representation is expected to reduce the number of offers required to reach agreement compared to dyads without graphical support. A formal offer is considered to be one submitted on all four issues (price, payment, delivery, and returns) using the NSS system as opposed to a verbal (textual) offer that might have concerned fewer than the four issues.

\section{$\mathrm{H}_{2}$ - Providing graphical support will reduce the number of offers required to reach agreement.}

When two individuals negotiate over time, a social relationship that may be friendly, neutral, or unfriendly develops (Lawler \& Yoon 1995). This relationship depends on the social context and the joint results produced by the relationship. The exchange relationship that develops with increased frequency of exchange is considered to be highly significant (Emerson 1981), and increase the probability of reaching agreement in a negotiation. A greater number of offer exchanges (exchange transactions) should increase the probability of a positive relationship developing and enhance the possibility of reaching agreement. More 
offers are expected to be submitted for successful negotiations than for failed negotiations.

\section{$H_{3}$ - More offers will be submitted for successful than unsuccessful negotiations.}

Although this hypothesis $\left(\mathrm{H}_{3}\right)$ does not specifically address the experimental comparison regarding the provision of graphical representation, it is included as it is of interest, and in order to provide context for the following hypotheses.

The negotiation process consists of two components, the situation and the negotiators. The affect state of the participants (feelings, moods, or emotional state) has a large impact on the eventual negotiation outcome. Positive affect (happiness, cooperation, etc.) is thought to enhance joint outcomes for negotiations while negative affect (anger, contentiousness, etc.) is thought to reduce joint outcomes (Carnevale \& Isen 1986). When a positive affect relationship (friendship, trust, etc.) occurs, a negotiator is less likely to use extreme offers or tactics to improve their position. Although trust is an important factor, it is not measured as it is beyond the scope of this study.

Frequent exchange was found to foster positive affect that yielded an affective commitment to the exchange process (Lawler \& Yoon 1995). Oliver et al (1994) determined that satisfaction with a negotiated settlement is positively 
associated with the desire for future interaction with the same opponent, an indirect indicator of affect.

\section{$\mathrm{H}_{4}$ - Positive affect will be higher for dyads having graphical support.}

If a person regards their interests as being similar to those of another, they tend to identify with the others' needs and goals and are more likely to help them (Staub 1978). Conversely, if they regard their interests as being in conflict with the other person they are less likely to cooperate or help them. Various factors may lead to a person defining others as part of their in-group or as part of their out-group. Using the plural pronoun 'we' to describe the other party indicates that they are regarded as part of the in-group (Staub 1978). A negotiator is more likely to have a coordinative orientation if they feel that person is part of their ingroup. Believing that another person is part of their in-group is correlated with a measure of psychological closeness, the ratio of the first person plural to the first person singular in communication with the other party (Pruitt 1981). As negotiations with graphical support are expected to have higher levels of positive affect, it is also expected that negotiations with graphical support will also be more likely to have a coordinative orientation reflected in a higher ratio of the first person plural to the first person singular in textual communication between the negotiators. 
Positive affect or pleasant feelings can have important effects in negotiation by encouraging cooperation and reducing anger and hostility (Carnevale \& Isen 1981; Baron 1990). Positive outcomes are more likely in a cooperative and friendly environment. Although graphical support does not directly enhance positive affect, it may mediate contentiousness and dyadic conflict due the overall improvement in transaction outcomes. Therefore, dyads with graphical support are expected to exhibit higher levels of positive affect which will positively affect the negotiation outcome

\section{$H_{5}$ - The we/l ratio will be higher for graphically supported dyads reaching agreement.}

According to the Nash solution (Nash 1950), it is fair to split the difference between recent offers to determine a settlement point. Even if this method was considered fair to both sides, there is often a problem determining where this point lies. Anchoring theory (Kahneman 1991), suggests that negotiators will often use an initial offer as a reference point. If both parties share the principle of fairness, a settlement should be easy to agree upon as both sides are likely to view the same settlement point as being correct. Also, by the principle of fairness, both sides are likely to view this as the inevitable outcome knowing the other side will not accept less (Carnevale \& Pruitt 1992; Kersten 2001). Research by Pruitt (1985) found faster and/or more reliable settlement was reached when an option outcome provided equal benefit to both parties, or was 
equidistant from the starting point such that it could be reached by equal concessions (Joseph \& Willis 1963). As splitting the difference is commonly considered fair the initial offers should bound the settlement point which should be equidistant from these offers. A graphical display provides an easily interpreted method of locating a middle position subsequent to the initial offers. It is therefore expected that graphical support will influence the eventual settlement point for negotiations reaching agreement by providing a visual basis to locate an easily recognizable settlement point equidistant to the initial offers.

\section{$\mathrm{H}_{6}$ - The settlement value will be equidistant from the initial offers for graphically supported dyads.}

\subsection{Experimental Methodology}

The experimental comparison is between the experimental model without graphical support and the full model with graphical support (control). Participants are randomly designated as either a buyer or a seller of bicycle parts and conducted the negotiation by logging in to the INSPIRE system. Other than the case material specific to their role, no direction was given during the negotiation. Each party chose their own preferences, limits, strategies, and goals. A three week time limit was allowed for the negotiation, although extra time could be requested. No training was given to any of the participants, although there was resource material (glossary, frequently asked questions, and a simplified (two 
issue) example not related to the negotiation case) available on the InterNeg web site.

\subsection{Data Collection}

Data was collected by three methods, the mandatory pre-negotiation questionnaire, the optional post-negotiation questionnaire, and automatically generated negotiation logs containing preference structures, messages, offers, and ratings. A seven point Likert scale ranging from 1 (high satisfaction) to 7 (low satisfaction) was used for all questionnaire responses unless otherwise stated. Negotiations were conducted using the no-graph model $(n=65)$. Results were available from ongoing negotiations using the fully functional (i.e., with graphical display) model $(n=3063)$. The full model dataset consisted of bilateral negotiations between participants from countries listed in Table 8.

Table 8: Bilateral Negotiations Full Model Dataset Countries

\begin{tabular}{|l|l|l|l|l|}
\hline Argentina & Ecuador & Israel & Phillipines & Taiwan \\
\hline Australia & Finland & Malaysia & Poland & United States \\
\hline Austria & Germany & Mexica & Russia & \\
\hline Canada & Holland & New Zealand & Spain & \\
\hline China & India & Norway & Switzerland & \\
\hline
\end{tabular}

Due to unknown causes, some negotiators did not negotiate. These instances are designated as 'one side only' in the data set and were discarded from both the no-graph and full model data sets. The total number of usable cases was 54 for the no-graph model and 2353 for the full model. The large 
number of pre-existing cases for the full model could not be replicated for the experimental (no-graph) model due to resource and time limitations. Although comparative sample sizes were preferable, this was not possible. The statistical methods used for data analysis will take into account the different sample sizes. Subjects using the no-graph model were paired in dyads according to Table 9.

Table 9: Negotiation Pairings by Country for the No-Graph Model

\begin{tabular}{|c|c|c|}
\hline Country 1 & Country 2 & Number of Dyads \\
\hline Austria & Germany & 31 \\
\hline Austria & Russia & 5 \\
\hline United States & Germany & 6 \\
\hline United States & United States & 23 \\
\hline
\end{tabular}

\subsection{Text Analysis}

Offers submitted by a negotiator may be accompanied by a message (Tables $6 \& 7$ ). Text communications were recorded for each individual for the duration of the negotiation. Messages were segregated into success and fail categories and analyzed. The average word count was determined for each negoiator and the frequency of pronouns in the messages was determined using LexiQuest Text Analysis (SPSS version 13, Chicago, Illinois). This software provides an alternative visual view of text information, showing the relative frequencies of sought words. Four categories of pronouns were searched: (1) I, (2) we, (3) I, me, my, and mine, and, (4) we, our and us. 


\subsection{Post-Negotiation Questionnaires}

Participants post-negotiation satisfaction levels were measured by responses to questions concerning (1) their satisfaction with the agreement that was reached, (2) if the outcome of the negotiation matched their prior expectations, and, (3) the perceived friendliness of the negotiation. A seven point Likert scale ranging from 1 (high satisfaction) to 7 (low satisfaction) was used. Measure (1) regarding negotiator satisfaction with the agreement will not be included in the data set for negotiations that did not reach agreement as the question specifically asks: "If you reached agreement..." (Appendix D), and is thus only applicable to successful negotiations. Participants willingness to work with their negotiation partner again was scored true $($ value $=1)$ or false (value $=$ 2). Levels of participant satisfaction and willingness to work with their negotiation partner again are considered to be indirect indicators of satisfaction, and positive or negative affect (Oliver 1993).

\subsection{Statistical Methods}

\subsubsection{Power}

In order to determine the sample size required, test power was determined (Table 10). Power, or being able to observe a treatment effect when it occurs, is a function of sample size, expected effect size, and the alpha (significance) level of the test (Rosner 2000). With a small effect size (mean difference of 0.1 ) high power required a sample size that was not obtainable in this study $(n=770)$. 
The number of cases $(n=65)$ gives power of approximately $9 \%$ (Table 10), which while not optimum, should be sufficient to detect large effects. This effect was selected as the smallest effect that would be important to detect as any smaller effect would not be of substantive significance.

Table 10: Calculation of Sample Size

\begin{tabular}{|c|c|c|c|c|c|}
\hline $\begin{array}{c}\text { Population } \\
\text { Mean } \\
\text { Difference }\end{array}$ & $\begin{array}{c}\text { Standard } \\
\text { Deviation }\end{array}$ & Alpha & $\begin{array}{c}\text { Sample } \\
\text { Size }\end{array}$ & Power & Tails \\
\hline 0.1 & 1.0 & 0.05 & 65 & 0.087 & 2 \\
\cline { 4 - 5 } & & 770 & 0.500 & 2 \\
\hline
\end{tabular}

Both parametric and nonparametric tests are used in this study (Chapter 10). Unless otherwise stated, all statistical tests were performed at the $95 \%$ probability level $(\alpha=0.05)$.

\subsubsection{Parametric Tests}

Parametric tests generally assume that the populations being compared have approximately normal distributions and equal variances (Rosner 2000). Data was compared for the two populations using a t-test; frequency distributions were plotted (histograms) to ensure normal distribution of the data. Alternatively, an F-test was used to determine if the populations had similar variance. Where there was the possibility that the populations did not have equal variance a t-test assuming unequal variance will be used (Welch's test). A one-sample t-test will be used to compare small sample groups to large sample groups as by taking 
the mean of the large group as fixed only the variation in the small group is accounted for.

\subsubsection{Nonparametric Tests}

Nonparametric statistics are distribution free statistics that do not require a normal distribution (Rosner 2000). The Chi-square test is used to determine if the experimental and control groups characteristic (e.g., reaching agreement) differ in proportion compared to those expected by chance. In situations where the sample size is small, as is expected for the experimental group postnegotiation questionnaires, or the requirements of Chi-square analysis are not met, Fishers Exact test will be used. Fishers Exact is generally used if the sample size is less than $\mathbf{2 0}$ or if the expected cell frequencies for a Chi-square analysis are less than five.

\subsection{Results and Data Analysis}

As the number of cases for the full model far exceeded the number for the no-graph model, an F-test was used to determine stable variance in the data. Four sets of data were tested (Table 11). All F-test results indicate similar variances of the populations the samples are from. Histograms (not shown) indicated normal distributions. 
Table 11: F-test Results for Variance

\begin{tabular}{|c|c|c|c|c|}
\hline & \multicolumn{2}{|c|}{ Model } & \multirow[b]{2}{*}{ F-test } & \multirow[b]{2}{*}{$p$ value } \\
\hline & Full & No-graph & & \\
\hline \multicolumn{5}{|c|}{ Case Difficulty } \\
\hline Mean & 2.19 & 2.55 & \multirow{3}{*}{0.9672} & \multirow{3}{*}{0.8258} \\
\hline Variance & 0.7161 & 0.7404 & & \\
\hline df & 4435 & 37 & & \\
\hline \multicolumn{5}{|c|}{ Issue Weighting } \\
\hline Mean & 2.86 & 2.90 & \multirow{3}{*}{0.9168} & \multirow{3}{*}{0.6502} \\
\hline Variance & 0.8320 & 0.9075 & & \\
\hline $\mathrm{df}$ & 4435 & 37 & & \\
\hline \multicolumn{5}{|c|}{ Option Weighting } \\
\hline Mean & 2.98 & 2.95 & \multirow{3}{*}{1.1627} & \multirow{3}{*}{0.5806} \\
\hline Variance & 0.8766 & 0.7539 & & \\
\hline df & 4435 & 37 & & \\
\hline \multicolumn{5}{|l|}{ First Offer } \\
\hline Mean & 93.2 & 92.1 & \multirow{3}{*}{1.0234} & \multirow{3}{*}{0.8948} \\
\hline Variance & 222.6 & 217.6 & & \\
\hline df & 1518 & 54 & & \\
\hline
\end{tabular}

Demographic and case difficulty information (Table 12) was collected using the pre-negotiation questionnaire (Appendix C). There is not a significant difference in the proportion of females and males participating in the experiment $(p=0.7731)$. A significant difference in case difficulty was observed for users of the no-graph model $(\bar{x}=2.55, p=0.0145)$ compared to those using the full model $(\bar{x}=2.19)$, although it should be noted that these responses were entered prior to either group using their respective system and that case information was identical for both models except for the buyer or seller difference. The difficulty in assigning weights to the issues $(p=0.8118)$ and options $(p=0.8377)$ was similar for both groups, and not significant in either instance. 
Table 12: Demographic \& Case Difficulty Data

\begin{tabular}{|c|c|c|c|c|c|}
\hline & \multicolumn{2}{|c|}{ Model } & \multirow[b]{2}{*}{ Test } & \multirow[b]{2}{*}{ df } & \multirow[b]{2}{*}{$p$ value } \\
\hline & Full & No-graph & & & \\
\hline Gender & & & $\begin{array}{l}\text { Chi- } \\
\text { square }\end{array}$ & & \\
\hline Percentage male & 52.8 & 58.2 & \multirow{2}{*}{0.0831} & \multirow{2}{*}{1} & \multirow{2}{*}{0.7731} \\
\hline Percentage female & 47.2 & 41.8 & & & \\
\hline Case Difficulty & & & t-value & & \\
\hline Mean & 2.19 & 2.55 & -2.56 & 38 & 0.0145 \\
\hline \multicolumn{6}{|l|}{ Issue Weighting } \\
\hline Mean & 2.86 & 2.90 & -0.240 & 38 & 0.8118 \\
\hline \multicolumn{6}{|l|}{ Option Weighting } \\
\hline Mean & 2.98 & 2.95 & 0.206 & 38 & 0.8377 \\
\hline
\end{tabular}

The data will be presented sequentially for each hypothesis.

\section{$H_{1}$ - Providing graphical support will increase the number of dyads reaching agreement.}

The proportion of successful and unsuccessful (i.e., the negotiation did not end with a compromise agreement) negotiations was determined for each model. The mean success rate for reaching agreement was $67.5 \%$ for the full model and $68.5 \%$ for the no-graph model (Table 13). These results are not significant $(p=$ 0.9995). Therefore, the hypothesis that graphical support would increase the number of dyads reaching agreement is not supported. 
Table 13: Proportion of Negotiations Reaching Agreement

\begin{tabular}{|c|c|c|c|c|c|}
\hline & \multicolumn{2}{|c|}{ Model } & & & \\
\hline & Full & No-graph & Test & df & p value \\
\hline $\begin{array}{c}\text { Reaching } \\
\text { Agreement }\end{array}$ & & $\begin{array}{c}\text { Chi- } \\
\text { square }\end{array}$ & & \\
\hline Success mean & 67.5 & 68.5 & $3.52 \times 10^{-7}$ & 1 & 0.9995 \\
\hline Fail mean & 32.5 & 31.5 & 3.5 &
\end{tabular}

\section{$\mathrm{H}_{2}$ - Providing graphical support will reduce the number of offers required to reach agreement.}

The number of formal offers made by each side was determined for users of the full and no-graph model that reached agreement (Table 14). The mean number of offers submitted was 8.7 for the full model and 8.0 for the no-graph model. These values were marginally significant $(p=0.0541)$ although contrary to the hypothesis as more offers were submitted to reach agreement using the full model. The median number of offers $(n=8)$ was the same for both models. The most frequent number of offers (mode) was higher for the full model $(n=8)$ than the no-graph model $(n=6)$. The minimum number of offers submitted to reach agreement was twice as many for the no-graph $(n=4)$ as the full model ( $n$ $=2$ ). The opposite situation occurred in terms of the maximum number of offers with more than twice as many being submitted for the full model $(n=37)$ as the no-graph model $(n=16)$. Overall, fewer offers were submitted to reach agreement using the no-graph model although the minimum number was twice as many. Both mode and the maximum number of offers submitted were lower for the no-graph model. 
Table 14: Number of Offers Submitted to Reach Agreement

\begin{tabular}{|l|c|c|c|c|c|}
\hline & \multicolumn{2}{|c|}{ Model } & & & \\
\hline \multirow{2}{*}{ Offers Submitted } & Full & No-graph & t-value & df & P value \\
\cline { 2 - 3 } & & & & & \\
\hline Mean & 8.7 & 8.0 & & & \\
\hline Minimum & 2 & 4 & & \\
\hline Maximum & 37 & 16 & \multirow{2}{*}{1.99} & \multirow{2}{*}{40} & 0.0541 \\
\hline Median & 8 & 8 & & & \\
\hline Mode & 8 & 6 & & & \\
\hline Standard deviation & 3.65 & 2.36 & & & \\
\hline Variance & 13.35 & 5.64 & & & \\
\hline
\end{tabular}

\section{$\mathrm{H}_{3}$ - More offers will be submitted for successful than unsuccessful negotiations.}

The mean number of offers submitted for successful negotiations was greater than for unsuccessful negotiations for both models (Table 15). These were significant for the full model $(p<<0.0000)$ and the no-graph model $(p=$ $0.0059)$, thus supporting the hypothesis. Median values submitted were identical for both models in terms of success $(n=8)$ and fail $(n=6)$. For both models, the mode ratio indicates the most frequent number of offers submitted was much higher for a successful negotiation as compared to an unsuccessful negotiation for both the full model (mode ratio 2.67) and no-graph model (mode ratio 3.00). 
Table 15: Comparison of Offers Submitted Between Negotiations

\begin{tabular}{|c|c|c|c|c|}
\hline \multirow[b]{2}{*}{ Offers Submitted } & \multicolumn{4}{|c|}{ Model } \\
\hline & $\begin{array}{l}\text { Success } \\
\text { Full }\end{array}$ & $\begin{array}{l}\text { Fail } \\
\text { Full }\end{array}$ & $\begin{array}{l}\text { Success } \\
\text { No-graph }\end{array}$ & $\begin{array}{c}\text { Fail } \\
\text { No-graph }\end{array}$ \\
\hline Mean & 8.7 & 6.6 & 8.0 & 5.1 \\
\hline Minimum & 2 & 2 & 4 & 1 \\
\hline Maximum & 37 & 30 & 16 & 12 \\
\hline Median & 8 & 6 & 8 & 6 \\
\hline Mode & 8 & 3 & 6 & 2 \\
\hline Mode ratio (success/fail) & \multicolumn{2}{|c|}{2.67} & \multicolumn{2}{|c|}{3.00} \\
\hline Standard deviation & 3.65 & 3.67 & 2.36 & 3.5 \\
\hline Variance & 13.35 & 13.45 & 5.64 & 12.2 \\
\hline $\mathrm{t}$-value & \multicolumn{2}{|c|}{12.56} & \multicolumn{2}{|c|}{3.03} \\
\hline $\mathrm{df}$ & \multicolumn{2}{|c|}{2204} & \multicolumn{2}{|c|}{23} \\
\hline p value & \multicolumn{2}{|c|}{$<<0.0000$} & \multicolumn{2}{|c|}{0.0059} \\
\hline
\end{tabular}

$\mathrm{H}_{4}$ - Positive affect will be higher for dyads having graphical support.

Participants post-negotiation satisfaction levels were measured by responses to questions concerning (1) their satisfaction with the agreement that was reached, (2) if the outcome of the negotiation matched their prior expectations, and, (3) the perceived friendliness of the negotiation (Table 16). Participants willingness to work with their negotiation partner again was scored true $($ value $=1)$ or false $($ value $=2)($ Table 16$)$.

Due to the low post-negotiation questionnaire response rate for the nograph model, the cases were segregated into two classes. These classes are 
high response rate encompassing the data from the full model and low response rate consisting of the data from the no-graph questionnaires. The former were analyzed using a one-sample t-test and the latter using Fisher's Exact test to account for the small sample sizes. Results are presented below (Table 17 and Table 18).

Table 16: Post-Negotiation Response Data Descriptive Statistics

\begin{tabular}{|c|c|c|c|c|c|c|}
\hline Model & Outcome & Question & Responses & Mean & $\begin{array}{l}\text { Std. } \\
\text { Error }\end{array}$ & Variance \\
\hline \multirow{7}{*}{ Full } & \multirow{4}{*}{ Success } & $\begin{array}{l}\text { Agreement } \\
\text { satisfaction }\end{array}$ & 2149 & 2.73 & 0.026 & 1.494 \\
\hline & & \begin{tabular}{|l|} 
Match expectations \\
\end{tabular} & 2106 & 3.22 & 0.031 & 2.037 \\
\hline & & Friendly negotiation & 2070 & 2.39 & 0.028 & 1.578 \\
\hline & & Work with opposite & 2046 & 1.30 & 0.010 & 210 \\
\hline & \multirow{3}{*}{ Fail } & \begin{tabular}{|l|} 
Match expectations \\
\end{tabular} & 558 & 5.17 & 0.073 & 2.955 \\
\hline & & Friendly negotiation & 545 & 3.79 & 0.067 & 2.470 \\
\hline & & Work with opposite & $5 \overline{41}$ & 1.64 & 0.021 & 0.232 \\
\hline \multirow{7}{*}{$\begin{array}{l}\text { No- } \\
\text { graph }\end{array}$} & \multirow{4}{*}{ Success } & $\begin{array}{l}\text { Agreement } \\
\text { satisfaction }\end{array}$ & 15 & 2.40 & 0.214 & 0.686 \\
\hline & & Match expectations & 15 & 2.73 & 0.371 & 2.067 \\
\hline & & Friendly negotiation & 14 & 1.86 & 0.254 & 0.901 \\
\hline & & Work with opposite & 15 & 1.20 & 0.107 & 0.171 \\
\hline & \multirow{3}{*}{ Fail } & Match expectatic & 4 & 5.75 & 0.750 & 2.250 \\
\hline & & Friendly negotiation & 4 & 3.25 & 0.750 & 2.250 \\
\hline & & Work with opposite & 4 & 1.50 & 0.289 & 0.333 \\
\hline
\end{tabular}

From Table 16, the means for if the outcome matched the expectations of the participant, and if the negotiation was considered to be a friendly one were all significantly higher for unsuccessful negotiations using the full model compared to successful negotiations using the same model. These data indicate a higher level of dissatisfaction for unsuccessful negotiations. Individuals were also less 
likely to be willing to work with their opposite again it the negotiation outcome was unsuccessful. All results were significant $(p<<0.000)$ (Table 17). Similar results (means) were observed for the no-graph model. None of the results were significant for the no-graph model (Table 18). For dyads that reached agreement, satisfaction with the agreement reached was similar for both models (Table 16).

Overall, participants reported successful negotiations to be similarly satisfying for both models, to more closely match initial expectations, be friendlier in nature, and more likely to result in a willingness to work with the opposite party in the future for negotiations using the full model (Table 16). Unsuccessful negotiations using the full model indicate much lower values for the negotiation matching their prior expectations, friendliness of the proceedings, and willingness to work with the other party in the future. All results for the full model were significant $(p<<0.000)$ (Table 17). Increased satisfaction with the negotiation process, and willingness to work with the other party in the future, are indicative of positive affect regarding the other party. 
Table 17: Test Results for Full Model Post-Negotiation Response Data

\begin{tabular}{|c|c|c|c|c|c|}
\hline Model & Outcome & Question & $\mathrm{t}$ value & df & $p$ value \\
\hline \multirow{7}{*}{ Full } & \multirow{4}{*}{ Success } & Agreement satisfaction & 103.47 & 2148 & \multirow{7}{*}{$<<0.000$} \\
\hline & & Match expectations & 103.40 & 2105 & \\
\hline & & Friendly negotiation & 86.49 & 2069 & \\
\hline & & Work with opposite & 128.31 & 2045 & \\
\hline & \multirow{3}{*}{ Fail } & Match expectations & 71.10 & 557 & \\
\hline & & Friendly negotiation & 56.22 & 544 & \\
\hline & & Work with opposite & 79.00 & 540 & \\
\hline
\end{tabular}

Fisher's exact test results (two-tailed) indicate that no significance for any of the classes evaluated using a $2 \times 2$ table. This test was chosen as the number of responses was less than 20 for each of the post-negotiation questions (Table 16). Although the post-negotiation questionnaire results for the no-graph model are similar to the full model (Table16), none are significant (Table 18). However, a comparison of the mean response values does indicate that there is at least a parallel in response suggesting similar satisfaction and willingness to work with the other party in future as was observed for the full model. The responses regarding satisfaction and willingness to work with the other party in the future are not significant. 
Table 18: Fisher's Exact (two-tailed) for No-graph Response Data

\begin{tabular}{|c|c|c|c|c|}
\hline \multirow{5}{*}{$\begin{array}{l}\text { No-graph } \\
\text { Model: Fail } \\
\text { ( } p \text { value) }\end{array}$} & \multicolumn{4}{|c|}{ No-graph Model: Success ( $p$ value) } \\
\hline & & $\begin{array}{c}\text { Match } \\
\text { expectations }\end{array}$ & $\begin{array}{c}\text { Friendly } \\
\text { negotiation }\end{array}$ & $\begin{array}{l}\text { Work with } \\
\text { opposite }\end{array}$ \\
\hline & $\begin{array}{c}\text { Match } \\
\text { expectations }\end{array}$ & 1.000 & 1.000 & 1.000 \\
\hline & $\begin{array}{c}\text { Friendly } \\
\text { negotiation }\end{array}$ & 1.000 & 0.333 & 1.000 \\
\hline & $\begin{array}{l}\text { Work with } \\
\text { opposite }\end{array}$ & 1.000 & 1.000 & 1.000 \\
\hline
\end{tabular}

Although these data do not support the hypothesis it must be noted that the extremely low response rate for the no-graph post-negotiation questionnaire may also be a factor.

\section{$\mathrm{H}_{5}$ - The we/l ratio will be higher for graphically supported dyads reaching agreement.}

Text communications were recorded for each individual for the duration of the negotiation. Messages were segregated into success and fail categories and analyzed (Table 19). Four categories of pronouns were searched: (1) I, (2) we, (3) I, me, my, and mine, and, (4) we, our and us (Table 19). The we/l ratio (category 2 divided by category 1 ) and the we/l total ratio (category 4 divided by category 3) were determined (Table 20). A statistical comparison between models appears in Table 21. 
Table 19: Pronoun Use Frequency in Dyadic Textual Communication

\begin{tabular}{|l|l|c|c|c|c|c|c|c|c|c|}
\hline \multirow{3}{*}{ Model } & \multirow{3}{*}{ Outcome } & \multirow{2}{*}{ Number } & \multicolumn{9}{|c|}{ Average } \\
\cline { 4 - 10 } & & & Word & \multicolumn{3}{|c|}{ We Total } & \multicolumn{4}{|c|}{ I Total } \\
\cline { 4 - 10 } & & & Count & We & Our & Us & I & Me & My & Mine \\
\hline \multirow{2}{*}{ Full } & Success & 5452 & 60 & 0.97 & 0.51 & 0.13 & 2.05 & 0.39 & 0.63 & 0.00 \\
\cline { 2 - 10 } & Fail & 2689 & 58 & 1.03 & 0.51 & 0.14 & 1.78 & 0.35 & 0.58 & 0.00 \\
\hline $\begin{array}{l}\text { No- } \\
\text { graph }\end{array}$ & Success & 74 & 394 & 8.82 & 3.73 & 1.15 & 15.97 & 2.23 & 3.57 & 0.03 \\
\cline { 2 - 10 } & Fail & 34 & 266 & 6.21 & 1.94 & 0.74 & 11.24 & 1.15 & 3.26 & 0.03 \\
\hline
\end{tabular}

Average word count is observed to be considerably greater for the nograph model as compared to the full model (Table 19), regardless of the negotiation outcome. Pronoun use is also higher in all categories, although this may simply reflect the larger message size observed for the no-graph model.

Table 20: Within Model for Pronoun Use in Textual Communication

\begin{tabular}{|c|c|c|c|c|c|c|c|c|c|}
\hline Model & Outcome & $\begin{array}{l}\text { We/l } \\
\text { Ratio }\end{array}$ & t-stat & $d f$ & $p$ value & $\begin{array}{l}\text { We/l } \\
\text { Total } \\
\text { Ratio }\end{array}$ & t-stat & df & $p$ value \\
\hline Full & $\begin{array}{l}\text { Success } \\
\text { Fail }\end{array}$ & 0.540 & -1.099 & 2940 & 2717 & $\begin{array}{l}0.625 \\
0.695\end{array}$ & -1.740 & 3385 & 0.0819 \\
\hline $\begin{array}{c}\text { No- } \\
\text { graph }\end{array}$ & $\begin{array}{l}\text { Success } \\
\text { Fail }\end{array}$ & $\frac{0.553}{0.552}$ & 1.318 & 105 & 0.1904 & $\begin{array}{l}1.591 \\
1.765\end{array}$ & 4.801 & 84 & $<<0.000$ \\
\hline
\end{tabular}

The we/l and we/l total ratio results are given in Table 20. For all cases, except for the no-graph we/l ratio (success $=0.553$, fail $=0.552$ ), these ratios were found to be lower for negotiations reaching agreement. The exception is effectively equivalent and not significant $(p=0.1904)$. The we/l ratio results for the full model $(p=0.2717)$ are not significant. A marginally significant result is 
noted for the we/l total ratio for the full model $(p=0.0819)$, and a significant result for the no-graph model $(p<0.000)$ in terms of reaching agreement. The we/l total ratio is also observed to be considerably higher for the no-graph model than the full model. The use of plural versus singular pronouns (i.e., the we/l total ratio) is also higher for those dyads that failed to reach agreement.

A comparison as to how the we/l and we/l total ratios affect reaching agreement between the full and no-graph models is given in Table 21. From Table 20, the we/l and we/l total ratios were seen to be lower for dyads reaching agreement. The results for the we/l ratio $(p=0.0098)$ and we/l total ratio $(p<<$ 0.000) were both observed to be significant for the comparison of the full and nograph models that reached agreement (Table 21). This was not the case for negotiations that failed to reach agreement for the we/l ratio $(p=0.2245)$ or the we/l total ratio $(p=0.3950)$. Thus, the hypothesis is not supported, as the we/l ratio is lower for graphically supported dyads reaching agreement.

Table 21: Between Model Comparison of We/l Ratio

\begin{tabular}{|c|c|c|c|c|c|}
\hline $\begin{array}{l}\text { Model } \\
\text { Comparison }\end{array}$ & Ratio & Outcome & t-value & Df & $p$ value \\
\hline \multirow{4}{*}{ Full vs. No-graph } & We/l & \multirow{2}{*}{ Success } & -2.652 & 73 & 0.0098 \\
\hline & We/l Total & & -5.419 & 71 & $<<0.000$ \\
\hline & We/l & \multirow{2}{*}{ Fail } & -1.236 & 36 & 0.2245 \\
\hline & We/l Total & & -0.8609 & 36 & 0.3950 \\
\hline
\end{tabular}


Due to the considerably higher average word count observed for the nograph model as compared to the full model (Table 19), regardless of the negotiation outcome, further analysis of the textual messages was performed. Successful negotiations sent approximately the same number of messages for both models ( 4.1 vs. 4.2 messages), but the number of messages sent by users of the no-graph model who did not reach agreement was lower (3.4 messages) than the full model dyads that did not reach agreement (3.9 messages). The average number of messages transmitted between the negotiators is higher for successful negotiations compared to failed negotiations for both models (Table 22). The maximum number of messages is much higher for the full model than the no-graph model, although the median number of messages is higher for the no-graph model $(n=4)$ compared to the full model $(n=3)$ (Table 22). Dyads reaching agreement had a higher mode for the no-graph model $(n=5)$ than did those using the full model $(n=2)$. Within model comparisons indicate that there is not a significant difference in the number of messages transmitted for the full model $(p=0.1689)$ but is a marginally significant difference for the no-graph model $(p=0.0701)($ Table 22). 
Table 22: Message and Word Count Descriptives

\begin{tabular}{|c|c|c|c|c|}
\hline & \multicolumn{4}{|c|}{ Model } \\
\hline & $\begin{array}{l}\text { Success } \\
\text { Full }\end{array}$ & $\begin{array}{l}\text { Fail } \\
\text { Full }\end{array}$ & $\begin{array}{l}\text { Success } \\
\text { No-graph }\end{array}$ & $\begin{array}{c}\text { Fail } \\
\text { No-graph }\end{array}$ \\
\hline \multicolumn{5}{|l|}{ Messages } \\
\hline Mean & 4.1 & 3.9 & 4.2 & 3.4 \\
\hline Minimum & 1 & 1 & 1 & 1 \\
\hline Maximum & 52 & 22 & 12 & 8 \\
\hline Median & 3 & 3 & 4 & 4 \\
\hline Mode & 2 & 2 & 5 & 1 \\
\hline Variance & 16.4 & 7.8 & 5.1 & 4.4 \\
\hline t stat & \multicolumn{2}{|c|}{1.376} & \multicolumn{2}{|c|}{1.840} \\
\hline $\mathrm{df}$ & \multirow{2}{*}{\multicolumn{2}{|c|}{$\begin{array}{c}1853 \\
0.1689\end{array}$}} & \multicolumn{2}{|c|}{69} \\
\hline$p$ value & & & & 01 \\
\hline \multicolumn{5}{|l|}{ Total Message Size per Dyad } \\
\hline Mean Words per dyad & 60.0 & 58.0 & 393.6 & 266.2 \\
\hline Minimum & 0 & 0 & 93 & 0 \\
\hline Maximum & 825 & 519 & 1538 & 1053 \\
\hline Median & 41 & 41 & 335 & 206 \\
\hline Mode & 23 & 15 & 137 & 24 \\
\hline Variance & 4001 & 3111 & 56404 & 63051 \\
\hline t stat & \multicolumn{2}{|c|}{-1.280} & \multicolumn{2}{|c|}{-2.491} \\
\hline df & \multicolumn{2}{|c|}{5988} & \multicolumn{2}{|c|}{61} \\
\hline p value & \multicolumn{2}{|c|}{0.2007} & \multicolumn{2}{|c|}{0.0155} \\
\hline Mean Words per Message & 60.6 & 57.8 & 93.0 & 78.0 \\
\hline
\end{tabular}

Considerable differences are evident in the message size between the full and no-graph models (Table 22). The total message size word count per dyad (i.e., the average total summed message size for both negotiators over the course of the negotiation) is more than six times greater for successful 
negotiations for users of the no-graph model $(n=393.6)$ compared to the full model $(n=60.0)$. This value decreases slightly for users of the full model $(n=$ 58) and the no-graph model $(n=266.2)$ who did not reach agreement, but is still more than four times higher for the latter group (Table 22). The number of words per message is also much higher for the no-graph model than the full model for both successful (60.6 vs. 93.0 ) and unsuccessful ( 57.8 vs. 78.0$)$ negotiations. Within model comparisons indicate that there is not a significant difference in the total message size per dyad for the full model $(p=0.2007)$ but is a significant difference for the no-graph model $(p=0.0155)$ (Table 22).

Comparison between models (Table 23) indicates no significant difference in the number of messages for those dyads reaching agreement $(p=0.7422)$ or those that failed to reach agreement $(p=0.1795)$. The total message size per dyad is significantly different for both unsuccessful and successful negotiations ( $p$ $<<0.0000)$. Although there does not appear to be a difference in terms of the number of messages sent between the models, the message size is much greater for the no-graph model regardless of the negotiation outcome (Table 23). 
Table 23: Between Model Comparison of Messages and Word Count

\begin{tabular}{|c|c|c|}
\hline & \multicolumn{2}{|c|}{ Model } \\
\hline & $\begin{array}{c}\text { Full vs. No-graph } \\
\text { (Success) }\end{array}$ & $\begin{array}{c}\text { Full vs. No-graph } \\
\text { (Fail) }\end{array}$ \\
\hline Messages & -0.330 & 1.37 \\
\hline $\mathrm{t}$ stat & 102 & 39 \\
\hline $\mathrm{df}$ & 0.7422 & 0.1795 \\
\hline $\mathrm{p}$ value & \multicolumn{3}{|c|}{} \\
\hline Total Message Size per Dyad & -12.087 & -4.834 \\
\hline $\mathrm{t}$ stat & 73 & 33 \\
\hline $\mathrm{df}$ & $<<0.0000$ & $<<.0000$ \\
\hline $\mathrm{p}$ value & \multicolumn{2}{|c|}{}
\end{tabular}

$H_{6}$ - The settlement value will be equidistant from the initial offers for graphically supported dyads.

If agreement was reached, the value was compared to the initial offers for each side for the full and no-graph models in order to determine if the settlement point was equidistant from the initial offers (Table 24). Settlements equidistant from the initial offers occurred only $25 \%$ of the time for users of the full model ( $\bar{x}$ $=0.250)$ and $38 \%$ of the time for users of the no-graph model $(\bar{x}=0.378)($ Table 25). 
Table 24: First Offer and Response Offer

\begin{tabular}{|c|c|c|}
\hline Full Model & First Offer & Response Offer \\
\hline Mean & 93.2 & 85.9 \\
\hline Median & 100 & 92 \\
\hline Mode & 100 & 100 \\
\hline Standard deviation & 14.92 & 18.60 \\
\hline Variance & 222.64 & 346.02 \\
\hline \multicolumn{3}{|c|}{ No-graph Model } \\
\hline Mean & 91.7 & 91.5 \\
\hline Median & 100 & 98 \\
\hline Mode & 100 & 100 \\
\hline Standard deviation & 14.24 & 11.52 \\
\hline Variance & 202.77 & 132.70 \\
\hline
\end{tabular}

A one sample t-test indicates neither the full model $(p=0.127)$ or the no-graph value $(p=0.918)$ is not significant (Table 25), which does not support the hypothesis that settlement would occur central to the initial offers. Comparison of the two models in terms of the proportion of dyads having settlements equidistant from the opening offers indicates a significant difference with Fisher's exact (2sided) test $(p<<0.000)$, but opposite to the hypothesis as fewer settlements were equidistant from the opening offers for the full (graphically supported) model (Table 25).

Table 25: Proportion of Settlements Equidistant From Initial Offers

\begin{tabular}{|c|c|c|c|c|c|}
\hline \multirow{6}{*}{ Equidistance } & \multirow[t]{2}{*}{ Model Comparison } & \multirow[t]{2}{*}{ Mean } & $\begin{array}{c}\text { One Sample t- } \\
\text { test }\end{array}$ & \multirow[t]{2}{*}{ df } & \multirow[t]{2}{*}{$\begin{array}{c}\mathrm{p} \\
\text { value }\end{array}$} \\
\hline & & & $t$ value & & \\
\hline & Full & 0.250 & 1.528 & 1517 & 0.127 \\
\hline & No-graph & 0.378 & 0.104 & 36 & 0.918 \\
\hline & & & Fisher's Ex & lue & \\
\hline & Full vs. No-graph & & $<<0.00$ & & \\
\hline
\end{tabular}




\subsection{Discussion}

Similar proportions of dyads reached agreement for both the full and nograph models (Table 13), approximately $68 \%$ for both. Although this proportion is higher than the $53 \%$ reported by Kersten and Zhang (2003) for the INSPIRE NSS, it is not known if the cases where one side did not negotiate (one-side only cases) were excluded from their value. For the pre-negotiation questionnaire, prior to either model being used by the negotiator, the no-graph respondents reported more difficulty $(\bar{x}=2.55)$ in comprehending the case than those assigned to the full model $(\bar{x}=2.19)$; this difference was significant $(p=0.0145)$ (Table 12). The reason for this difference is unknown, but may reflect a greater comprehension difficulty for those assigned to the no-graph model, a lower English proficiency, or be an artefact. That this result could be an artefact is probable as no difference in issue weighting (Table 12), option weighting (Table 12), or the proportion of cases reaching agreement was observed.

The hypothesis that graphical support would increase the number of dyads reaching agreement was not supported. It was thought that the provision of graphical support would decrease the cognitive load for individuals and/or improve cognitive performance (Larkin \& Simon 1987), thus allowing them to reach more efficient, and more frequent, agreement. As there was no observed difference in the frequency of reaching agreement (Table 13), graphical representation does not appear to improve dyadic performance. 
The graphical information provided to full model users was the same information provided in tabular form to no-graph users. Given sufficient time, a negotiator could eventually arrive at the same decision result (computational equivalence) as one using graphical support even though the representation format is not informationally equivalent. As decision speed was not determined, it is not know if there was a decision time benefit for users of the full model compared to those using the no-graph model as was found by Jarvenpaa (1989) and Vessey and Galletta (1991). If the decision process is capacity-constrained due to cognitive load limitations, graphical support would be expected to improve performance. No difference in negotiation success was observed between the two models (Table 13). This negotiation encompasses four issues and has only a limited number of offers to select from (Table 4). For more complex negotiations with a greater numbers of issues being negotiated simultaneously, cognitive capacity constraints might be more subject to improvement by the provision of NSS graphical support. It is also unknown if differences in individual cognitive constraints or cognitive load affected the outcome.

The proportion of females and males was not statistically different (Table 12), although the proportion of males was higher for the no-graph model (58.2\%) than the full model (52.8\%). Kersten and Zhang (2003) found that males have more difficulty reaching agreement than females; Ulijn and Lincke (2004) state that males tend to be more competitive in a $\mathrm{CMC}$ setting while females tend to be 
cooperative. With a higher proportion of males using the no-graph model gender dominance may have affected the proportion of negotiations reaching agreement. Although the difference is not quantified, Kersten and Zhang (2003) state that the effect was not large. As there was not a significant gender difference in the sample for either model (Tabel 12), it seems unlikely that a gender difference would affect the proportion of dyads reaching agreement (Table 13).

Users of the no-graph model submitted fewer offers on average $(\bar{x}=8.0)$ than users of the full model $(\bar{x}=8.7)$ (Table 14). This was found to be marginally significant $(p=0.0541)$. As all negotiations were allowed the same amount of time, it is reasonable to assume that equal numbers of offers could be expected for both models. That there was a difference, and that the mode differed by $25 \%$, implies that NSS graphical representation allows offers to be formulated by the user more quickly. This could be due to the representation aid allowing the user to determine the relative value of each offer in the negotiation space without the necessity of lengthy, and time consuming, mental calculations. As negotiations generally involve incremental positional changes in a learning situation, any assistance provided to determine both trends and position relative to a reference value (e.g., BATNA) would decrease the time required to formulate offers and would allow more offers in a similar time as was observed.

The number of offers submitted for unsuccessful versus successful 
negotiations, for both the full $(p<<0.000)$ and no-graph models $(p=0.0059)$ was significantly different (Table 15). This is in agreement with the results of Kersten and Zhang (2003) using the full model data set who determined that a greater number of offers increased the probability of reaching agreement. The mode ratio for number of offers (success/fail) was 2.67 for the full model and 3.00 for the no-graph model. The greater the number of offers submitted, the more likely agreement becomes regardless of the provision of graphical support, although the minimum number of offers for settlement was greater $(n=4)$ for the no-graph model than for the full model $(n=2)$.

These data may indicate that the offer formulation process is more complex, or at least more lengthy, for users without graphical support as the number of offers submitted in the same period of time was lower for both successful and unsuccessful negotiations for the no-graph system (Table 15). Where incongruence occurs between the problem representation and the task (i.e, offer evaluation and formulation) the task requires more cognitive resources. In alternative processing, as opposed to attribute processing, information is processed on several attributes of a single alternative before information is processed on any other alternative. The format the information is presented in (i.e., alternative or attribute format) dictates the processing format for the decision maker (Painton \& Gentry 1985). In a multi-issue negotiation, a graphical display will allow parallel evaluation of the alternative presented (the offer) on 
several attributes. This is thought to be more difficult without graphical support and, by the cost/benefit principle, this incongruence must invoke some cost, either in increased time (effort) or in decreased accuracy (error), or both (Jarvenpaa 1989). Either could account for fewer offers being submitted without graphical support.

Repeated exchanges over time, as in the case of a multi-issue negotiation, are expected to create a relationship that can be positive, negative or neutral (Emerson 1981; Lawler \& Yoon 1995). Relationships that are more positive are thought to be associated with an affect state influencing the behaviour of the participants and mediating the negotiation outcome in a beneficial manner. Post-negotiation feelings of satisfaction and inclination to interact with the opposite party again are considered an indirect measure of positive interaction and affect (Baron 1990; Oliver et al. 1994). The impact on negotiation outcome is due to greater positive affect resulting in more interpersonal trust and cooperative behaviour. Indicators of positive affect include post-negotiation feelings of satisfaction, if the negotiation matched prior expectations, perceived friendliness of the negotiation, and inclination to work again with the opposite party. These measures were all higher for successful negotiations for both models (Table 16). Responses were consistent on each measure between models (Table 16). All measures were significant for the full model $(p<<0.000)$ (Table 17), although none was significant for the no-graph 
model (Table 18). Overall, the responses suggest that negotiation success has a greater influence on feelings of affect and satisfaction than the provision of graphical support.

Communication is a necessary aspect of negotiation (Gulliver 1979; Pruitt 1981). Messages are often considered as separate from offers, and used to either rationalize the offer or convince the other party to concede (Carnevale \& Pruitt 1992). Kersten and Zhang (2003) state that the number of offers exchanged influences the negotiation outcome more than the exchange of messages. Messages are presumed not to have a statistically significant impact on reaching agreement. Intra-model counts (Table 15) indicate, at a significant level (full model $p<<0.000$; no-graph model $p=0.0059$ ), more offers are made for negotiations reaching agreement than those that are unsuccessful.

There was not a significant difference in the number of messages for users of the full model reaching agreement or not, but is a marginally significant effect for the no-graph model (Table 22). A comparison of the models indicates no significance for negotiations that did, or did not, reach agreement (Table 22). However, the total message size per dyad is considerably different between the graphically supported model and the model without graphical support for those that reached agreement (message sizes of 60 and 394 words, respectively) and those that did not reach agreement (message sizes of 58 and 266 words, 
respectively) (Table 22). The total dyadic message size is over 300 words greater for the no-graph model than the full model with graphical support. A within model comparison is not significant for total message size for the full model $(p=0.2007)$ but is significant for the no-graph model $(p=0.0155)$ (Table 22). Average message size is also much higher for the no-graph model regardless of the negotiation outcome (Table 22).

When a between model comparison of the number of messages sent for each dyad is made (Table 23), no difference is noted for successful or unsuccessful negotiations ( $p=0.7422$ and $p=0.1795$, respectively). A similar comparison for the total message size per dyad indicates that the message size for successful $(p<<0.0000)$ and unsuccessful $(p<<0.0000)$ negotiations are significantly larger for no-graph users. As the number of messages in similar between the models, but the total message size is much greater, it is possible that the lack of graphical support requires greater explanation by the negotiators in order to clarify and rationalize their positions and offers and to obtain information from the other party. The effort required to select and send a package offer using the INSPIRE system is much less than that required to type the large messages evident for the no-graph model (Table 22), making it unlikely that this would be done without purpose. Graphical support may therefore serve as an explanatory aid bridging the cognitive gap between the negotiators. Although textual communication can also bridge the gap, it appears require a 
much greater number of words than a graph of the same information. The increased amount of textual communication for users of the no-graph model (Table 19) implies that greater explanatory dialogue is required without graphical support. Users of the no-graph model may be more talkative than those using the full model, or the nature of the international pairings may bring together individuals with common cultural interests (e.g., the Austria-Germany group). However, this seems an unlikely explanation for the significant difference in total message size per dyad. An equally plausible explanation is that without graphical support more explanation is required in order to rationalize and convince using textual messages what is immediately clear with graphical representation.

Rangaswamy and Shell (1997) found that simply using computer technology did not improve negotiation outcomes in multi-issue negotiations as compared to face-to-face negotiations. They feel that achieving integrative trades depends on maintaining high aspirations in an environment conducive to learning. High expectations provide the motivation to search for integrative trades rather than satisficing, while a problem-solving orientation provides the approach for identifying alternative proposals to offer to the other party allowing gains for both parties. Information exchange is required for these processes, and is higher for dyads without graphical support in terms of message size (Table 19). Successful negotiators seek alternatives that are satisfactory to both 
parties, without excessively moderating their own demands. This probably requires more offers (Table 15) and information exchange (Table 22) to explain and persuade, as was observed for successful negotiations compared to unsuccessful negotiations.

Where a negotiator sticks relentlessly to their position, and only supplies more information to justify their stand, agreement becomes less likely. No data was collected regarding positional stubbornness and repeated messages, but as similar proportions reached agreement for both models this explanation seems an unlikely explanation as positional stubbornness is not generally conducive to reaching agreement.

The we/l ratio is thought to be indicative of cooperation toward the other party (Staub 1978), and therefore lead to more problem-solving during the negotiation, possibly due to inducing feelings of commonality and liking for the dyad. The hypothesis was therefore that a higher we/l ratio would be observed for dyads having graphical support reaching agreement. A comparison of the use of pronouns in the text messages (Table 20) indicates that the we/l and we/l total ratios are higher for failed negotiations. For the no-graph model, there is effectively equivalence for the we/l ratio and a similar result for the we/l total as for the full model, a higher value for failed negotiations. The results for the we/l ratio are not significant for negotiation success versus failure for the full $(p=$ 
$0.2717)$ or the no-graph $(p=0.1904)$ models (Table 20$)$. The we/l total ratio was marginally significant $(p=0.0819)$ while the no-graph ratio was significant ( $p$ $<<0.000$ ) for success versus failure. Ulijn and Lincke (2004), report the use of first person pronouns (l, me, my) to be twice as high in electronic communication compared to FTF communication. They also report comparable values for first person pronoun use in CMC compared to FTF negotiation situations, but do not give pronoun ratios. These researchers also found that pronoun use, and context, varies depending upon the culture of the negotiator, and feel that this reflects a culture-dependent ability to employ a cooperative win-win strategy. As culture was beyond the scope of this study it is not known if this is the case here. Culture, education and profession are reported to have no significant impact on negotiation success (Kersten \& Kersten 2002).

When the we/l and we/l total ratios are compared between the full and no-graph models (Table 21), both ratios are associated with success at a significant level $(p=0.0098$ and $p<<0.000$, respectively). This is not the case when the models are compared in terms of failing to reach agreement $(p=$ 0.2245 and $p=0.3950$, respectively). Contrary to the hypothesis, a higher frequency of use of singular pronouns (i.e., a self-centred, individualistic orientation) results in higher success rates. As more integrative agreements are thought to result from maintaining high aspirations in a learning environment (Rangaswamy \& Shell 1997), the we/l and we/l total ratios indicate that a more 
individualistic, distributive orientation may improve the probability of reaching agreement. These results may reflect the importance of the orientation of a negotiator (individualistic and problem-solving) to the negotiation outcome. This reflects the social motives of the individual negotiator as social motive composition influences the use of distributive or intergrative negotiation strategies; individualistic members tend to use more distributive strategies (Weingart et al. 2002). These authors also found that negotiation strategies changed during the course of the negotiation. Distributive strategies peaked at the beginning of the negotiation and gradually decreased; integrative strategies increased significantly at the midpoint.

Although a higher we/l ratio may be indicative of friendliness and commonality, these results do not indicate that an increased use of plural pronouns results in a greater probability of reaching agreement. If one party is not stubborn about their goals the reason is often a desire to avoid conflict (Pruitt, 1981). A desire to avoid conflict may diminish their own benefit, and the joint benefit. When each party likes the other, but is unsure as to how they are viewed by the other party, a desire to avoid conflict may occur (Hancock and Sorrentino, 1980). Social motives may also affect the type of strategy used by the negotiator. The lower values observed for the we/l ratio may reflect a problem-solving approach combined with a mutual lack of confidence regarding how much trust can be placed in the other party. As each 
negotiator must cooperate in order to reach agreement, but must be competitive in order to achieve an integrative outcome, this combination may create the conditions necessary to reach an integrative settlement (Gulliver 1979). People are sociobiologically collaborative within an identity group, but their competitive behaviour can be triggered by the risk of threat or loss. Contrary to the economics based model of negotiation, the most common threats do not involve economic loss, but of status or self-esteem (Greenhalgh and Chapman, 1995). For example, one party may be willing to sacrifice utility for the sake of an ongoing relationship, or at least be less comfortable taking a position that is sure to cause conflict. Greenhalgh and Chapman (1995) feel that the nature of the relationship formed may be the strongest predictor of the negotiation outcome. When a party is unsure as to what amount of trust in the relationship is warranted, they may be cooperative but maintain an individualistic orientation reflected in a higher level of the use of singular pronouns.

According to Kahneman (1991), people evaluate gains and losses relative to a fixed reference point. Without a method to determine a reference point, people will often choose the most evident or readily available reference. For individuals negotiating under uncertainty, this point will most likely be their opening offer. As graphical representation (full model) makes this value evident on the graph, it is probably the most readily available reference point for a negotiator able to view the graph. For both models, the opening offer by the first 
mover had a mode of 100 (Table 24). Using this as the reference point positional movement towards agreement could be viewed as a loss, especially as the positional changes are presented as a line graph of the utility rating for all issues. Reaching agreement requires positional movement by both parties. Other than in the Boulwarian take-it-or-leave-it situation, issue trading or logrolling usually occurs after the initial offer(s). Negotiated outcomes are influenced by initial offers, particularly when uncertainty or ambiguity impacts on the issues (Whyte \& Sebenius 1997). The anchor point chosen may also affect aspiration levels and hence the negotiation outcome. As the opening offers will usually bound the settlement region (Raiffa 1996), visualization of the offer space created by the opening bid will effectively reduce the size of the settlement zone. Without visualization, only the individuals' reference point or anchor will be used to determine the response offer. This seems to be the case as the initial offer for the no-graph model was approximately the same as the response offer ( 91.7 vs. 91.5), but not for the full model (93.2 vs. 85.9 ).

As negotiators often consider it fair to split the difference (Nash 1950; Pruitt 1981), it was expected that the settlement point for successful negotiations would be equidistant from the initial offers with greater frequency for graphically supported negotiations. Only $25 \%$ of the full model settlement points and $38 \%$ of the no-graph settlement points were central to the initial offers (Table 25); these values were not significant. Comparing the full and no-graph models yielded a 
significant result for the number of dyads having settlements equidistant to the opening offers $(p<<0.000)$, but contrary to the hypothesis.

Although it might be fair to split the difference, this was not the actual outcome for either model. The negotiation process for both models results in a non-central settlement point implying that one party gained more than the other relative to the initial offers. The corollary of this is that one party made more positional concessions or movement than the other party. This inequality relative to the opening offers was greater for users of the full model than the no-graph model. As the no-graph model has a higher frequency of settlement closer to equidistance, the lack of graphical representation may result in lower positional commitment by the parties as they are less confident as to the relative distance of an offer relative to the counteroffer. People estimate unknown values by starting from the anchor (initial value), that is then adjusted as perceptions or information changes. Lim (2002) determined that multimedia presentation only improved the comprehension of explanative but not descriptive information. This is thought to improve the recall of conceptual information and aid problem solving but not the retention of verbatim information. Providing a graphical representation may result in a hardening of positions by negotiators due to anchoring as they are presented with a relative position foremost with a lesser recall of the other party's positional rationale. Final estimates of the settlement point may be biased towards the anchor, resulting in positional inflexibility. Users 
of the model without graphical display were unable to view this graph and had to rely more on textual and tabular information. This resulted in much larger messages (information) being transmitted between the negotiators, which may have resulted in the observed increase in equidistant settlement points for the no-graph users.

If a graph alters decision accuracy, it must have a concomitant effect not only on the efficiency of perception but also on the efficiency of some underlying cognitive information processing (Lohse 1997). Faster perceptual inferences from the graphical aid will enhance performance only if cognitive resources are capacity constrained and those cognitive resources are freed to be used elsewhere in the problem solving process. Cognitive limitations, such as working memory capacity, are not dependent on the type of graphical aid provided. Graphs cannot automatically improve performance for complex tasks. Improved problem-solving or decision-making depends on both graphical perception and cognition. Subtle graphic design changes may alter the manner in which information is processed, thus improving information acquisition as a function of working memory capacity constraints which limit our ability to store information from sequential information processing operations (Lohse 1997). Enhanced graphical design features (e.g., colour or grid lines) that improve our ability to process information in parallel increase the efficiency of perceptual information acquisition tasks. By increasing the efficiency of information acquisition, 
designers of graphic decision aids can distribute some of the cognitive burden to perceptual information acquisition tasks and improve performance.

Graphical representation will not necessarily affect performance over information presented in another format that is informationally equivalent. As utility values were presented in tabular form for the no-graph model, this could be considered computationally equivalent in terms of the decision-making process. The cognitive fit or information processing paradigm of Vessey and Galletta (1991), states that it is less efficient to manipulate the information but that the outcome will generally be the same. The mental representation provided by the full model NSS is more likely to have cognitive fit compared to the tabular form (no-graph model) due to incongruence between the task and the decision aid. According to Payne (1982), decision strategy selection is a deliberate compromise between the benefits of minimizing errors and the cognitive costs (effort) in a particular task environment. The organization of information on a display affects this cost-benefit trade-off by making some strategies easier to use than others. The cost/benefit principle suggests that incongruence must invoke some cost, either in increased time (effort) or in decreased accuracy (error), or both. Incongruent situations may make decision makers acquire information in the direction encouraged by the display format, but evaluate the information in the direction required by the formulated evaluation strategy. Although tabular information might be computationally equivalent, a cost in terms of decision time 
could occur, but not in terms of outcome as reflected in the similar proportions of dyads reaching agreement for both models.

If the lack of graphical support resulted in longer times required to formulate decisions regarding offer acceptance and counter-offers, time constraints and deadlines would become a greater factor. Kahai (1999) empirically demonstrated a negative correlation between acceptance and agreement for group outcomes using CMC. This may indicate that the negotiator was willing to satisfice due to the impending deadline even though they were not in agreement with the settlement point. Participants using the full model made more offers than the no-graph model (Table 14), and therefore may have been less willing to satisfice as deadlines had less impact on the progress of their negotiation. Kersten and Zhang (2003) found that the majority of negotiations (approximately $70 \%$ ) that continue to the deadline are unsuccessful. It is not known if this is due to impasse or the participants are still considering accepting an offer or making a counter-offer when the deadline was reached. As there was little difference in the proportion reaching agreement for either model, but was a difference in the number of offers submitted, an answer cannot be inferred from these data.

NSS issue representation might be improved by using a bar graph representing each issue separately combined with the line graph currently used. 
Human cognitive limitations make sequential calculations difficult simultaneously, but more easily accomplished if presented in a parallel manner graphically. This could improve cognitive performance by allowing the negotiator to decompose the total utility value and relate each part to their preferences.

\subsection{Conclusion}

The hypothesis that graphical support would improve the proportion of bilateral negotiations reaching agreement was not supported, nor was a decrease in the number of offers required to reach agreement for the full model supported by the results.

An increased number of offers increases the probability of reaching agreement for both the full model and the no-graph model. Fewer offers were submitted for the successful and unsuccessful dyads using the no-graph model. When considered together with the large increase in message size noted for the no-graph model (over 300 words greater for successful negotiations) compared to the full model, lack of graphical support seems to require more extensive explanation of the position justification and offer rationalization in messages. There was a significant difference in the total message size per dyad between the two models. 
Limitations of this study are discussed in the next section, followed by Future Research.

\subsection{Limitations of This Study}

Although this study was not conducted in a restricted laboratory setting, as is the norm for negotiation studies, it does include some of the same restrictive features. For example, the participants were mainly students. As these individuals had no stake in the outcome (i.e., real firms were not affected by the outcome), consequences did not directly affect them as would occur in the real world. This may have reduced commitment to the negotiation task as compared to real negotiations involving superiors and principals. The range of options used for offer construction is also not reflective of a real negotiation. Limiting the possible offers to a very few choices constrains the number of offer possibilities in a way foreign to most real negotiations.

The extent the users of the full model made use of the graphical display, or if they used the graphical display, is not known. Anecdotal information indicates that the majority of users do access the graphical display feature when available, but the proportion is not known. This must therefore be considered a limitation of the study as the comparison is made between users with graphical display and those without. 
The large difference in the number of cases for the full and no-graph models is a limitation. An equal number of cases would have been preferable, but was not possible due to time and resource constraints, and the large number of full model cases already in existence. The international nature of the InterNeg system, in terms of pairings between culturally different individuals, may also be a limitation. Pairings are random depending on requests for negotiation sessions; no attempt was made in this study to determine if culture had an influence.

Timing may also have affected the performance of the participants. As the negotiations were conducted asynchronously, it is not known if attention or fatigue problems may have affected the performance of any of the participants. It is also expected that due to the three week duration of the experiment varying levels of external pressure (illness, exams, assignment deadlines, etc.) may have influenced individual performance by their affect on concentration.

No data was collected regarding the amount of time, or difficulty, individual negotiator's had in making decisions. Individual working memory capacity is unknown for the participants and, if there was a large difference between dyadic participants, this may have influenced the outcome due to the cognitive limitations of one party. Neither is it known if the technological capabilities were equivalent for each bilateral negotiation. 
Considering these limitations, this study contributes to the research on the use of graphical representation in NSS as it provides insight into the graphical interface use by negotiators in an real, although experimental, negotiation setting. Additionally, it examines some of the cognitive processes involved in the negotiation process.

\subsection{Future Research}

With any computer system, familiarity and expertise of the individual user is variable. Training sessions to familiarize users with system functionality and capabilities would be of use prior to beginning the bilateral negotiations in order to ensure each participant has an approximately equal ability to use the INSPIRE NSS. The large difference in cases was a limitation for this study. Subsequent studies might use either a stratified sample or new cases of equal numbers for both systems. Cultural differences should also be taken into consideration such that pairing should be similar and not disadvantaged due to language difficulties as all negotiations are in the English language.

As graphical support may reduce cognitive load in a multi-issue negotiation, the time required to decide on and transmit offers would be of interest. The time required to reach agreement could also be compared for the two models. Due to the possible ambiguity of phrasing, more extensive text 
analysis is required in order to determine if pronoun use is actually indicative of the negotiator being cooperative, contentious, or neutral. This would require either a smaller data set or the availability of computer-assisted text analysis.

A comparison of interest would be to determine if revealing individual preferences by both sides results in agreement being reached more often, or more integrative agreements. This could be done by providing graphical display of the individual issue preferences in bar graph format. This format, deconstructing the utility rating to reflect the individual issues, might also be considered for the current system.

How negotiators make use of their perceptual and cognitive capabilities to process information impacts on how, and if, they reach agreement is an area of research of benefit to the business community. Providing more efficient graphical aids for NSS in order to reduce the cognitive load on the decision maker, for example by enhancing graphical features, would aid the negotiation process. The specific features that would allow this might be the subject of further research. Specifically, what modifications would allow greater information extraction from the graphical representation. This may require combining graphical aids with artificial intelligence to allow embedded intelligence in graphics software to better meet the needs of individual negotiators. 


\subsection{References}

Aumann, R. J. and L. S. Shapley (1992). Long-Term Competition - A Game-Theoretic Analysis. 2001.

Baccharach, S. B. and E. J. Lawler (1981). Bargaining, Power, tactics, and outcomes. San Francisco, California., Jossey-Bass Publishers.

Balke, W. M., K. R. Hammond, et al. (1973). "An Alternate Approach to LaborManagement Relations." ASQ: 311-327.

Baron, R. A. (1971). "Behavioral effects of interpersonal attraction: Compliance with requests from liked and disliked individuals." Psychonomic Science 25: 325-326.

Baron, R. A. (1990). "Environmentally induced positive affect: Its impact on selfefficacy, task performance, negotiation, and conflict." Journal of Applied Social Psychology 20(368-384).

Barry, B. and R. Oliver (1996). "Affect in Dyadic Negotiation: A Model and Propositions." Organizational Behavior and Human Decision Processes 67(2): 127-143.

Bartos, O. J. (1977). "Simple Model of Negotiation: A Sociological Point of View." Journal of Conflict Resolution. 21(4): 565-579.

Berger, P. L. and T. Luckmann (1967). The social construction of reality: A treatise in the sociology of knowledge. Garden City, New York., Doubleday Books.

Bernoulli, D. (1954). "Exposition of a new theory on the measurement of risk." Econometrica 22: 23-36.

Berry, L. M. (1998). Psychology at Work: An Introduction to Industrial and Organizational Psychology. New York, New York, McGraw-Hill.

Bettman, J. and P. Kakkar (1977). "Effects of Information Presentation Format on Consumer Information Acquisition Strategies." Journal of Consumer Research 3: 233-240.

Camerer, C. F. (1997). "Progress in Behavioral Game Theory." Journal of Economic Perspectives 11(4): 167-188.

Card, S., T. Moran, et al. (1983). The psychology of human-computer interaction. Hillsdale, NJ, Lawrence Erlbaum Associates, Inc.

Carnevale, P. J. and A. M. Isen (1981). Negotiator mood moderates the barrier effect. Paper presented at the annual meeting of the Eastern Psychological Association., Boston.

Carnevale, P. J. and A. M. Isen (1986). "The influence of positive affect and visual access on the discovery of integrative solutions in bilateral negotiation." Organizational Behavior and Human Decision Processes 37: 1-13.

Carnevale, P. J. and E. J. Lawler (1986). "Time Pressure and the Development of Integrative Agreements in Bilateral Negotiations." Journal of Conflict Resolution. 30(4): 636-659.

Carnevale, P. J. and D. G. Pruitt (1992). "Negotiation and mediation." Annual Review of Psychology 43(1): 531-582. 
Clark, J. M. and A. Paivio (1991). "Dual coding theory and education." Educational Psychology Review 3(3): 149-210.

Coase, R. (1960). "The Problem of Social Cost." Journal of Law and Economics 3: 1-44.

Cross, J. G. (1969). The economics of bargaining. New York, New York., Basic Books.

Cross, J. G. (1977). "Negotiation as a Learning Process." Journal of Conflict Resolution. 21(4): 581-606.

Dawes, R. M. (1979). "The robust beauty of improper linear models in decision making." American Psychologist 34: 571-582.

De Dreu, C. K., L. R. Weingart, et al. (2000). "Influence of Social Motives on Integrative Negotiations: A Meta-Analytic Review and Test of Two Theories." Interpersonal Relations and Group Processes 78(5): 889-905.

De Moor, A. and H. Weigand (2004). "Business Negotiation Support: Theory and Practice." International Negotiation 9: 31-57.

Delaney, M., A. Foroughi, et al. (1997). "An Empirical Study of the Efficacy of a Computerized Negotiation Support Systtem (NSS)." Decision Support Systems 20(3): 185-197.

Deutsch, M. (1958). "Trust and Suspicion." Journal of Conflict Resolution. 2(4): 265279.

Deutsch, M. (1973). The resolution of conflict: constructive and destructive processes. New Haven, Connecticut, Yale University Press.

Deutsch, M. (1982). Interdependence and psychological orientation. Cooperation and Helping Behavior: Theories and Research. V. J. Derlega and J. Grzelak. New York, Academic Press: 15-42.

Deutsch, M., Y. Epstein, et al. (1967). "Strategies of inducing cooperation: an experimental study." Journal of Conflict Resolution. 11(3): 345-360.

Einhorn, H. J. and R. H. Hogarth (1981). "Behavioral Decision Theory: Processes of Judgement and Choice." Annual Review of Physchology 32: 53-88.

Emerson, R. M. (1981). Social exchange theory. Social psychology: Sociological perspectives. M. Rosenberg and R. H. Turner. New York, New York., Basic Books: $30-65$.

Fiske, S. T. and S. E. Taylor (1991). Social cognition. New York, McGraw-Hill.

Foroughi, A. (1998). "Minimizing Negotiation Process Losses With Computerized Negotiation Support Systems." Journal of Applied Business Research 14(4): 1526.

Fry, E. (1981). "Graphical Literacy." Journal of Reading 24(5): 389-392.

Fry, W. R., I. J. Firestone, et al. (1983). "Negotiation process and outcome of stranger dyads and dating couples: Do lovers lose?" Basic and Applied Social Psychology 4: 1-16.

Graham, J., A. Mintu, et al. (1994). "Explorations of Negotiation Behaviors in Ten Foreign Cultures Using a Model Developed in the United States." Management Science 40(1): 72-95.

Granovetter, M. (1985). "Economic action and social structure: The problem of embeddedness." American Journal of Sociology 91: 481-510. 
Greenhalgh, L. and D. I. Chapman (1995). Joint Decision Making: The Inseparability of Relationships and Negotiation. Negotiation as a Social Process. R. M. Kramer and D. M. Messick. Thousand Oaks, California., SAGE Publications.: 166-185. Gulliver, P. H. (1979). Disputes and Negotiations: A Cross-Cultural Perspective.

Toronto, Ontario., Academic Press, Inc.

Hammond, K. R. (1965). "New directions in research on conflict resolution." Journal of Social Issues 21: 41-66.

Hammond, K. R. (1971). "Computer graphics as an aid to learning." Science 172: 903908.

Hill, R. and G. Wyse (1989). Animal Physiology. New York, Harper \& Row.

Hirshleifer, J. (1984). The Economic Approach to Conflict, UCLA Dept. of Economics. 2001.

Hirshleifer, J. (1993). "The Affections and Their Passions - Their Economic Logic." Rationality and Society 5(2): 185-202.

Holsapple, C. W., H. Lai, et al. (1998). "A Formal Basis for Negotiation Support System Research." Group Decision and Negotiation 7: 203-227.

Jarvenpaa, S. L. (1989). "The Effecto of Task Demands and Graphical Format on Information Processing Strategies." Managment Science 35(3): 285-303.

Jelassi, M. and A. Foroughi (1989). "Negotiation Support Systems: An Overview of Design Issues and Existing Software." Decision Support Systems 5: 167-181.

Jonides, J., E. Smith, et al. (1993). "Spatial working memory in humans as revealed by PET." Nature 363: 623-625.

Joseph, M. L. and R. H. Willis (1963). "An experiment analog to two party bargaining." Behavioral Science 8: 117-127.

Kahai, S. and R. Cooper (1999). "The Effect of Computer-Mediated Communication on Agreement and Acceptance." Journal of Management Information Systems 16(1): 165-188.

Kahneman, D. (1991). "Reference points, anchors, norms, and mixed feelings." Organizational Behavior and Human Decision Processes 51(296-312).

Kahneman, D. (2002). Maps of Bounded Rationality: A Perspective on Intuitive Judgement and Choice, Princeton University. 2005.

Kahneman, D. and A. Tversky (1973). "On the psychology of prediction." Psycholgical Review 80: 251-273.

Kahneman, D. and A. Tversky (1979). "Prospect theory: An analysis of decision under risk." Econometrica 47: 263-291.

Kahneman, D. and A. Tversky (1984). "Choices, Values, and Frames." American Psychologist. 39: 341-350.

Kandori, M., G. Mailath, et al. (1993). "Learning, Mutation, and Long Run Equilibria in Games." Econonometrica 61(1): 29-56.

Kaplowitz, S. A. (1977). "The Influence of Moral Considerations on the Perceived Consequences of an Action." Journal of Conflict Resolution. 21(3): 475-500.

Kemper, R. E. and D. R. Kemper (1994). Negotiation literature: a bibliographic essay, citations, and sources. Metuchen, New Jersey, The Scarecrow Press, Inc. 
Kersten, G. (1988). "A Procedure for Negotiating Efficient and Non-efficient Compromises." Decision Support Systems 4(2).

Kersten, G. (2001). "Modeling Distributive and Integrative Negotiations. Review and Revised Characterization." Group Decision and Negotiation 10: 493-514.

Kersten, G. (2002). E-negotiations: Towards Engineering of Technology-based Social Processes., InterNeg Research Papers.

Kersten, G. and M. Kersten (2002). Internet technologies in teaching, training \& research. InterNeg project and Inspire system, Global Interdependence and Language, Culture and Business CIBER 2002. 2005.

Kersten, G. and S. Noronha (1998). "Supporting International Negotiation with a WWWbased System." Decision Support Systems 25: 135-154.

Kersten, G., S. Noronha, et al. (1999). Are all e-commerce negotiations auctions? InterNeg Reports.

Kersten, G. and G. Zhang (2003). "Mining Inspire Data for Determinants of Successful Internet Negotiations." Central European Journal of Operations Research 11(3): 297-316.

Kimmel, M. J., D. G. Pruitt, et al. (1980). "Effects of trust, aspiration, and gender on negotiation tactics." Journal of Personality and Social Psychology 38: 9-23.

Kramer, R. M. and D. M. Messick, Eds. (1995). Negotiation As A Social Process. Thousand Oaks, California, SAGE Publications, Inc.

Kristensen, H. and T. Garling (1997). "The Effects of Anchor Points and Reference Points on Negotiation Process and Outcome." Organizational Behavior and Human Decision Processes 71(1): 85-94.

Larkin, J. and H. Simon (1987). "Why a Diagram is (Sometimes) Worth 10,000 Words." Cognitive Science 11: 65-100.

Lawler, E. J. and J. Yoon (1995). Structural Power and Emotional Processes in Negotiation. Negotiation As A Social Process. R. M. Kramer and D. M. Messick. Thousand Oaks, California., SAGE Publications: 143-165.

Lebow, R. N. (1996). The Art of Bargaining. Baltimore, The Johns Hopkins University Press.

Lim, J. (2000). "An experimental investigation of the impact of NSS and proximity on negotiation otucomes." Behaviour \& Information Technology 19(5): 329-338.

Lim, K. H. and I. Benbasat (2002). "The Influence of Multimedia on Improving the Comprehension of Organizaitonal Information." Journal of Management Information Systems 19(1): 99-127.

Lim, L. and I. Benbasat (1993). "A Theoretical Perspective of Negotiation Support Systems." Journal of Management Information Systems 9(3): 27-44.

Loewenstein, G., L. Thompson, et al. (1989). "Social Utility and Decision Making in Interpersonal Contexts." Journal of Personality and Social Psychology 57(3): 426441.

Lohse, G. L. (1997). "The role of working memory on graphical information processing." Behaviour \& Information Technology 16(6): 297-308.

Luce, R. D. and H. Raiffa (1957). Games and Decisions. New York, New York., Wiley. 
Massey, A. P. and W. A. Wallace (1996). "Understanding and facilitating group problem structuring and formulation: Mental representations, interaction, and representation aids." Decision Support Systems 17: 253-274.

Mayer, R. E. (1985). Structure analysis of science prose: Can we increase problemsolving performance? A Theoretical and Practical Handbook for Analzying Exploratory Text. B. Britton and J. Black. Mahwah, N.J., Lawrence Erlbaum: 6587.

Molm, L. D. (1994). "Dependence and Risk: Transforming the Structure of Social Exchange." Social Psychology Quarterly 57(3): 163-176.

Montgomery, D. A. (1999). "Human Sensitivity to Variability Information in Detection Decisions." Human Factors 41(1): 90-105.

Naquin, C. E. (2003). "The agony of opportunity in negotiation: Number of negotiable issues, counterfactual thinking, and feelings of satisfaction." Organizational Behavior and Human Decision Processes 91: 97-107.

Nash, J. F. (1950). "The bargaining problem." Econometrica 18: 155-162.

Nash, J. F. (1953). "Two-Person Cooperative Games." Econometrica 21: 128-140.

Neale, M. A. and M. H. Bazerman (1985). "The Effects of Framing and Negotiator Overconfidence on Bargaining Behaviors and Outcomes." Academy of Management Journal 28: 34-49.

Oliver, R. L., P. V. Balakrishnan, et al. (1994). "Outcome satisfaction in negotiation: A test of expectancy disconfirmation." Organizational Behavior and Human Decision Processes 60: 252-275.

Oliver, T. A. F. S. (1993). "Self-efficacy and computers." Journal of Computer-Based Interactions 20: 81-85.

Painton, S. and J. Gentry (1985). "Another Look at the Impact of Information Presentation." Journal of Consumer Research 12: 240-244.

Paivio, A. (1986). Mental Representations. A Dual Coding Approach. New York, Oxford University Press.

Patchen, M. (1970). "Models of cooperation and conflict: A critical review." Journal of Conflict Resolution. 14: 289-407.

Payne, J. W. (1982). "Contingent Decision Behavior." Psychological Bulletin 92(2): 382402.

Pen, J. (1952). "A general theory of bargaining." The American Economic Review. 42: 24-42.

Polzer, J. T., E. A. Mannix, et al. (1995). Multiparty Negotiation in Its Social Context. Negotiation As A Social Process. R. M. Kramer and D. M. Messick. Thousand Oaks, California, SAGE Publications: 123-143.

Pracht, W. and J. Courtney (1988). "The effects of an interactive graphics-based DSS to support problem structuring." Decision Sciences 19(3): 598-621.

Pruitt, D. G. (1971). "Indirect communication and the search for agreement in negotiation." Journal of Applied Social Psychology 1: 205-239.

Pruitt, D. G. (1981). Negotiation Behavior. Toronto, Ontario., Academic Press.

Pruitt, D. G. and H. Syna (1985). "Mismatching the opponent's offers in negotiation." Journal of Experimental Social Psychology 21(1): 103-113. 
Pylyshyn, Z. (1984). Computation and cognition. Cambridge, MA, MIT Press.

Raiffa, H. (1982). The art and science of negotiation. Cambridge, Belknap Publishing. Raiffa, H. (1996). Lectures on Negotiation Analysis. Cambridge, Mass., PON Books. Rangaswamy, A. and G. R. Shell (1997). "Using Computers to Realize Joint Gains in Negotiations: Toward an "Electronic Bargaining Table." Managment Science 43(8): 1147-1163.

Robinson, W. N. and V. Volkov (1998). "Supporting the Negotiation Life Cycle." Communications of the ACM 41(5): 95-102.

Rosner, B. (2000). Fundamentals of Biostatistics. Pacific Grove, California, Duxbury Thomsom Learning.

Ross, L. and R. Nisbitt (1991). The person and the situation. New York, McGraw-Hill.

Schelling, T. (1960). The strategy of conflict. Cambridge, Mass., Harvard University Press.

Schoop, M., A. Jertila, et al. (2003). "Negoisst: a negotiation support system for electronic business-to-business negotiations in e-commerce." Data \& Knowledge Engineering 47: 371-401.

Sebenius, J. K. (1992). "Negotiation Analysis: A Characterization and Review." Management Science 38(1): 18-38.

Simon, H. A. (1978). On the forms of mental representation. Minneapolis, University of Minnesota Press.

Slovic, P., M. Finucane, et al. (2002). The affect heuristic. Heuristics and biases. T. Gilovich, D. Griffin and D. Kahneman. Cambridge, Cambridge University Press: 397-420.

Staub, E. (1978). Positive social behavior and morality (Vol. 1): Social and personal influences. New York, New York, Academic Press.

Stevens, C. M. (1958). "On the Theory of Negotiation." Quarterly Journal of Economics. 72(1): 77-97.

Sugiyama, L. S., J. Tooby, et al. (2002). "Cross-cultural evidence of cognitive adaptations for social exchange among the Shiwiar of Ecuadorian Amazonia." PNAS: 11537-11542.

Swaab, R., T. Postmes, et al. (2004). "Negotiation Support Systems: Communication and Information as Antecedents of Negotiation Settlement." International Negotiation 9: $59-78$.

Swaab, R., T. Postmes, et al. (2002). "Multiparty Negotiation Support: The Role of Visualization's Influence on the Development of Shared Mental Models." Journal of Management Information Systems 19(1): 129-150.

Thompson, L., E. Peterson, et al. (1995). Social Context in Negotiation: An InformationProcessing Perspective. Negotiation as a Social Process. R. M. D. M. M. Kramer. Thousand Oaks, California, SAGE Publications: 5-36.

Tsui, A. S. and B. Barry (1986). "Interpersonal affect and rating errors." Academy of Management Journal 29: 586-599.

Tversky, A. (1969). "Intrnasitivity of Preferences." Psychological Review 76: 31-48.

Tversky, A. and D. Kahneman (1974). "Judgement under uncertainty: Heuristics and biases." Science 185: 1124-1131. 
Ulijn, J. M. and A. Lincke (2004). "The Effect of CMC and FTF on Negotiation Outcomes between R \& D and Manufacturing Partners in the Supply Chain: An Anglo/Nordic/Latin Comparison." International Negotiation 9: 111-140.

Umanath, N. and R. Scammell (1988). "An experimental evaluation of the impact of data display format on recall performance." Communications of the ACM 31(5): 562570.

Umanath, N., R. Scammell, et al. (1990). "An examination of two screen/report design variables in an information recall context." Decision Sciences 21(1): 216-240.

Umanath, N. S. and R. W. Scamell (1988). "An Experimental Evaluation of the Impact of Data Display Format on Recall Performance." Communications of the ACM 31(5): 562-570.

Van Dijk, T. A. and W. Kintsch (1983). Strategies of Discourse Comprehension. New York, Academic Press.

Vessey, I. (1991). "Cognitive Fit: A Theory-Based Analysis of the Graphs Versus Tables Literature." Decision Sciences 22: 219-240.

Vessey, I. and D. Galletta (1991). "Cognitive fit: An empirical study of information acquisition." Information Systems Research 2(1): 63-84.

Walther, J. B. (1992). "Interpersonal effects in computer-mediated interaction: A relational perspective." Communication Research 19: 52-90.

Walton, R. E. and R. B. McKersie (1965). A behavioral theory of labor negotiating. New York, New York., McGraw-Hill.

Weber, M. (1947). The Theory of Social and Economic Organization. New York, New York, Free Press.

Weigand, H., A. De Moor, et al. (2003). "B2B Negotiation Support: The Need for a Communication Perspective." Group Decision and Negotiation 12: 3-29.

Weingart, L., R. Brett, et al. (2002). Conflicting Social Motives in Negotiating Groups. AoM Conflict Management Division 2002 Mtgs. No. 12097.

Whyte, G. and J. K. Sebenius (1997). "The Effect of Mulitple Anchors on Anchoring in Individual and Group Judgement." Organizational Behavior and Human Decision Processes 69(1): 75-85.

Wickens, C. D. and C. M. Carswell (1995). "The proximity compatibility principle: Its psychological function and relevance to display design." Human Factors 37: 473 494.

Wilkenfeld, J., S. Kraus, et al. (1995). "GENIE: A decision support system for crisis negotiations." Decision Support Systems 14: 369-391.

Young, O. R. (1975). Bargaining: Formal theories of negotiation. Urbana., University of Illinois Press.

Yukl, G. A. (1974). "Effects of opponent's initial offer, concession magnitude, and concession frequency on bargaining behaviour." Journal of Personality and Social Psychology 30: 332-335.

Zachary, W. (1986). "A cognitively based functional taxonomy of decision support techniques." Human-Computer Interaction 2(1): 25-63.

Zartman, I. W. (1977). "Negotiations as a joint decision-making process." Journal of Conflict Resolution. 21: 619-638. 


\title{
14.0 Appendix A: Cypress Cycles Manufacturing Case
}

\author{
The Cypress Cycles Negotiation
}

Cypress Cycles is a small manufacturer of expensive mountain bikes. The company grew out of a small shop that originally modified stock bikes for the local clientele to take into the surrounding mountains. These modified bikes proved so popular that a separate company with facilities in a nearby industrial park was set up to produce them. As the bikes are virtually hand built they are very expensive and the market is limited. Customer loyalty is high but competition is stiff and sales growth has slowed.

In order to capitalize on the firm's reputation for producing advanced, high quality bicycles the management team has decided to introduce a new line of hybrid bikes which will appeal to the recreational cyclist. It will be of high quality but mass produced at a considerably lower price than the high end product. The company has adopted two main principles in the design of the new line. First, the quality of the product must be high enough that it does not detract from the existing business. Second, there must be a large enough gap between the two lines so that owners of the high end cycles are not tempted to substitute the less expensive model although they might be tempted to buy one for everyday use.

Before entering production you need to secure supplies of sprockets and gear assemblies. Your current supplier is not able to provide the parts that you need at a cost that will fit with the projected price of the new line. After canvassing other potential suppliers you realize that there is no local producer who will be able to fulfil your needs. Therefore you have begun negotiations with a few potential suppliers from abroad.

The first of these is Itex, a diversified manufacturer which has recently begun to market bicycle parts in your country. You have visited their plant and examined their products. It appears that they would be able to provide the parts you need. Other customers whom you have contacted speak well of Itex.

You are now ready to begin negotiations for the first of the parts you need, rear wheel gear assemblies. There are four issues which must be negotiated each of which has several discrete possibilities (options).

1. Price (in US dollars). The higher the price the better for Itex.

- $\$ 3.47$

- $\$ 3.71$ 
- $\$ 3.98$

- $\$ 4.12$

- $\$ 4.37$

2. Delivery. The longer the time the better for Itex.

- 20 days

- 30 days

- 45 days

- 60 days

3. Payment. The shorter the time the better for Itex.

- Upon delivery

- 30 days after delivery

- 60 days after delivery

4. Returns. Option 1 is the least preferred and option 3 the most preferred.

1. Full price on all returned parts. Parts returned at Cypress' option. Itex pays shipping on all returned goods.

2. Five percent spoilage allowed. If more than five percent of a shipment is unacceptable the whole shipment is returned for a $75 \%$ refund.

3. Ten percent spoilage allowed. If more than $10 \%$ of a shipment is unacceptable the whole shipment is returned for a $75 \%$ refund.

Your team has been sent by Cypress Cycles to conduct the negotiations. You know that Cypress would like to conclude the negotiations quickly so that they can begin production. You realize that you will not be able to get the best option on all four issues but you would like to get a good deal. However, if you cannot get an acceptable deal there are other suppliers who may be able to provide what you need.

Done reading

Last modified: Tue Apr 9 19:22:47 EDT 1996 by SJN. Please send vour comments to Sunil Noronha. 


\subsection{Appendix B: Itex Manufacturing Case}

\section{The Itex Manufacturing Negotiations}

Itex Manufacturing began life in the 1950s as a small metal processor. Initially Itex made pots and pans, kettles and other simple metal products. When the electronics industry began to expand ltex was able to secure contracts to supply casings, capstans and other metal components for these products. Itex gained a local reputation for supplying high quality housings for computer components, especially monitors. Securing these contracts required that the company purchase equipment to provide special finishes, but regular investment for upgrading had become normal practice.

About ten years ago, however, business had begun to decline. This was due, in part, to the increased use of plastics for many of the components that Itex used to provide and increased competition. For a time the company declined in sales and size but more recently the firm had successfully begun to move toward producing and marketing components for products which required a high degree of precision and finish although they were seldom technically sophisticated themselves. Itex components are currently found in items such as medical devices, office equipment and motorcycles. Competition, however, is fierce and Itex tries to expand its production in other market segments. Lately they have begun producing gears and gear assemblies for higher end bicycles.

The company has now been approached by Cypress Cycles. Cypress is one of the larger makers of high end mountain bikes. They are starting a new line of cheaper, but still high quality hybrid bicycles. Purely by chance the Itex president met at a convention with the president of Cypress. They had lunch together and discussed about possibility of Itex supplying sprocket and gear assemblies.

Further talks were conducted subsequently to the presidents meeting. Itex studied the feasibility of the manufacturing the assemblies and their profitability. After preliminary discussions four issues remained to be solved, namely, price, delivery time, payment and contract length. The finance department determined that the price cannot be below $\$ 3.75$, however, favourable terms of payment and return policy may push the price down to approximately $\$ 3.50$. Manufacturing and shipping departments are convinced that they can meet 30 day delivery time and probably even 20 days.

After preliminary talks you are meeting to try to reach an agreement. The following four issues are on the table. The possibilities (options) for each issue are listed below.

1. Price (in US dollars). The higher the price the better for Itex. 
- $\$ 4.37$

- $\$ 4.12$

- $\$ 3.98$

- $\$ 3.71$

- $\$ 3.47$

2. Delivery. The longer the time the better for Itex.

- 60 days

- 45 days

- 30 days

- 20 days

3. Payment. The shorter the time the better for Itex.

- Upon delivery

- 30 days after delivery

- 60 days after delivery

4. Returns. Option 1 is the least preferred and option 3 the most preferred.

1. Full price on all returned parts. Parts returned at Cypress' option. Itex pays shipping on all returned goods.

2. Five percent spoilage allowed. If more than five percent of a shipment is unacceptable the whole shipment is returned for a $75 \%$ refund.

3. Ten percent spoilage allowed. If more than $10 \%$ of a shipment is unacceptable the whole shipment is returned for a $75 \%$ refund.

Your team has been given the task of reaching an agreement with Cypress, if possible. Itex would like to get this contract, not only because of the business it would secure, but because Cypress has a substantial reputation and their use of your products would certainly enhance product visibility. On the other hand the deal must be as fair one or it will cost the firm too much in time and effort to service a contract which is not profitable.

Done reading 


\subsection{Appendix C: Pre-Negotiation Questionnaire}

In order to evaluate and improve the InterNeg system we would like to collect some information about your experience with the system. Please answer all the questions below. The information you provide here will not be available to anyone but the InterNeg researchers. Your feedback is a very important part of this experiment, and it will help make better tools available to you. We very much appreciate your cooperation.

Thanks -- The InterNeg Team

1. What is your age?

2. What is your Gender? Female Male

3. What is your primary occupation?

4. In which country were you born?

5. In which country do you now reside?

How long have you resided in this country?

6. Have you lived in a foreign country for more than two months? If so please specify.

7. What is your difficulty level in English? Check one for verbal and one for written.

\begin{tabular}{|c|c|}
\hline Verbal & Press here for option \\
\hline Written & Press here for option \\
\hline
\end{tabular}

8. What do you consider your mother tongue (first language learned) to be?

9. Please indicate how often you use the following computer and Internet applications:

\begin{tabular}{|c|c|}
\hline Application software & Press here for option \\
\hline Email & Press here for option \\
\hline WWW & Press here for option \\
\hline Internet Relay Chat (IRC) & Press here for option \\
\hline Internet Agents & Press here for option \\
\hline
\end{tabular}

10. Do you regularly contribute to a Newsgroup? Yes No

11. Do you regularly read a Newsgroup? Yes No 
12. How often do you access the Internet?

13. Do you have your own WWW web page? Yes No

14. What technology feature do you feel is the most important for conducting a negotiation using the internet?

15. How would you rate your experience at negotiating?

Very experienced No experience

16. Indicate on the scale below how easy or difficult it was to understand the case.

Extremely easy Extremely difficult

17. How easy or difficult was it to assign weights to the different issues?

Extremely easy Extremely difficult

18. How easy or difficult was it to assign weights to the options within each issue?

Extremely easy Extremely difficult

19. What agreement do you predict you and your counterpart will reach for this case?

\begin{tabular}{|c|c|}
\hline Price & Press here for option \\
\hline Delivery & Press here for option \\
\hline Payment & Press here for option \\
\hline Returns & Press here for option \\
\hline
\end{tabular}

20. What is the lowest possible offer you would be prepared to accept from your counterpart?

\begin{tabular}{|c|c|}
\hline Price & Press here for option \\
\hline Delivery & Press here for option \\
\hline Payment & Press here for option \\
\hline Returns & Press here for option \\
\hline
\end{tabular}

21. Based on the case description you expect negotiations to be:

Very friendly Very hostile

22. Do you foresee any special problems conducting this negotiation in the electronic medium? If so, please specify/elaborate. 


\subsection{Appendix D: Post-Negotiation Questionnaire}

In order to evaluate and improve the InterNeg system we would like to collect some information about your experience with the system. Please answer all the questions below. The information you provide here will not be available to anyone bu the InterNeg researchers. Your feedback is a very important part of this experiment, and it will help make better tools available to you. We very much appreciate your cooperation.

Thanks - The InterNeg Team

1. Are you planning to use the Internet more often after your initial experience with InterNeg?

$$
\text { Yes No }
$$

2. Indicate on the scale below how easy or difficult you found it to use the InterNeg system? Extremely easy Extremely difficult

3. How clear did you find the instructions for the use of InterNeg?

Perfectly clear Not clear at all

4. What feature(s) of the InterNeg system did you like the most?

5. What feature(s) of the InterNeg system did you like the least?

6. Would you have preferred that InterNeg be available in another language? Which language?

7. If you exchanged messages (other than offers), were the messages helpful?

Extremely helpful Detrimental to the negotiation

8. Did you find the rating displayed with your and your partner's offers useful?

Extremely useful Detrimental to the negotiation

9. Did you use the graph representing the history of your negotiations? Yes No

If you did use the history graph, did you find it (select all that apply)

- Informative? Yes No

- influencing your actions? Yes No

- Influencing your assessment of your opponent's actions?Yes No

10. Did you use the post-settlement mechanism? Yes No

If you did use the post-settlement mechanism, then did you accept an offer different from your original settlement?

No

would you accept such a mechanisms in a real life negotiations? Yes

No 
11. Rate your own bargaining strategies?

$\begin{array}{ll}\text { Informative } & \text { Uninformative } \\ \text { Persuasive } & \text { Push-over } \\ \text { Honest } & \text { Deceptive } \\ \text { Exploitative } & \text { Accommodating } \\ \text { Cooperative } & \text { Self-interested }\end{array}$

12. If you reached an agreement, how satisfied are you with that agreement? Extremely satisfied Extremely unsatisfied

13. Did the outcome of the negotiation match what you thought it would be before you began exchanging offers? Completely Not at all

14. How much control did you have over the negotiation process?

Very much in control Not at all in control

15. Would you call your negotiations:

Very friendly Very hostile

16. How satisfied are you with your performance as a negotiator in this exercise?

Extremely satisfied Extremely unsatisfied

17. Did your partner disclose any of the following during the negotiation:

Her/his country? Yes No

Her/his identity? Yes No

If your partner did not disclose her/his country, what is your best guess?

(enter country/region or continent)

If your partner did not disclose his/her identity, do you think that you know the person you were negotiating with? Yes No

18. What can you say about your partner in the negotiations?

$\begin{array}{ll}\text { Informative } & \text { Uninformative: } \\ \text { Persuasive } & \text { Push-over: } \\ \text { Honest } & \text { Deceptive: } \\ \text { Exploitative } & \text { Accommodating: } \\ \text { Cooperative } & \text { Self-interested: } \\ \text { Unreliable } & \text { Reliable: } \\ \text { Likable } & \text { Unlike able: } \\ \text { Irrational } & \text { Rational: } \\ \text { Untrustworthy } & \text { Trustworthy: } \\ \text { Kind } & \text { Unkind: } \\ \text { Fair } & \text { Unfair: } \\ \text { Flexible } & \text { Rigid: }\end{array}$

19. Was anything done by your opponent during the negotiation a surprise to you?

Yes No

If yes, what was it that surprised you? 
20. Would you like to work with your negotiation partner on some other project? Yes No

21. How interested would you be in seeing the partner with whom you negotiated?

Extremely interested Not at all interested

22. Where you able to learn enough about your partner to be able to predict her/his next offer?

Learned a lot Learned thing

23. Did you feel that you understood the priorities of your partner in the negotiation?

Always Never

24. Given your experience with InterNeg, would you use a negotiation support system again? (Select all that apply):

To practice your negotiation skills?

To prepare for a negotiation?

$\begin{array}{ll}\text { Yes } & \text { No } \\ \text { Yes } & \text { No } \\ \text { Yes } & \text { No }\end{array}$

To conduct an actual negotiation with another party? Yes No

25. Please tell us why you would or would not use InterNeg:

If you have any further questions, comments, suggestions, we are interested in hearing them. .......Thanks once again. 